\title{
DIE
}

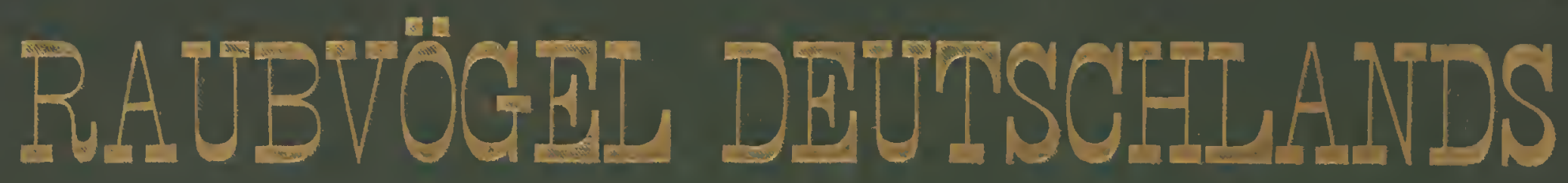

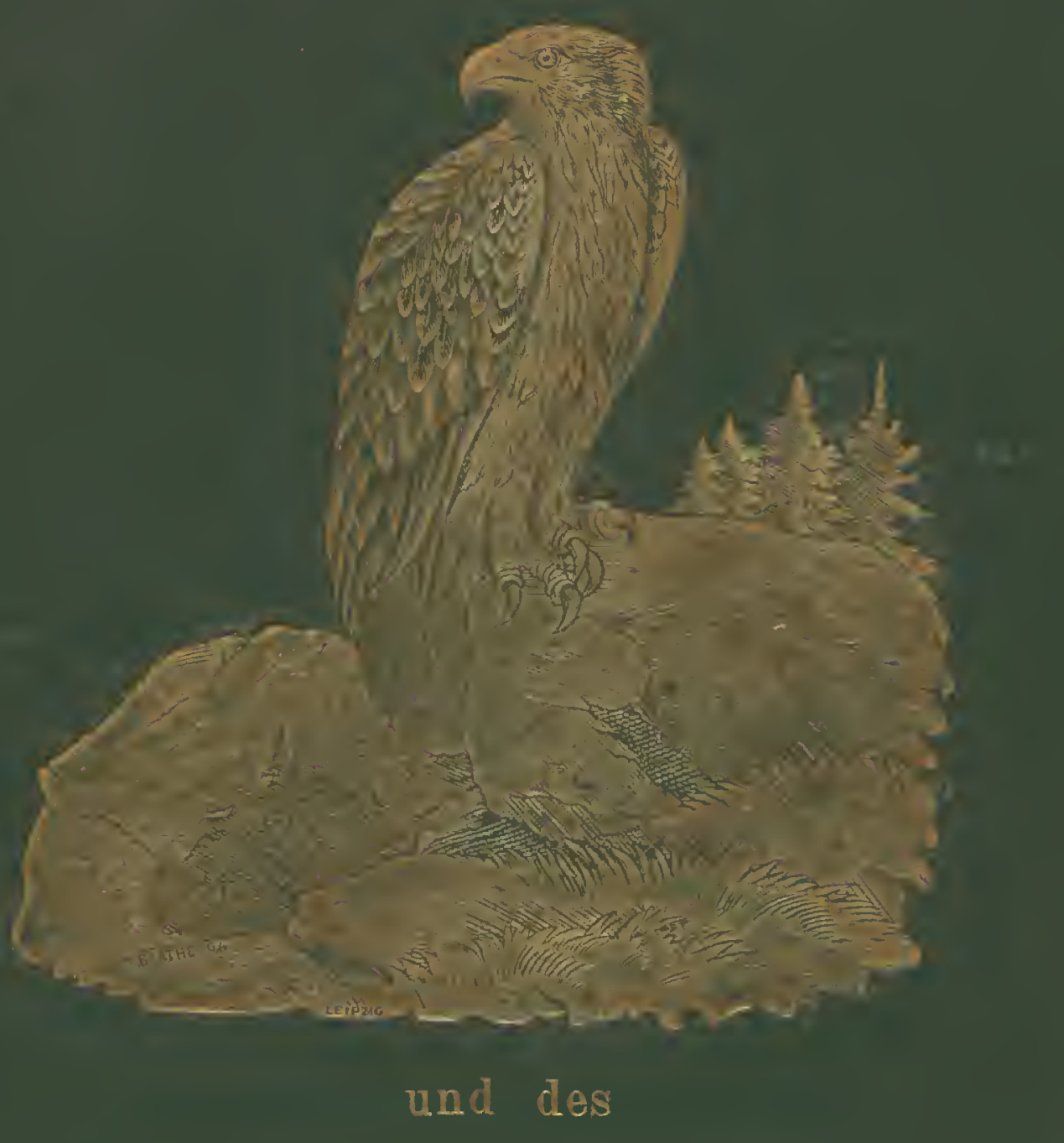

angrenzenden Mittel-Europas

VON

0. จ. RIESENTHAL

IR h Qhererareter 





\section{Raubvögel Deutschlands}

\section{des angrenzenden Mitteleuropas.}

Darstellung und Beschreibung der in Deutschland und den benachbarten Ländern von Mitteleuropa vorkommenden Raubvögel.

\section{Allen Naturfreunden}

besonders aber

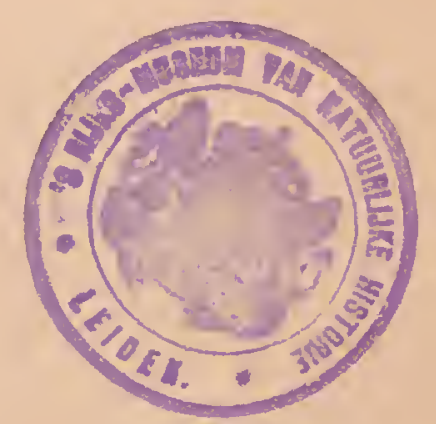

der deutschen Jägerei

gewidmet von

\section{0. v. Riesenthal,}

Oberförster, Mitglied der allgemeinen deutschen ornithologischen Gesellschaft zu Berlin

und des allgemeinen deutschen Jagdschutz-Vereins etc.

\section{ATLAS.}

\section{CASSEL.}





\section{Inhalts-Verzeichniss zum Atlas.}

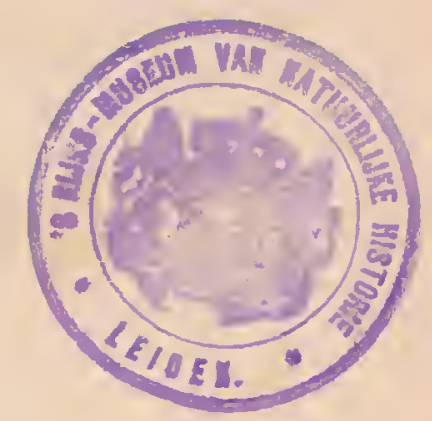

Buteo vulgaris, Bechsl., Gemeiner Bussard. - lagopus, Brünn., Ranhfüssiger Bussard

Pernis apivorus, Linn., Wesponbnssard, $\delta$ ad. et juv. . . . . . . . .

- Derselbe, 우a. et juv. . . . . .

Astur palnmbarins Bechst., Hühnerhabicht

- nisus, Linn., Sperber . . . . . .

Milvus regalis, Briss., Rother Milan . . .

- migraus, Bodd., Seliwarzbrauner Milan

Circns aëruginosus, Linn., Rohrweihe $\delta$ et 9 ad.

- Dieselbe, б juv., ㅇ ad. . . . . .

- cineracens, Monl., Wiesenweihe . .

- pygargus, Cuv., Kornweihe . . .

- pallidns, Bruch., Steppenweihe . .

Buteo ferox, Gmel., Adler-Bussard . . .

- desertorum, Daud., Steppen-Bussard .

Elauus melanopterus, Daud., Sehwarzflïgelicher

Falkcnmilan . . . . . . . .

Falco candieans, auct., Islïndiseher Jagdfalkc $\delta$

- Derselbe, ㅇ․ . . . . . . . .

Falco aretieus, Ilolböll, Grönlïndiseher Jagdfalke, \& . . . . . . .

- gyrfuleo, Schleg., Norwegiseher Jagdfalle, $\delta$. . . . . . . . .

— Derselbe, ㅇ. . . . . . . . .

- saqer, Schleg., Würgfalke. . . . .

- Feldeggii, Schleg., Feldeggs-Falke .

- peregrinus, Linn., Wanderfalke, $q$ ad., ठ juv. . . . . . . . . . . . XXIY.

- Derselbe, $\&$ med. ad., o ad. . . . . XXV.

Jagdfalke, auf der Faust, Fessel etc. . . XXVI.

Falkenkappen, Feclerspiel und Falknertasehen XXVII.

Falco subbuteo Linn., Lerehenfalke . . . XXVIII

- Elennorae, Gené, Elconorenfalke. . XXIX.

- aesalon, Linn., Merlinfalke . . . . XXX.

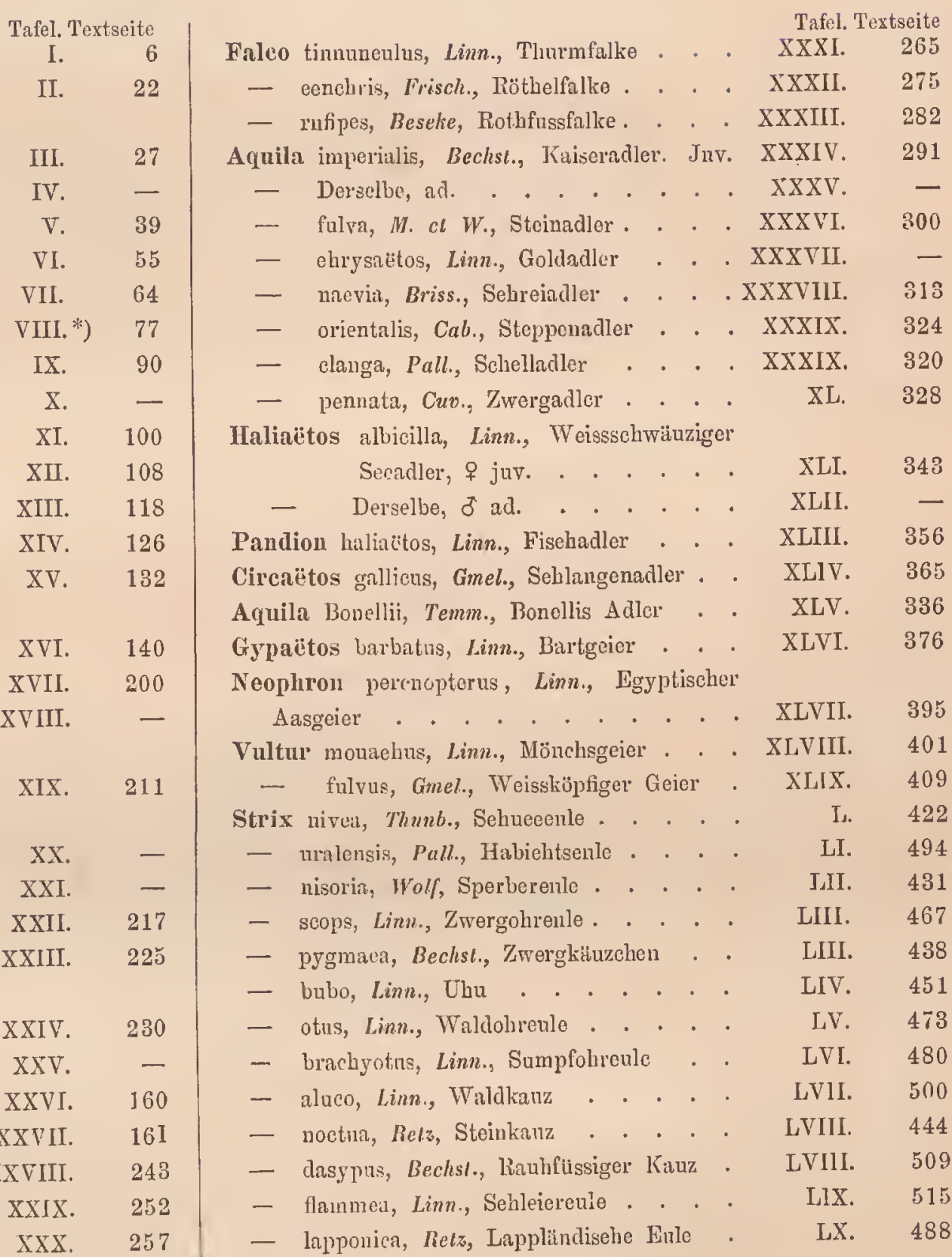





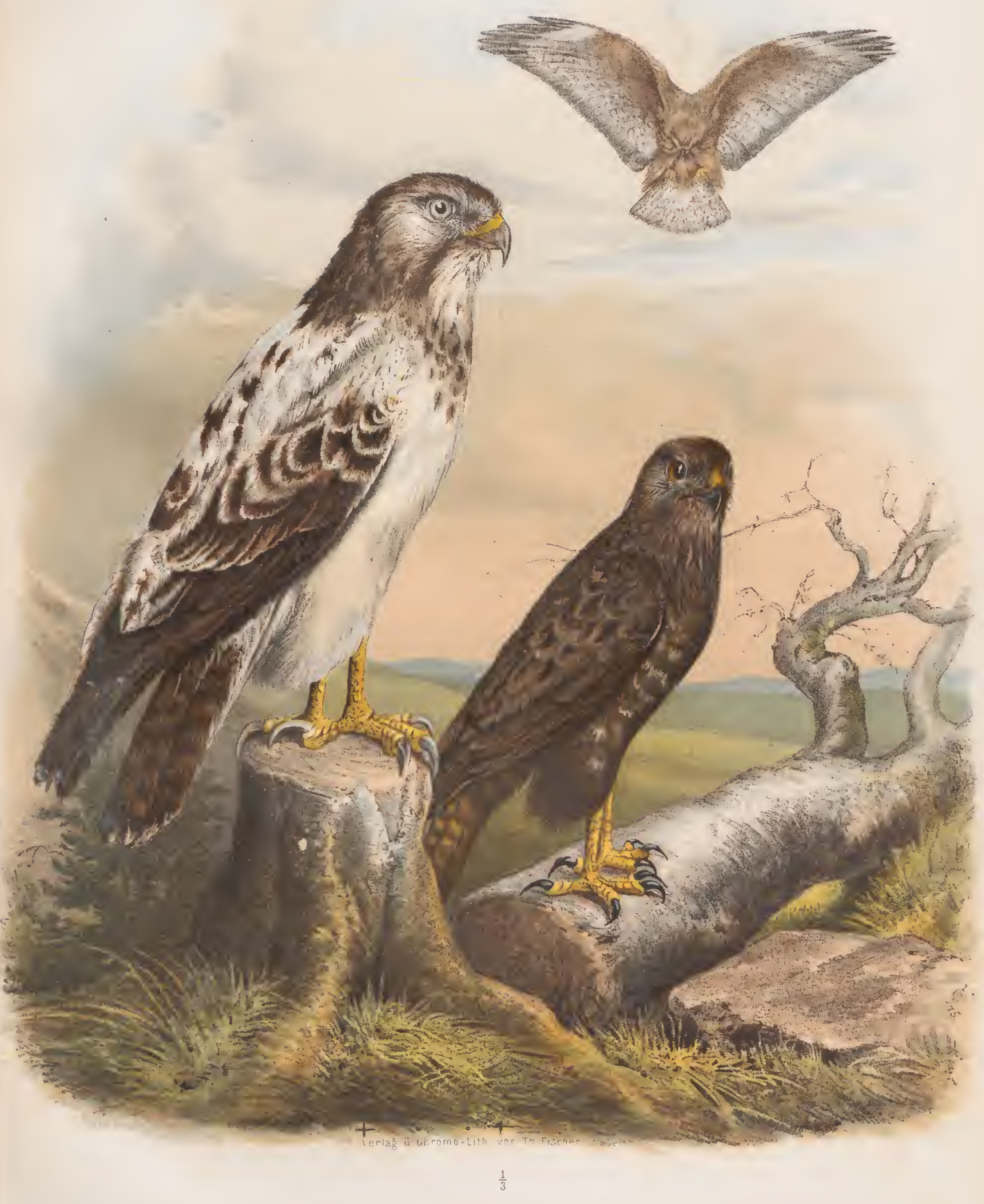

Weisse VaI

BUTEO VULGARIS, BECHST.

Gemeiner Bussard.

Hellbraune Farbung
Gemeine 


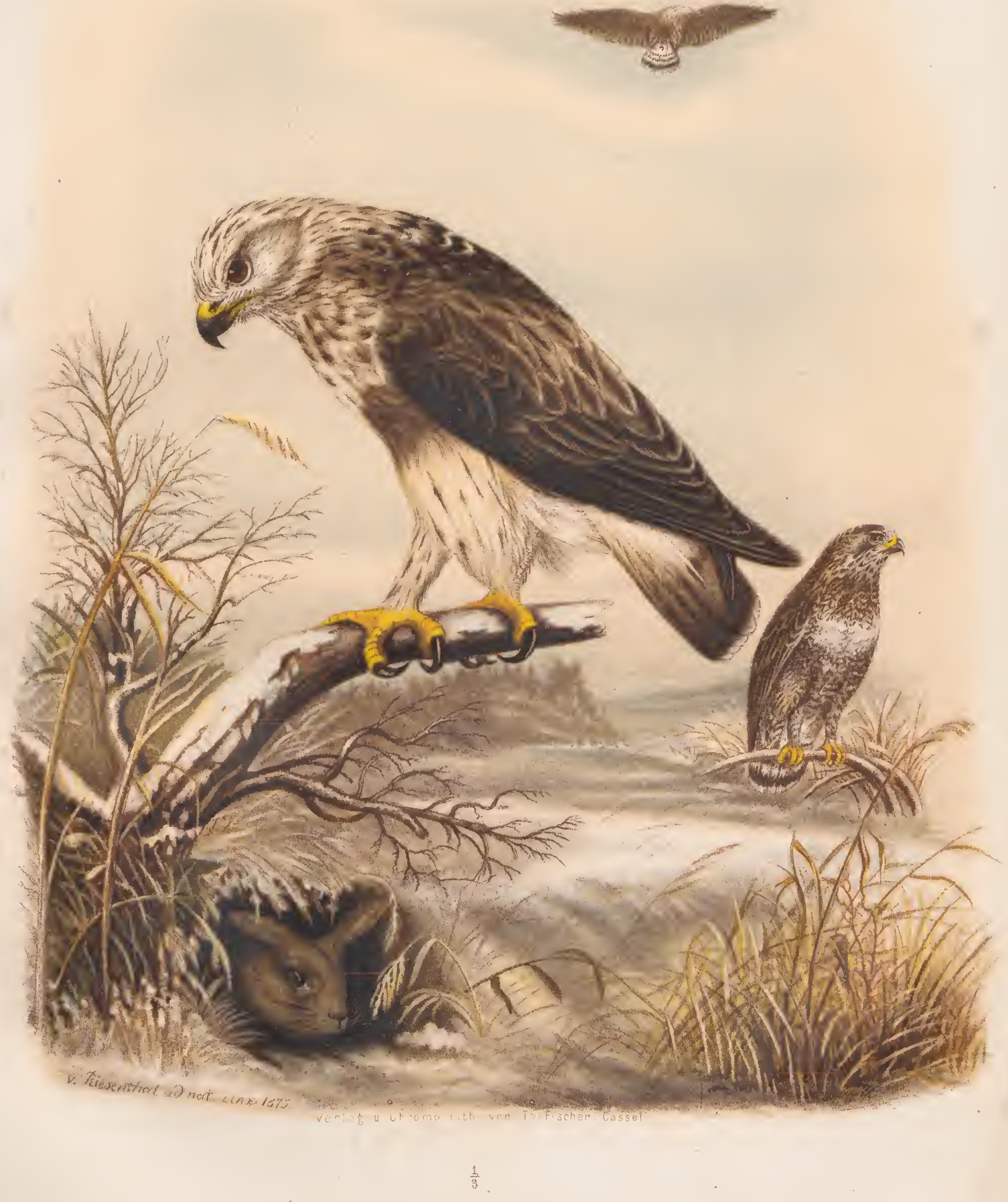

BUTEO LAGOPUS, BRÜNN. 


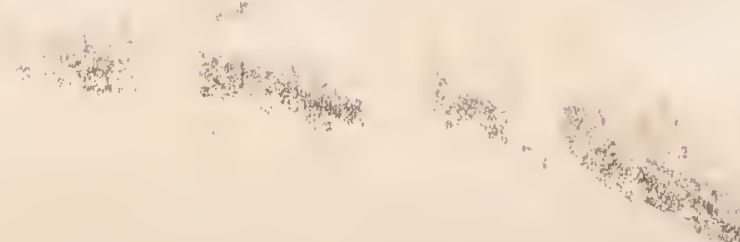




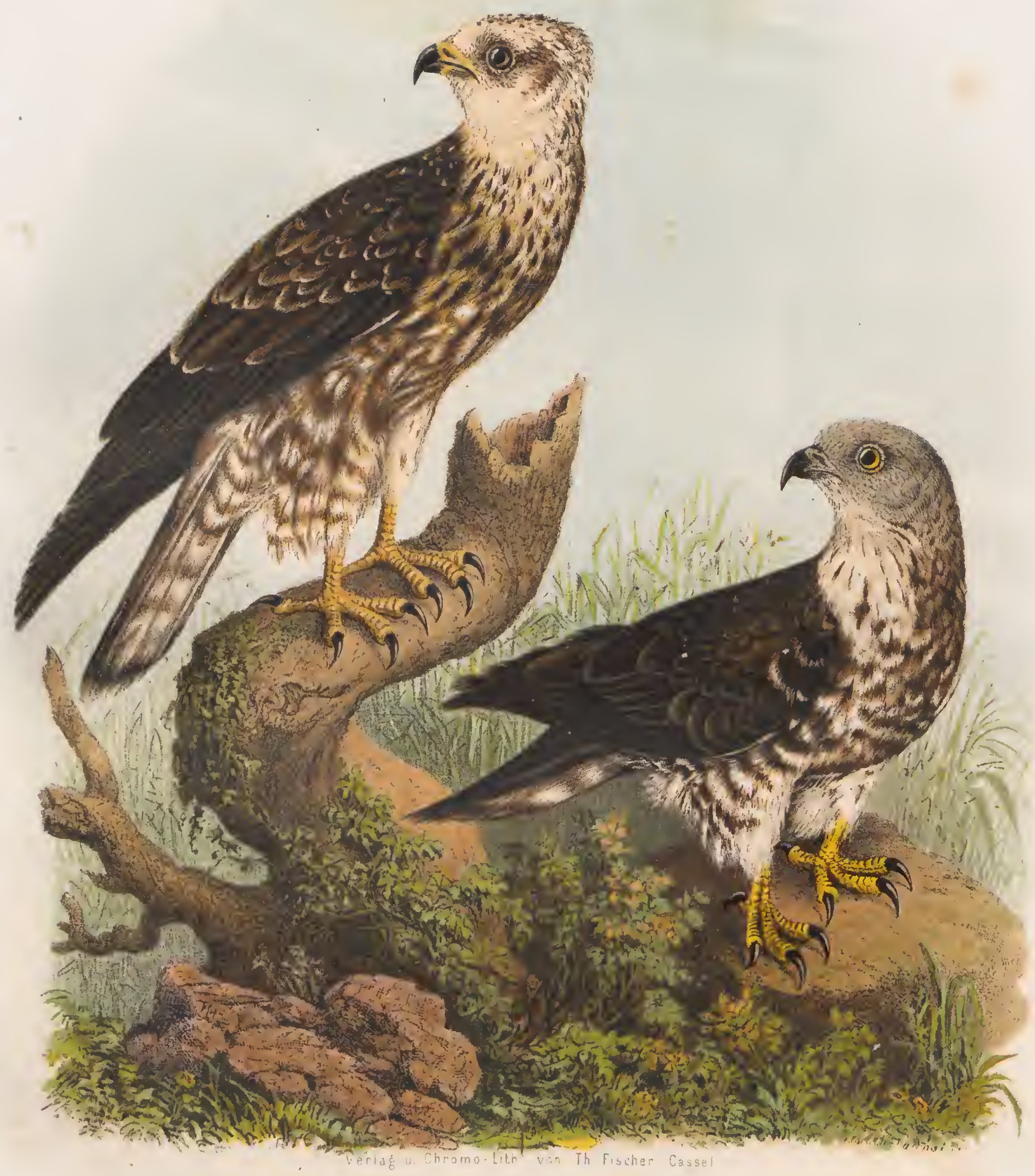

PERNIS APIVORUS. 



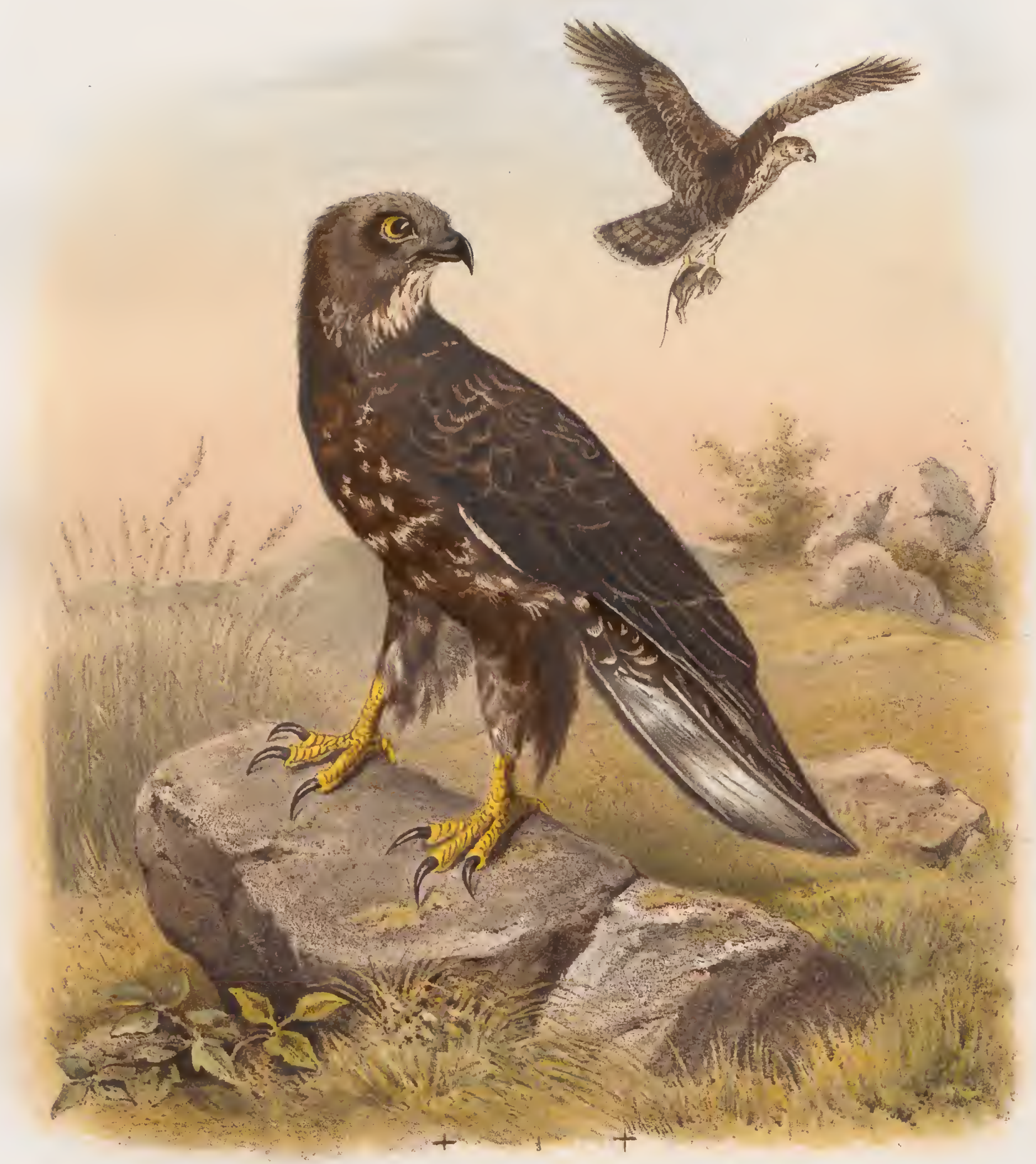

Verlag u. Chromo-Lith von Th. Fischer. Lâsee!

$\frac{1}{3}$

PERNIS APIVORUS, LINN.

Wesperbussard 


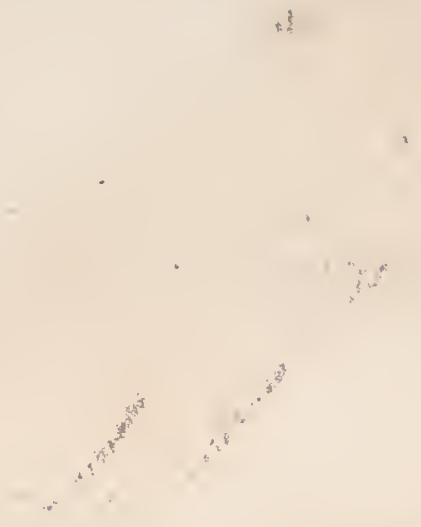

$10=3$ 


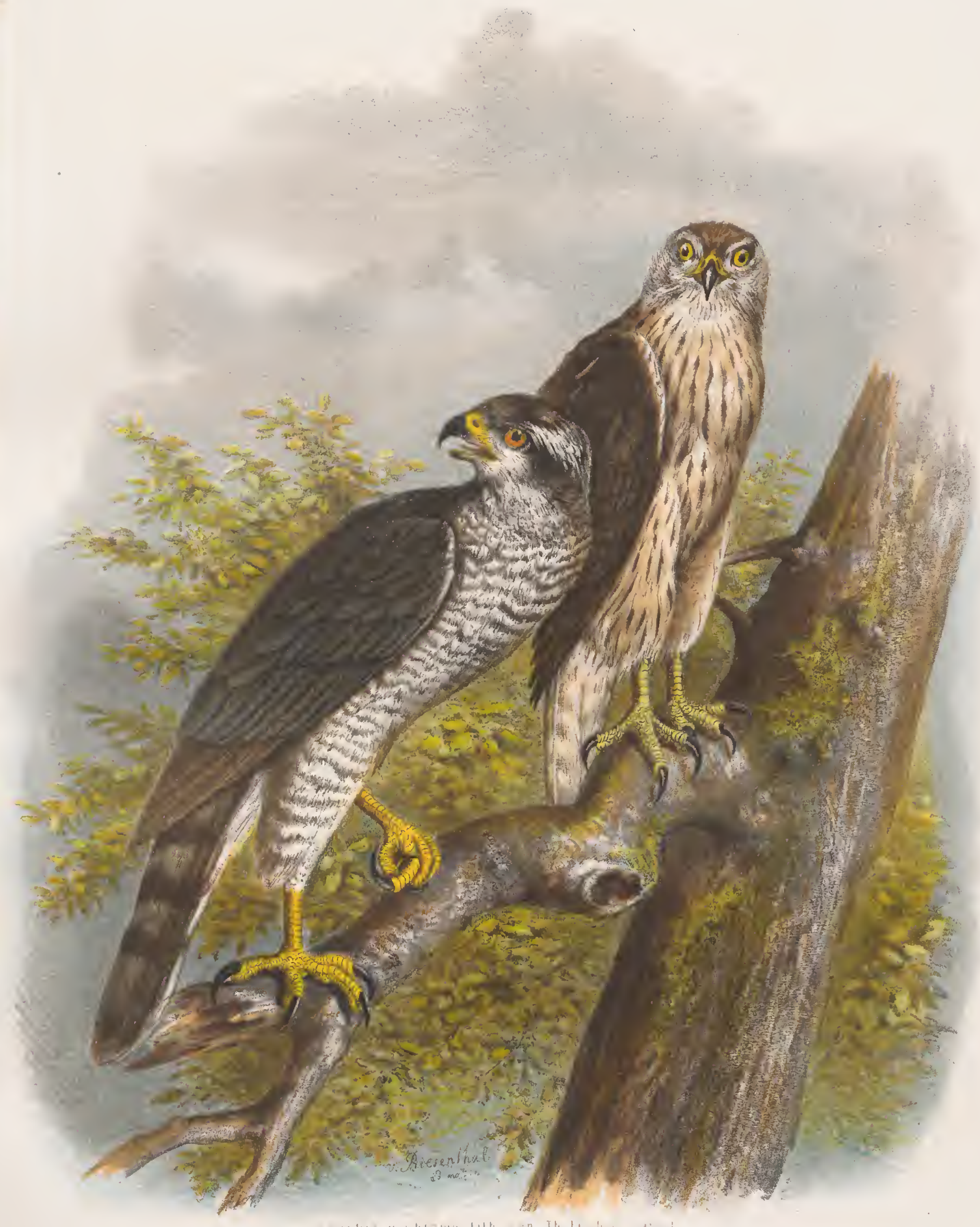


Taf. MI

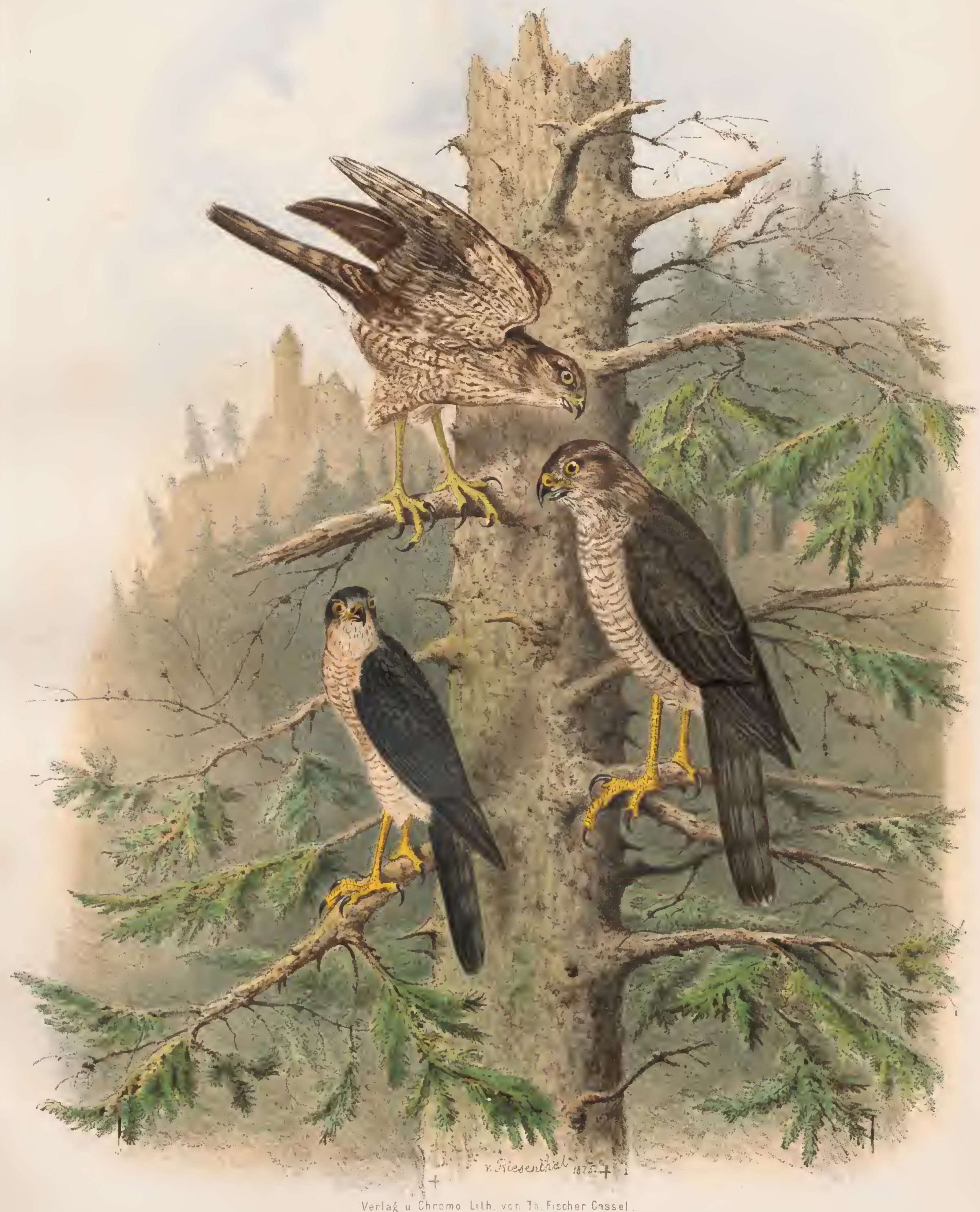




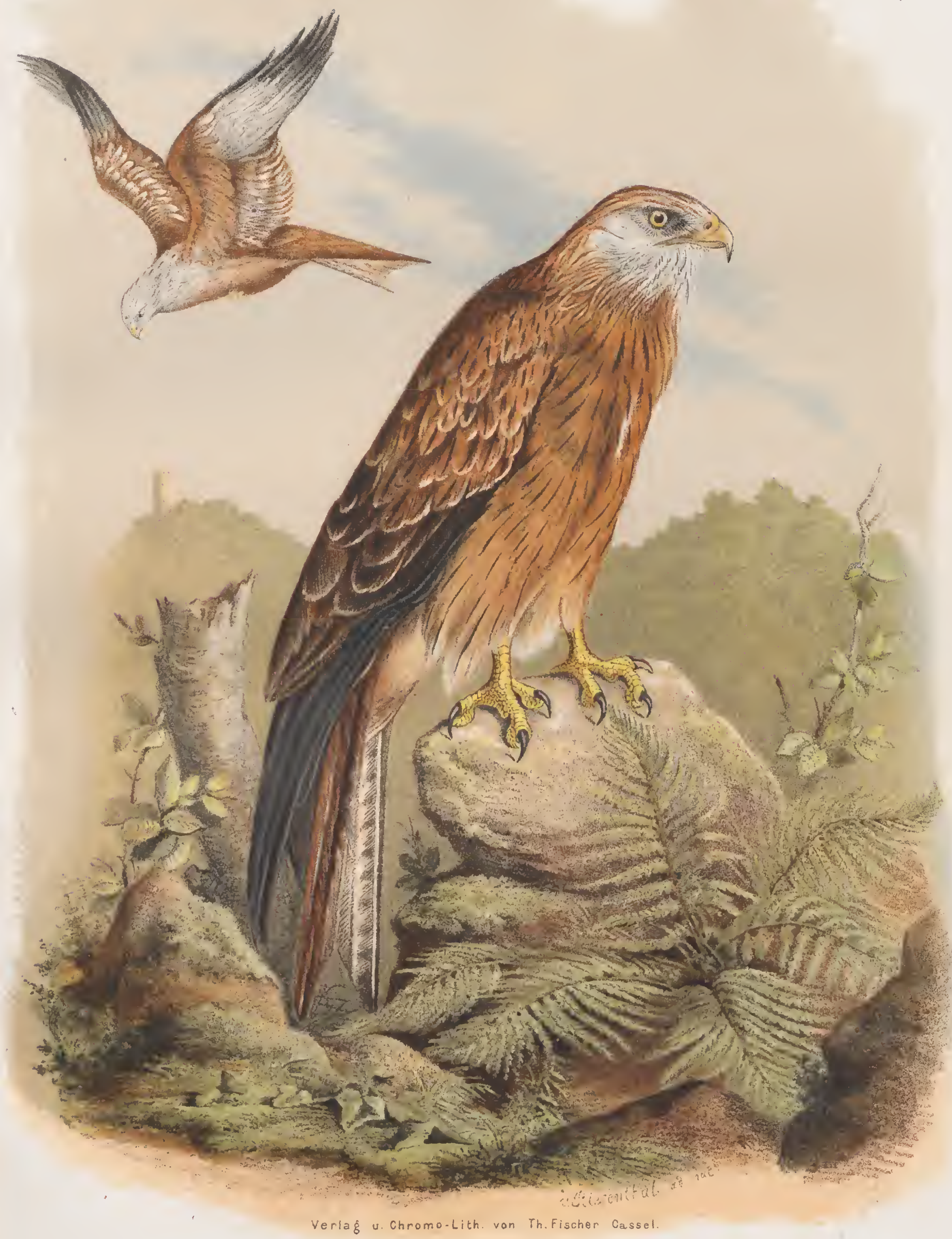





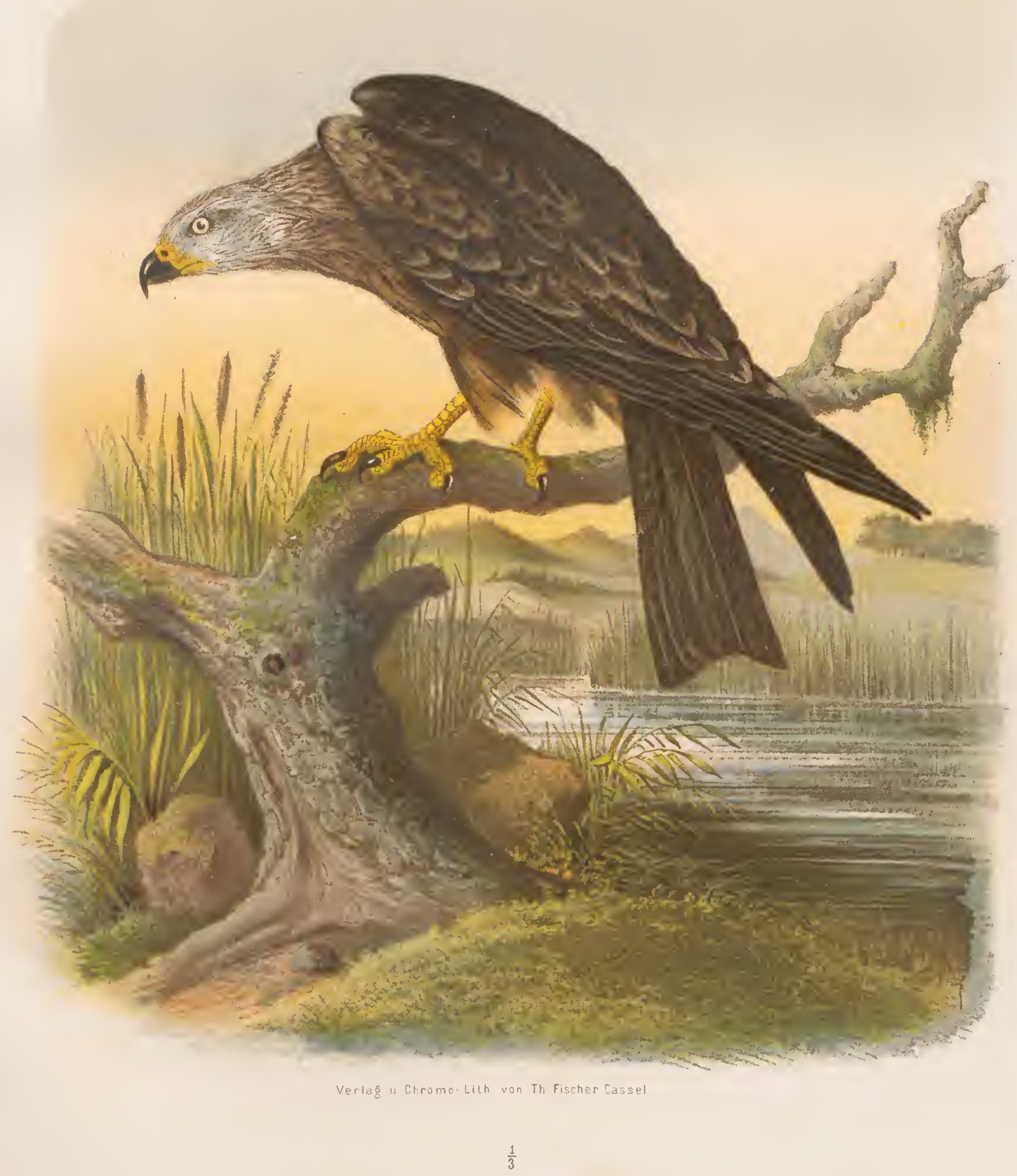

MILVUS MIGRANS. BODD.

Schwarzbrauner Milan

Altes Weibchen 



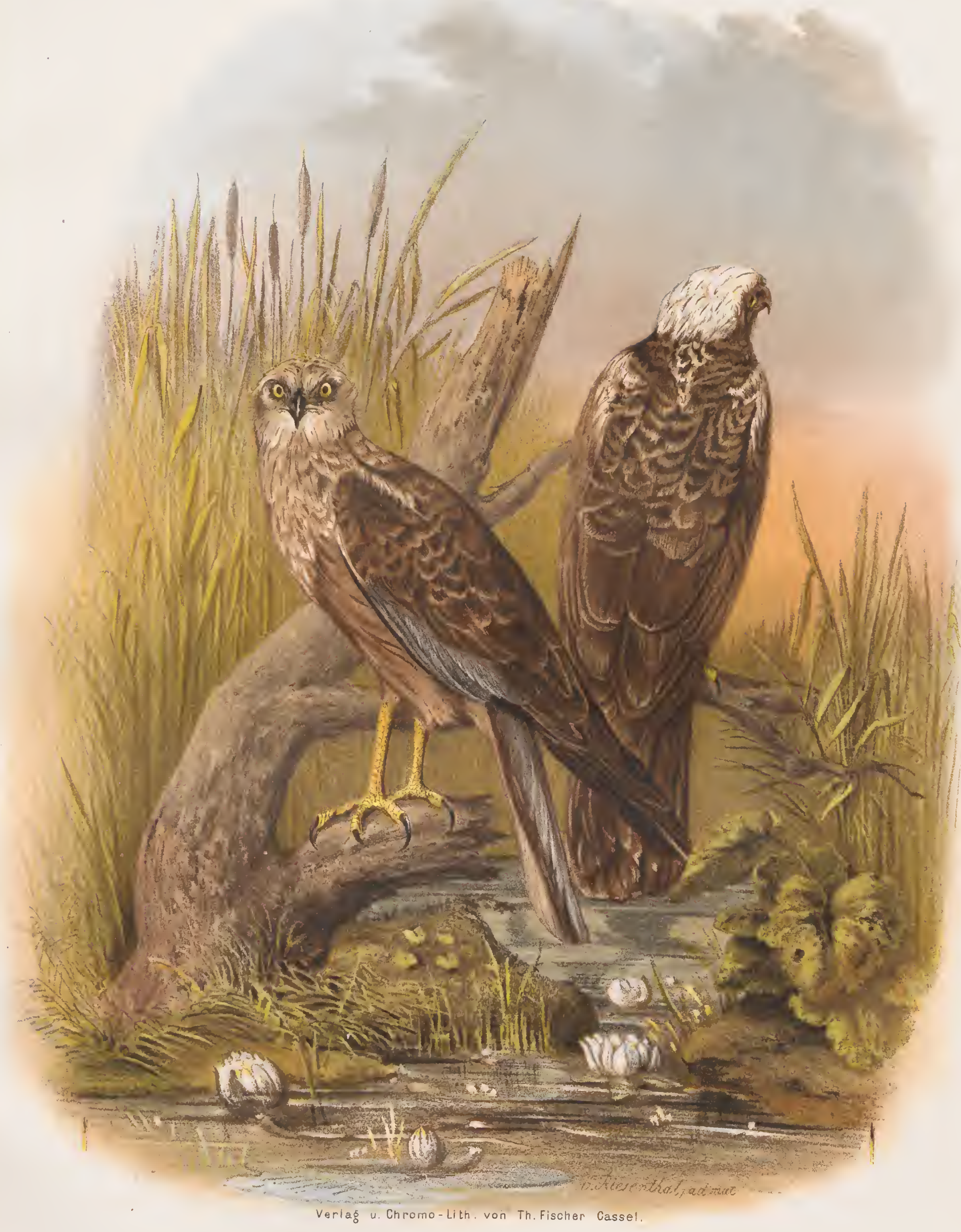

CIRCUS AERUGINOSUS, LINN. 



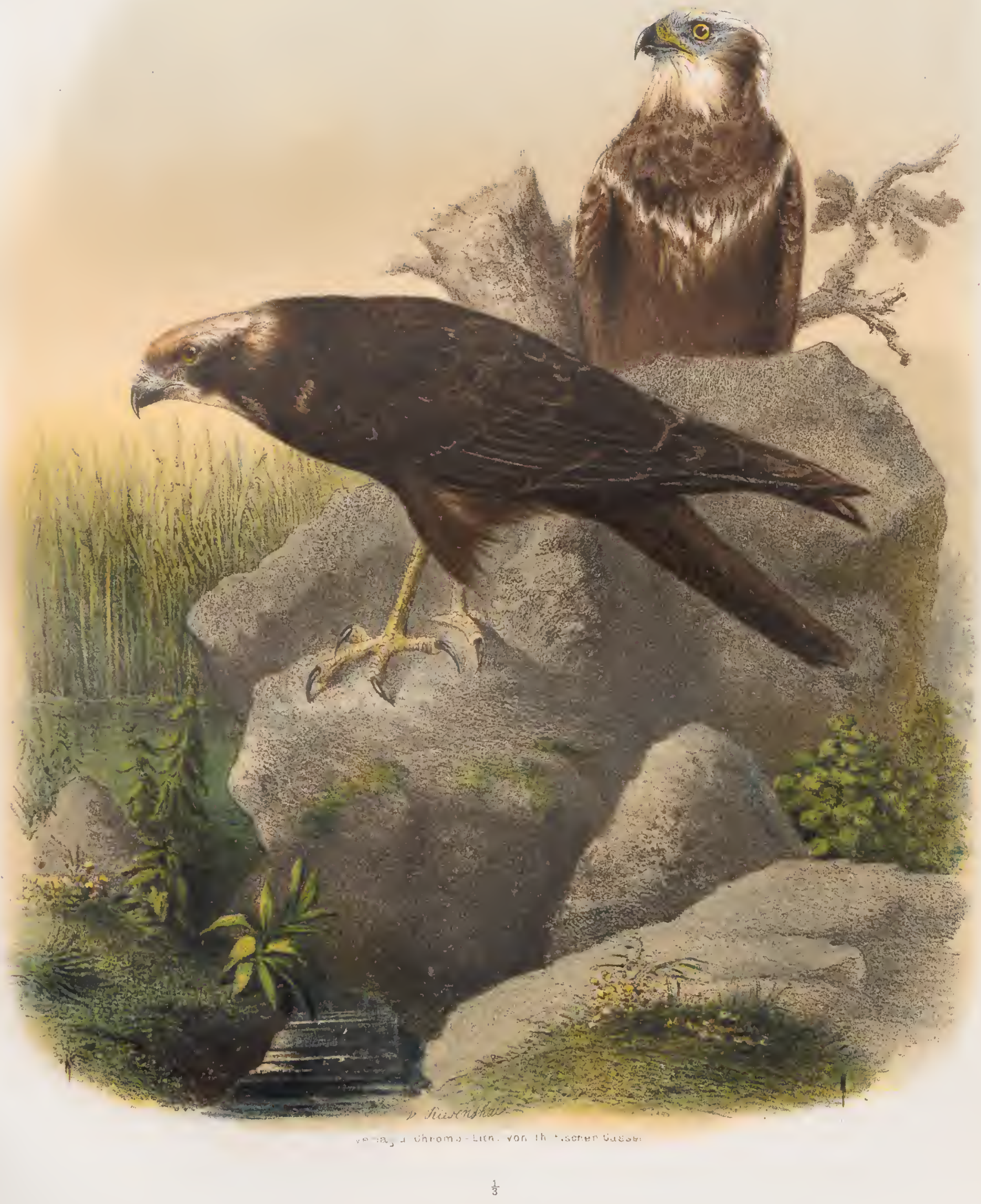





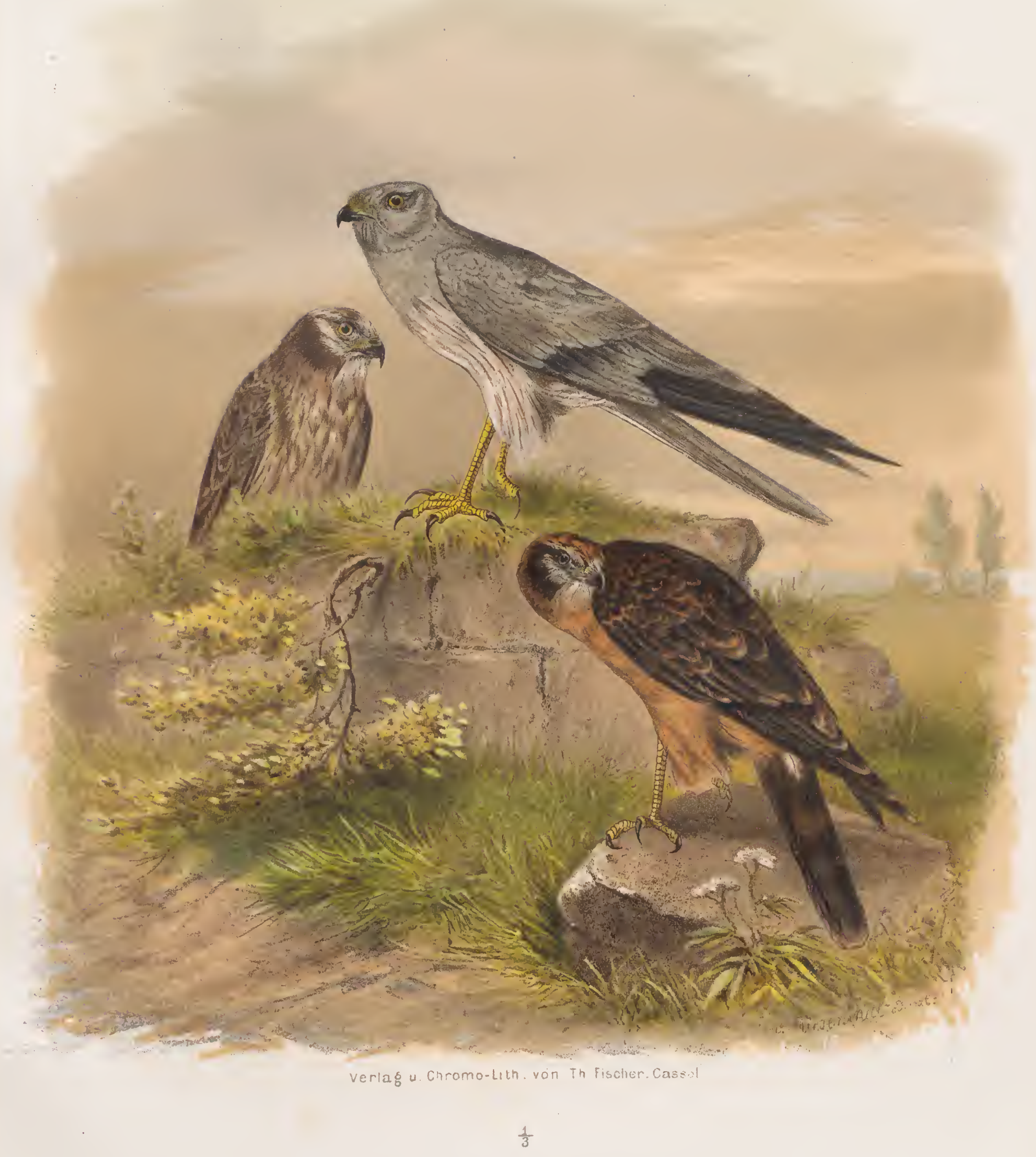

Altes Weibohen

CIRCUS CINERACEUS, MONT. Wiesenweine. 
I 


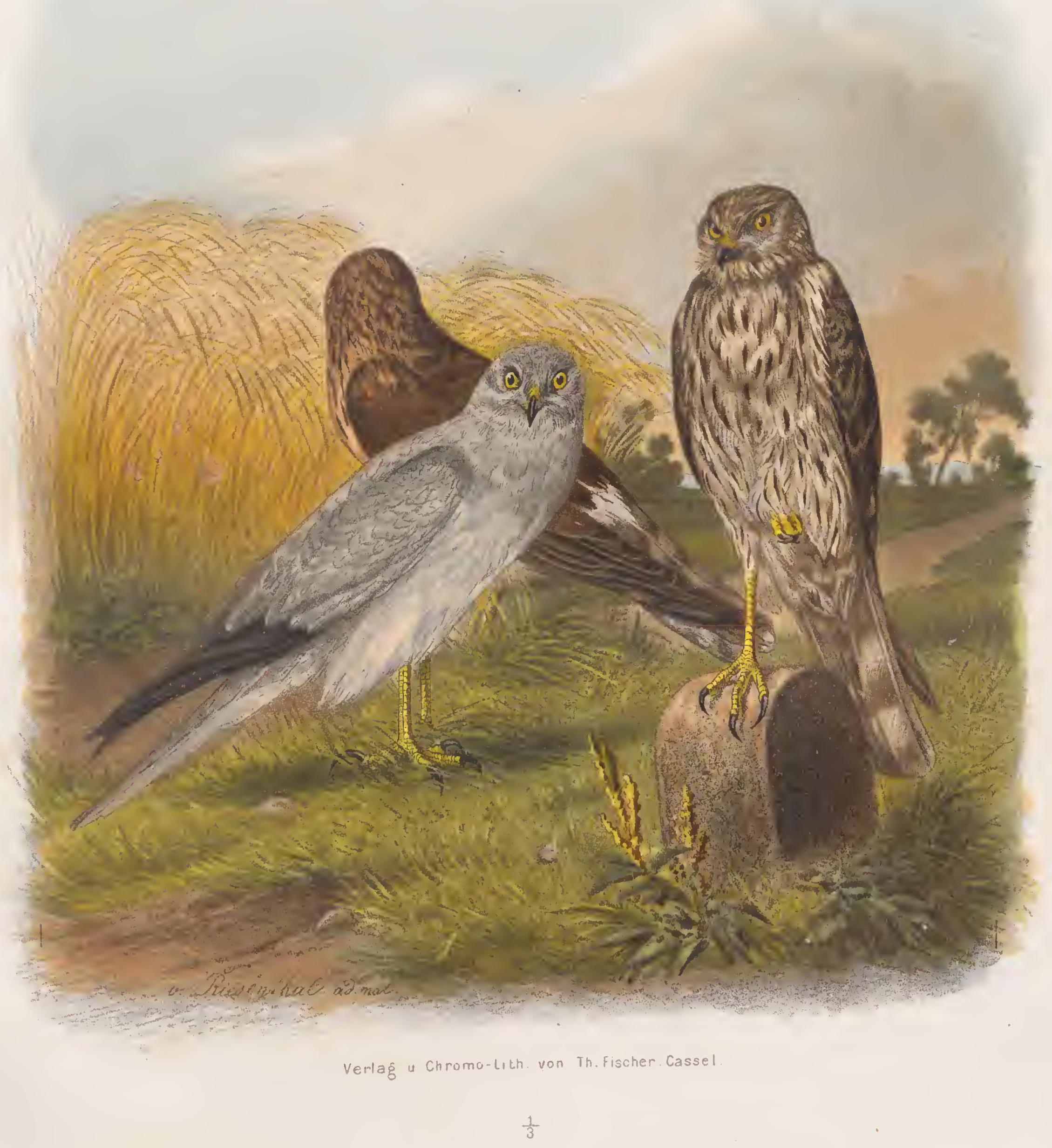

CIRCUS PYGARGUS, CUV. 



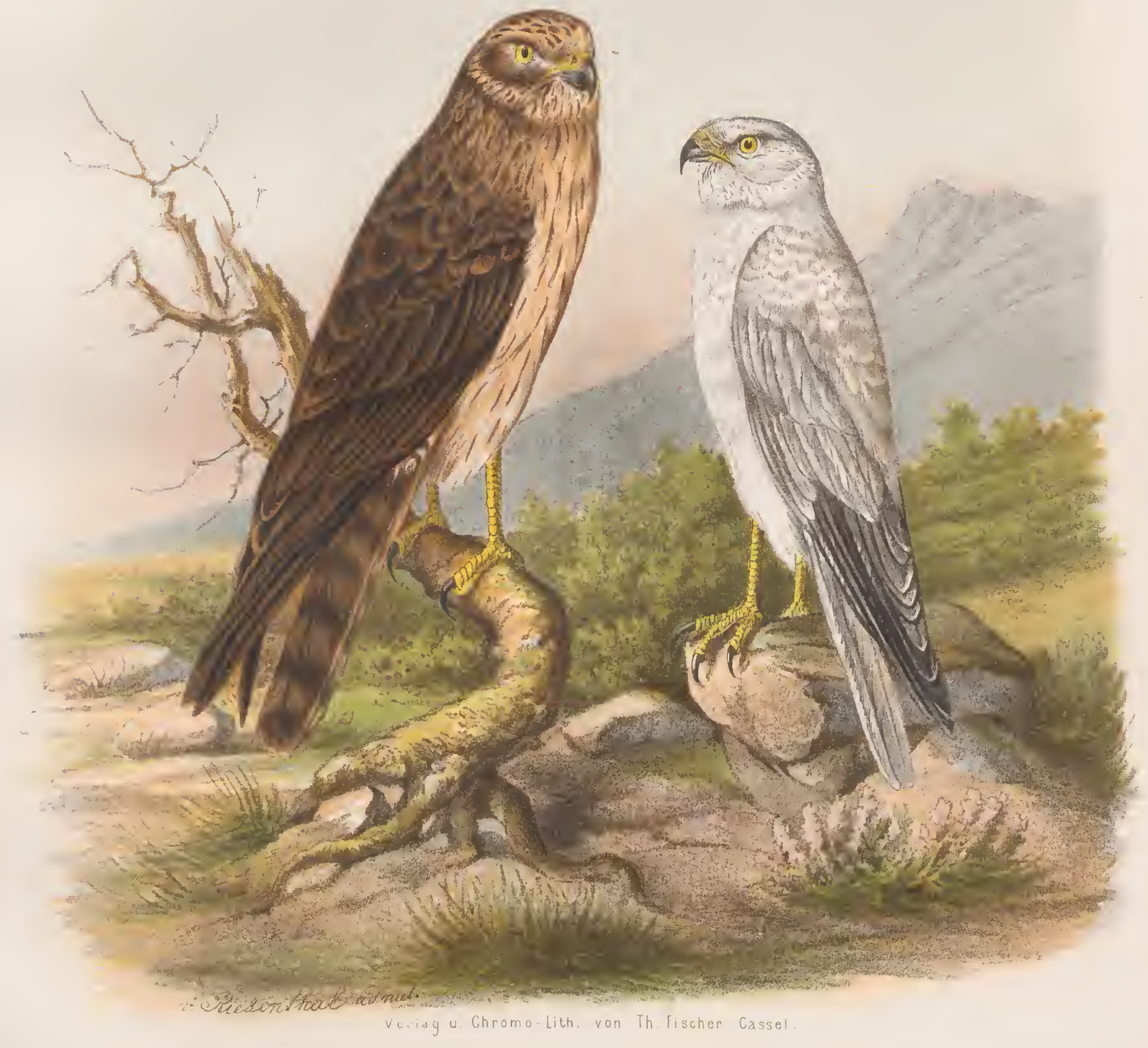

CIRCUS PALLIDUS, BRUCH.

Steppenweihe. 


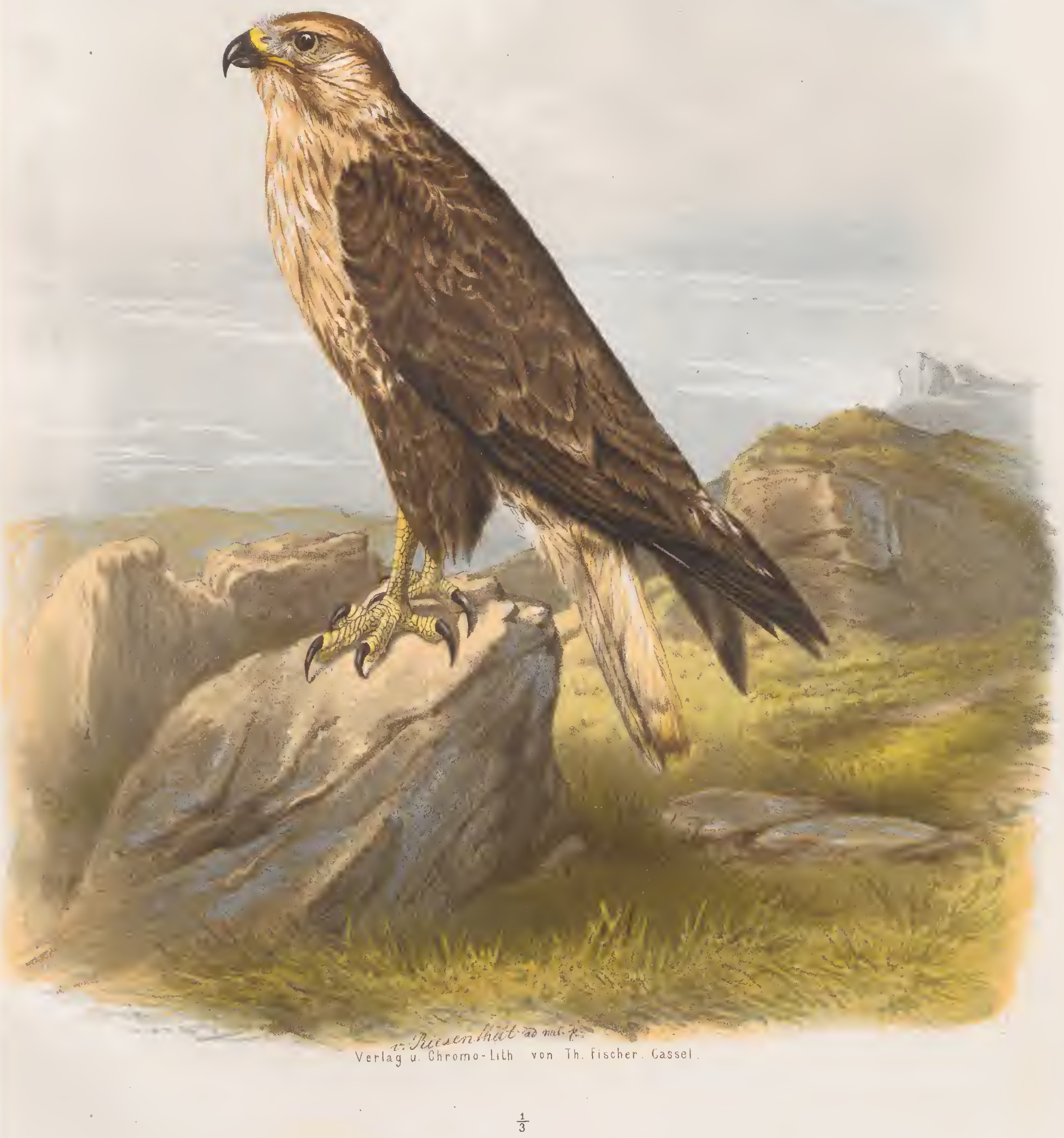

BUTEO FEROX, GMEL.

Adler Bussard. 



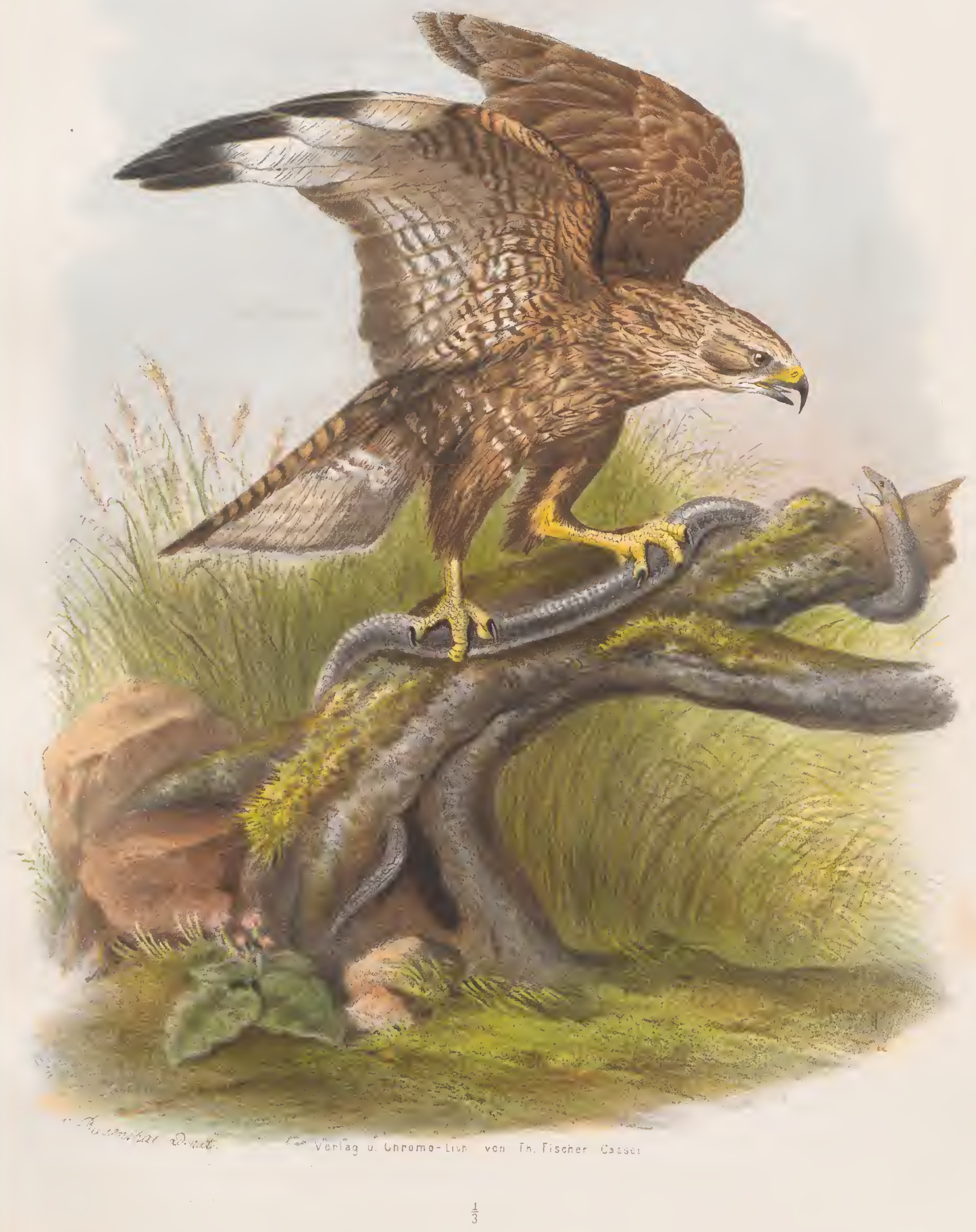

BUTEO DESERTORUM, DAUD.

Steppen-Bussard. 



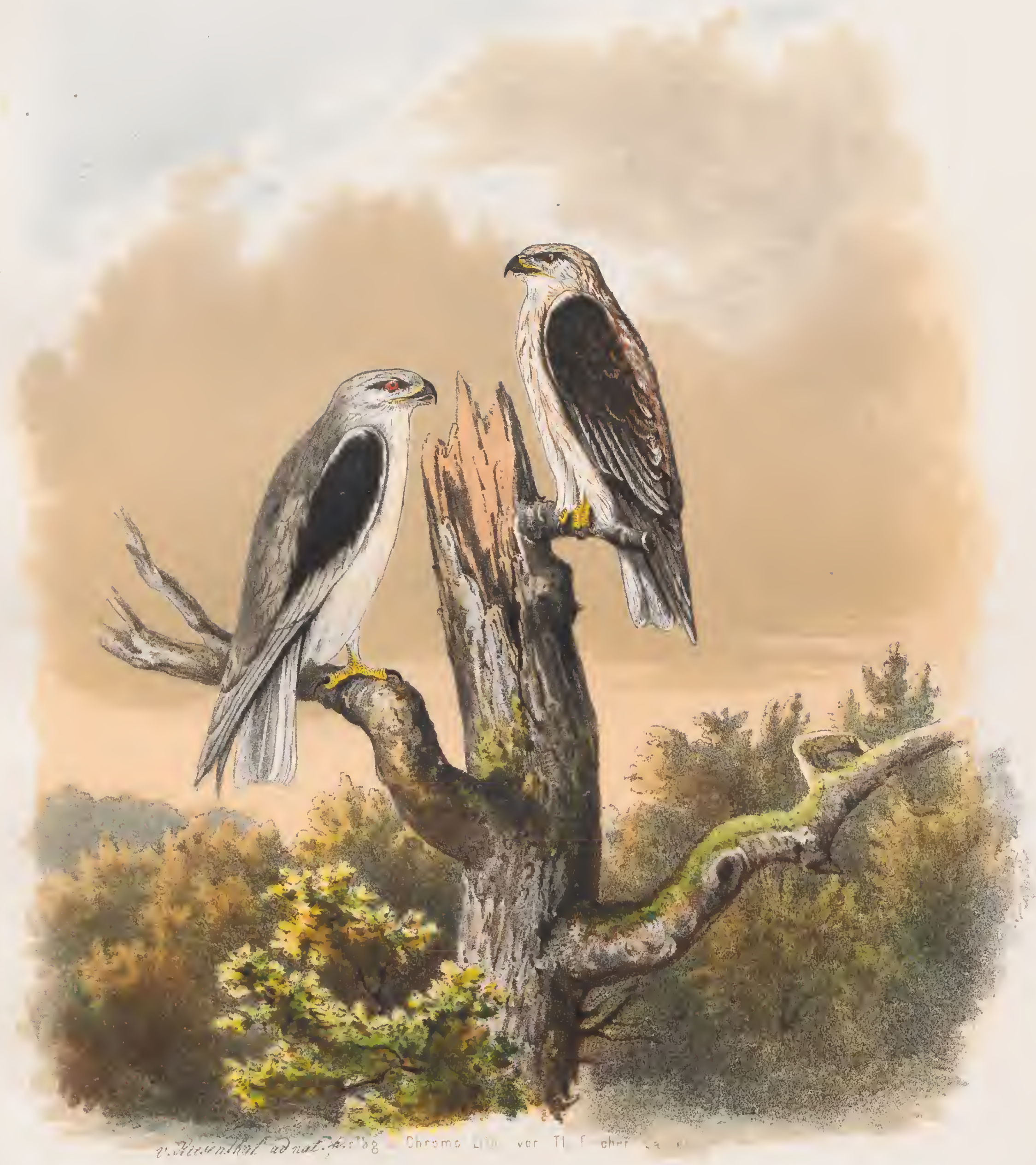

ELANUS MELANOPTERUS, DAUD. Schwarzflügelicher Falkenmilan. Alt. Jung. 



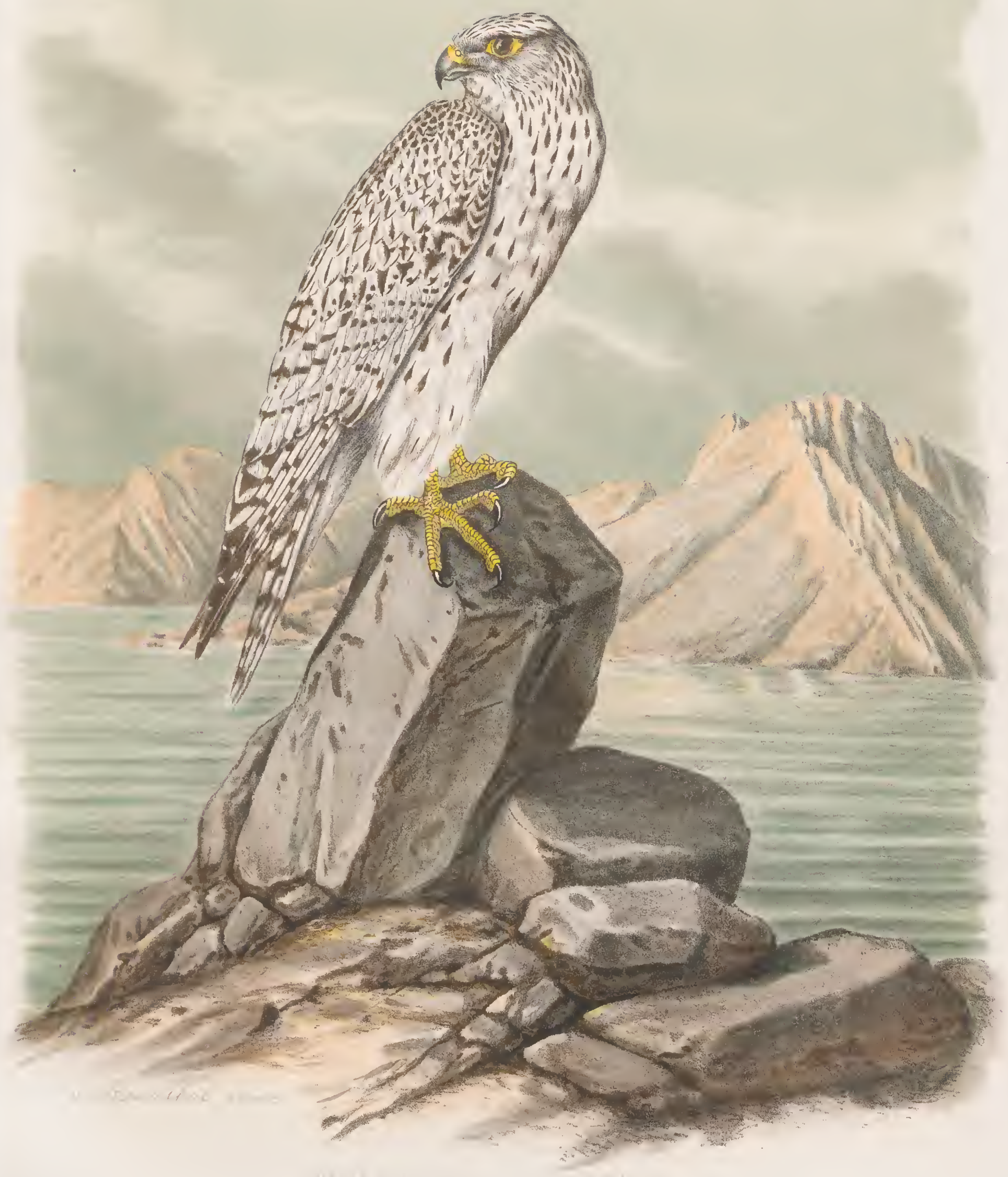

FALCO CANDICANS, AUCT. Isfandischer jaódfalke. 



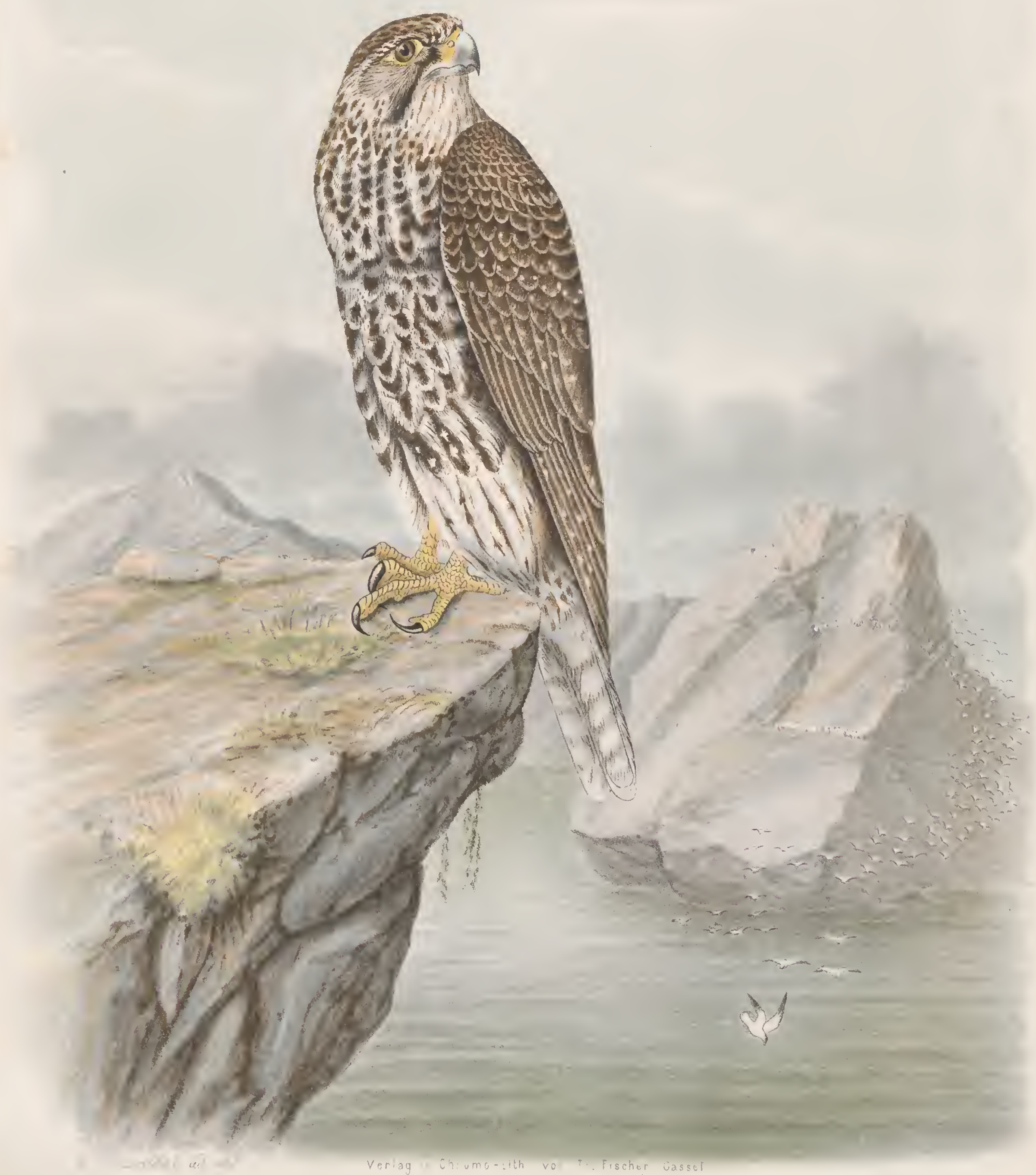

FALCO CANDICANS, AUCT. Isländischer Jagdfalke. Jüngeres Weibchen. 

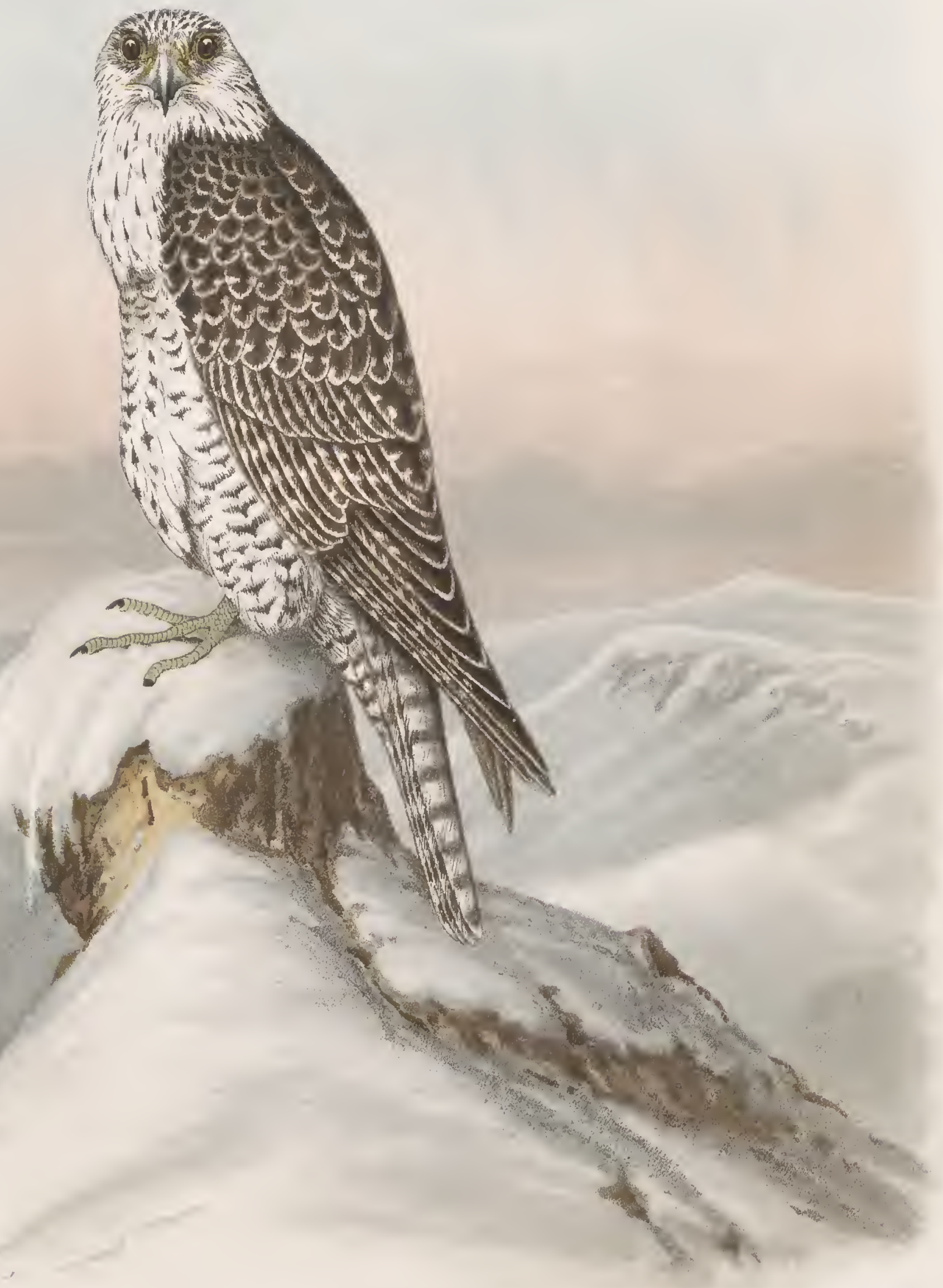

FALCO ARCTICUS, HOLBÖLL. Gröniandischer Jagdfalke. 


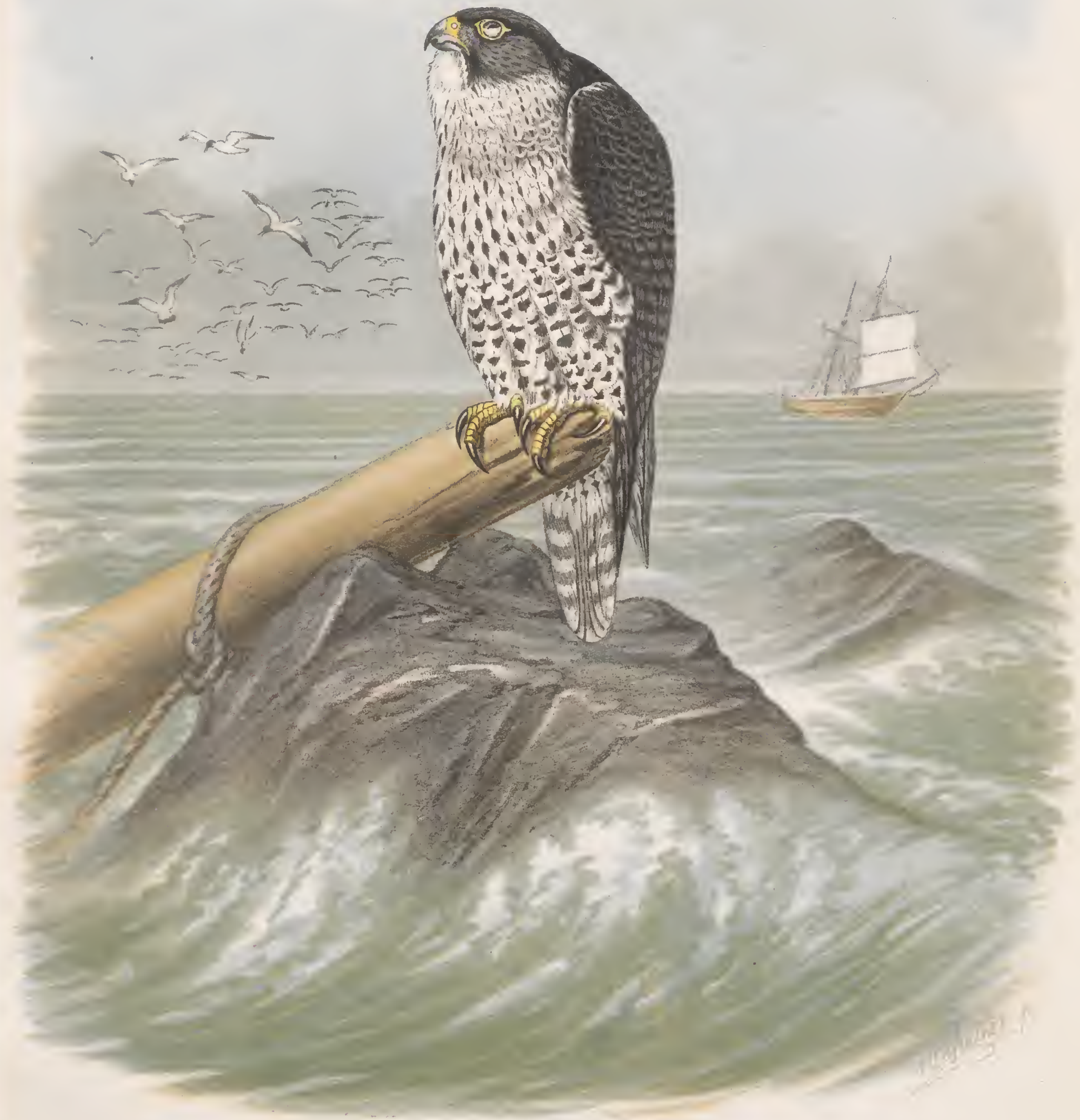

FALCO GYRFALCO, SCHLEG.

Norwegischer Jagdfalke. 

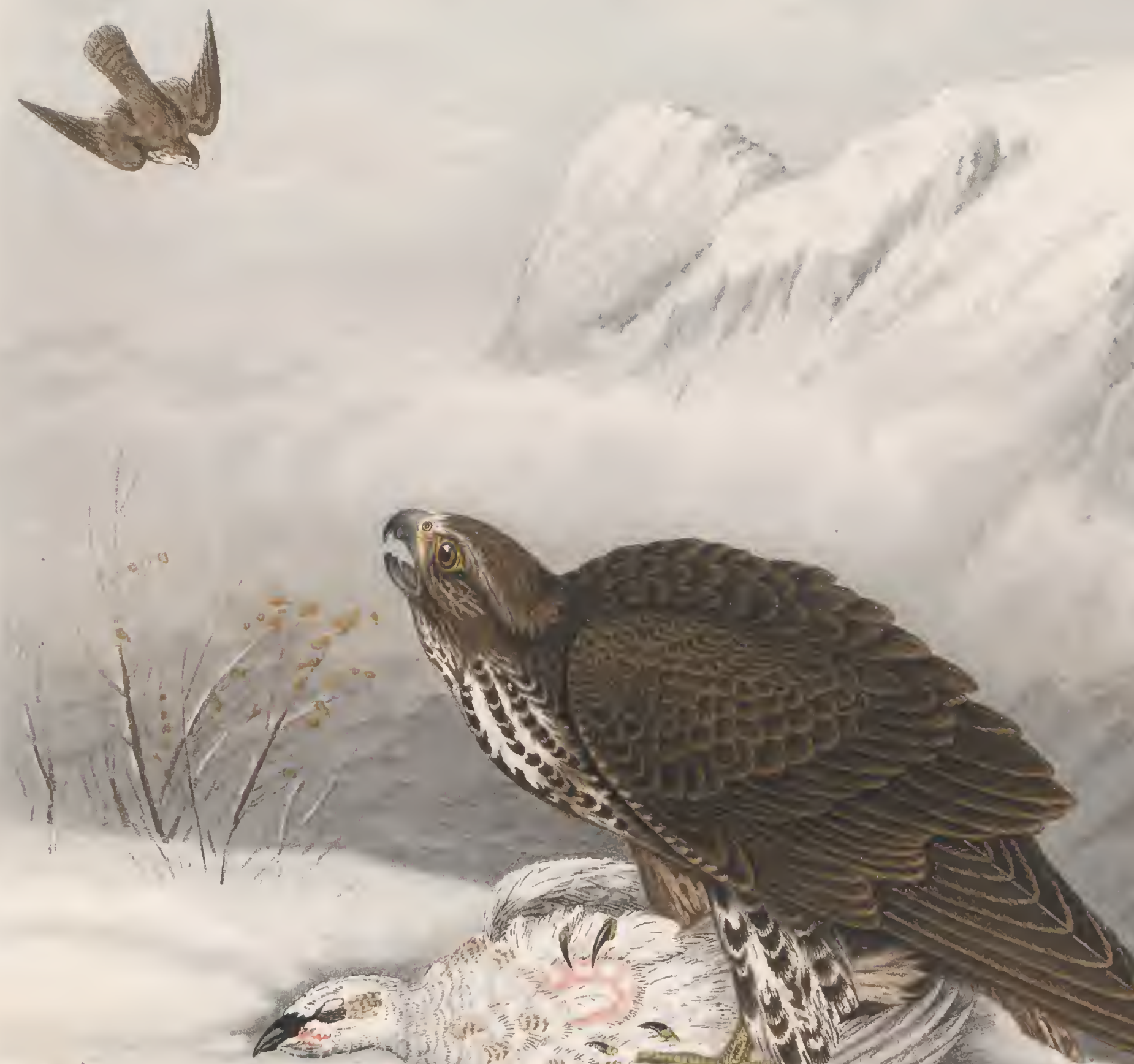

.
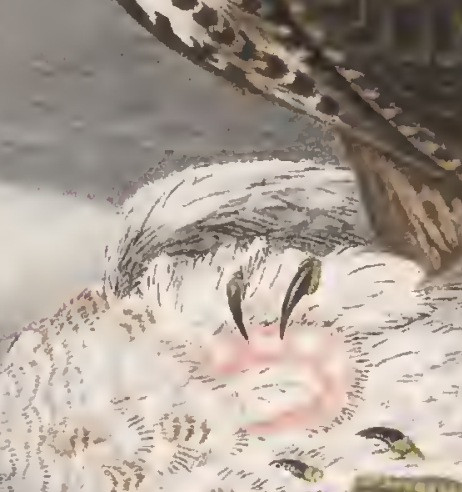

and 5
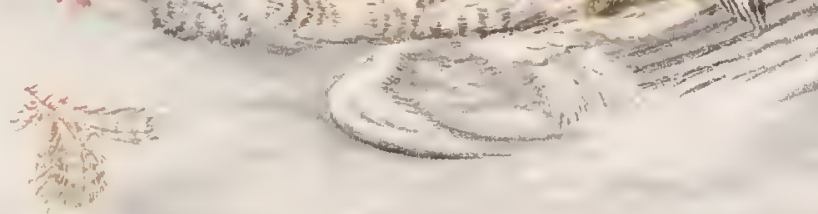

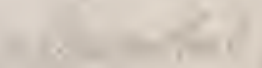

FALCO GYRFALCO, SCHLEG.

Norwegischer Jagdfalke 



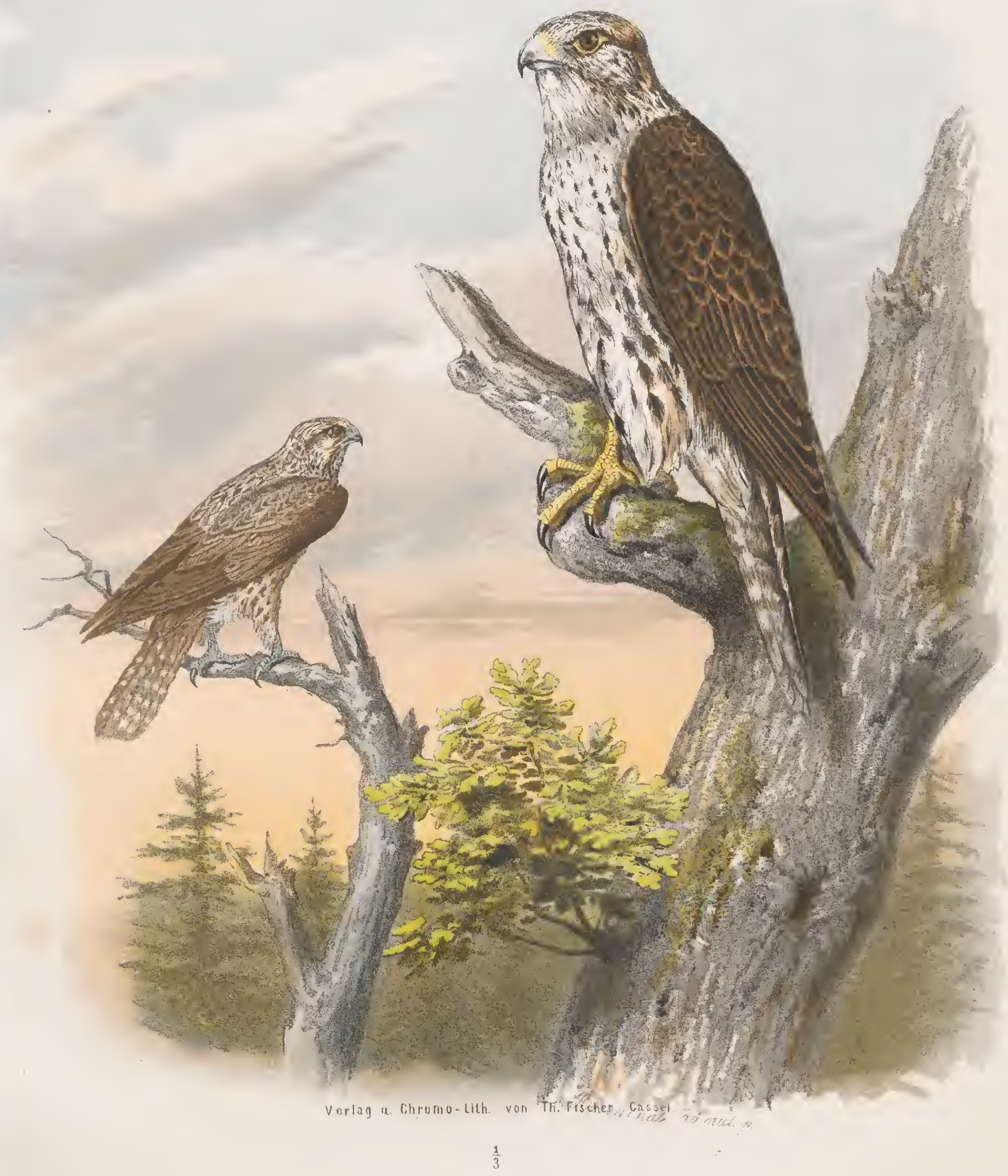

FALCO SAOER, SCHLEG.

Würgfalke.

Junges Weibchen. Altes Männchen 


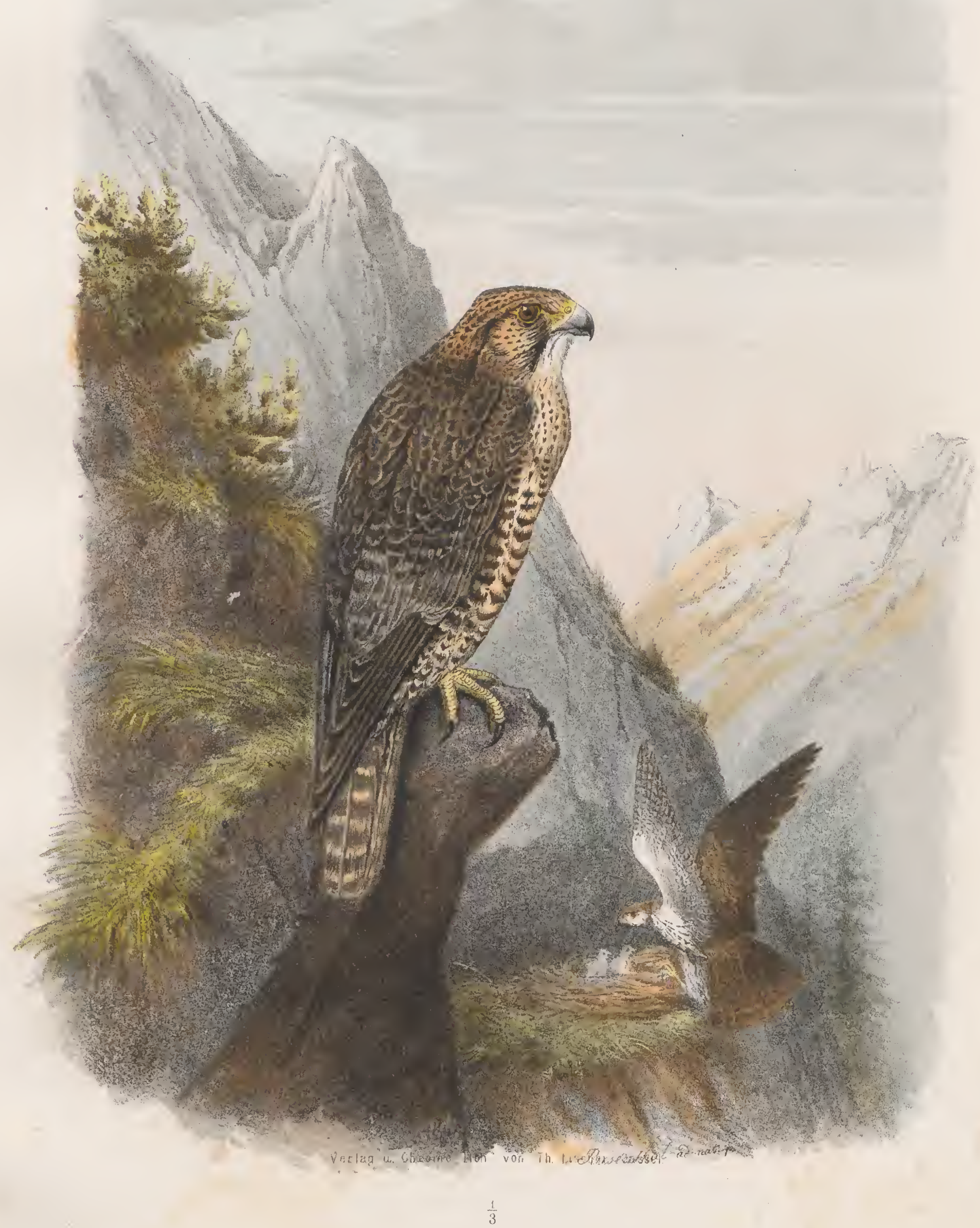

FALCO FELDEGGII, SCHLEG.

Feldeggs-Falke

Altes Männchen Jüng: Weibchen 


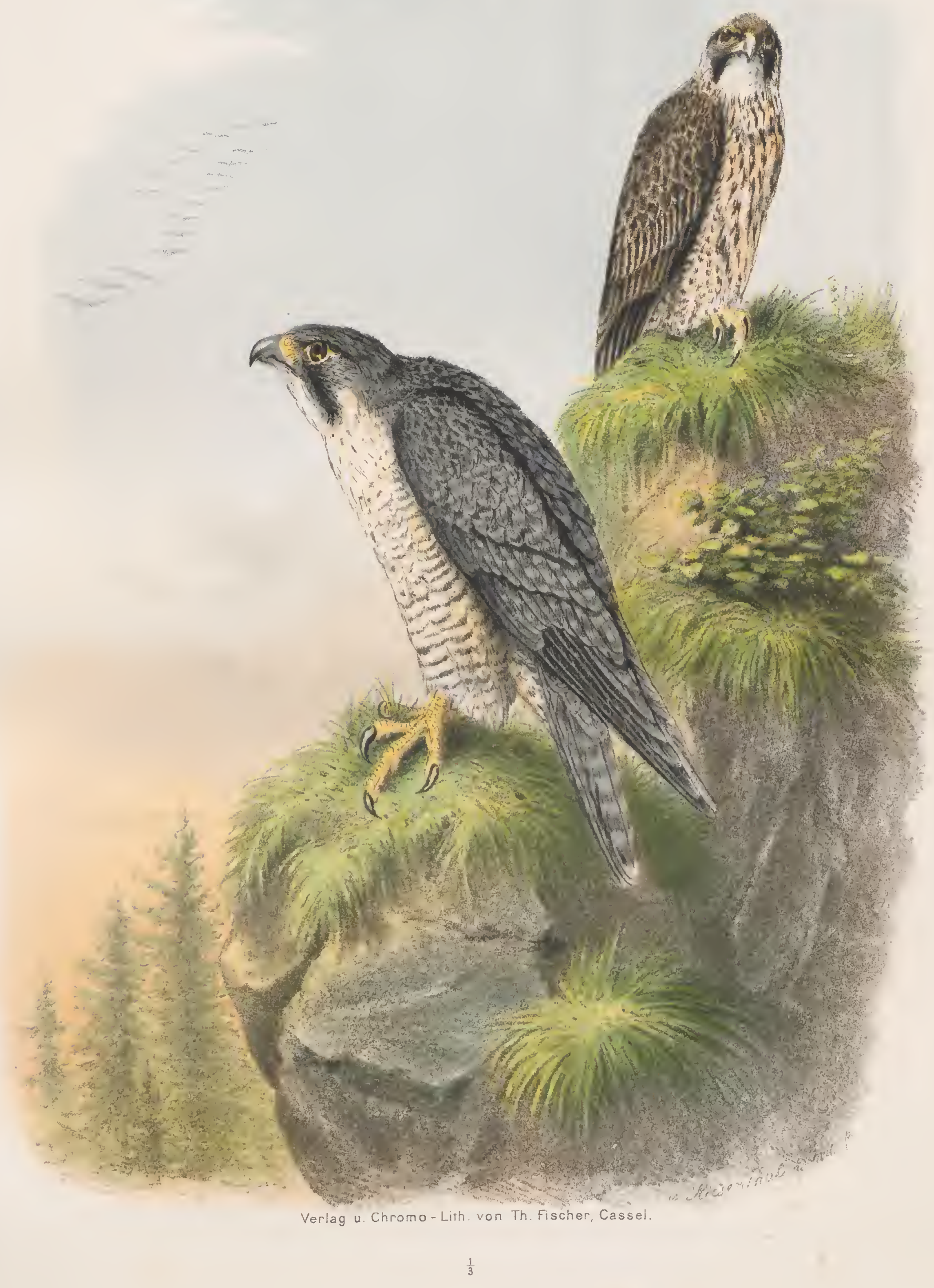

FALCO PEREGRINUS, LINN.

Wanderfalke. 


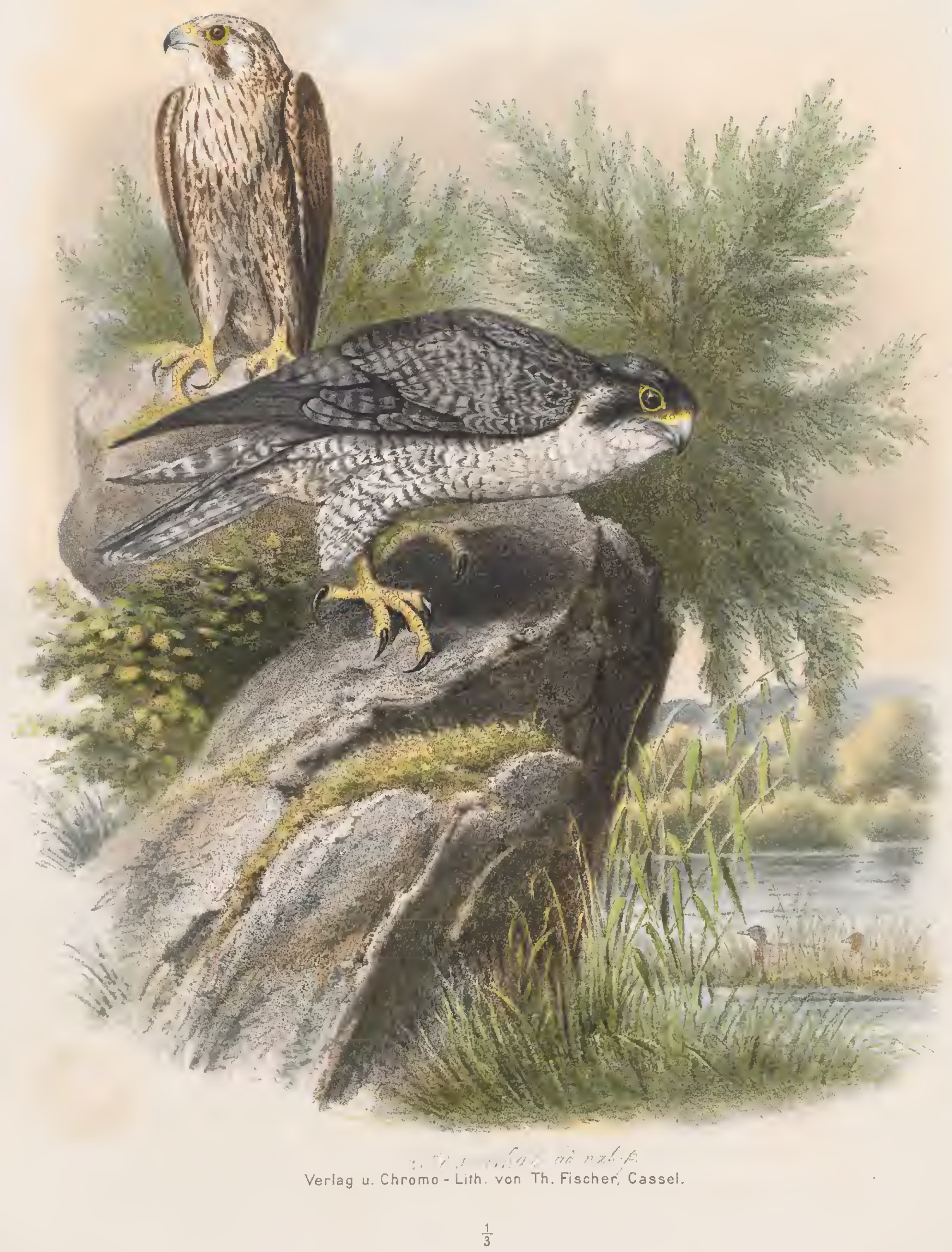

FALCO PEREGRINUS, LINN.

Wanderfalke. 



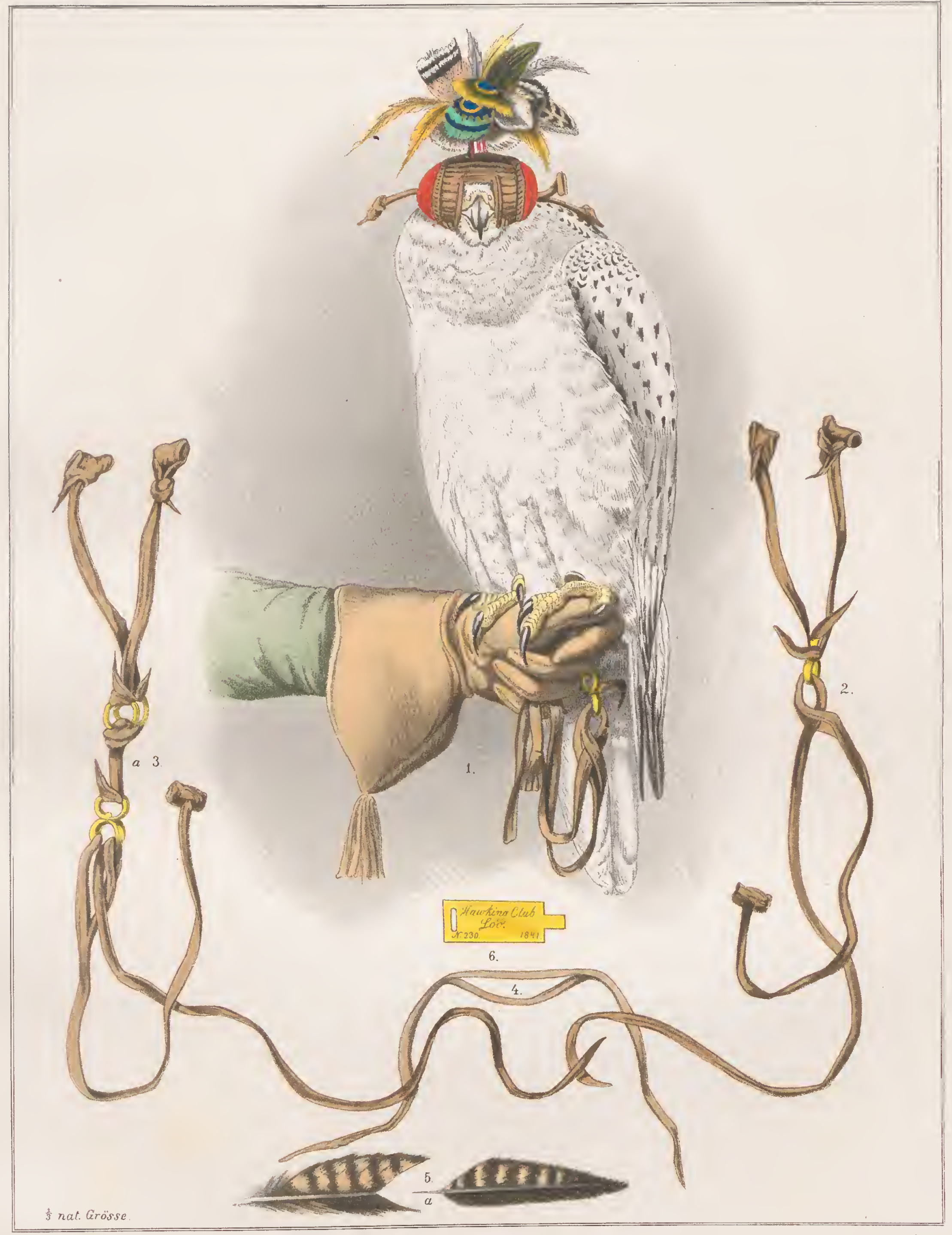

v. Riesenthal p. n. Tr, d. Fars.

Verlag und ('hromo-Lith. won Th. Fischer, Cassel.

Fig. 1. Der Falke jagdgerecht auf der Faust. - Fig. 2. Fessel für Falken. - Fig. 3. Fcssel für Habichte, a, die Kurzfessel. - Fig. 4. Schleife, den Falken die Flügel festzubiaden. - Fig. 5. Wiederhergestcllte Feder; a, die eingeschobene Nadel. - Fig. 6. Messingtafel, an die Füssc von Falken geschlagener Reiher zu befestigen, welchen man die Freiheit wicdergab. 



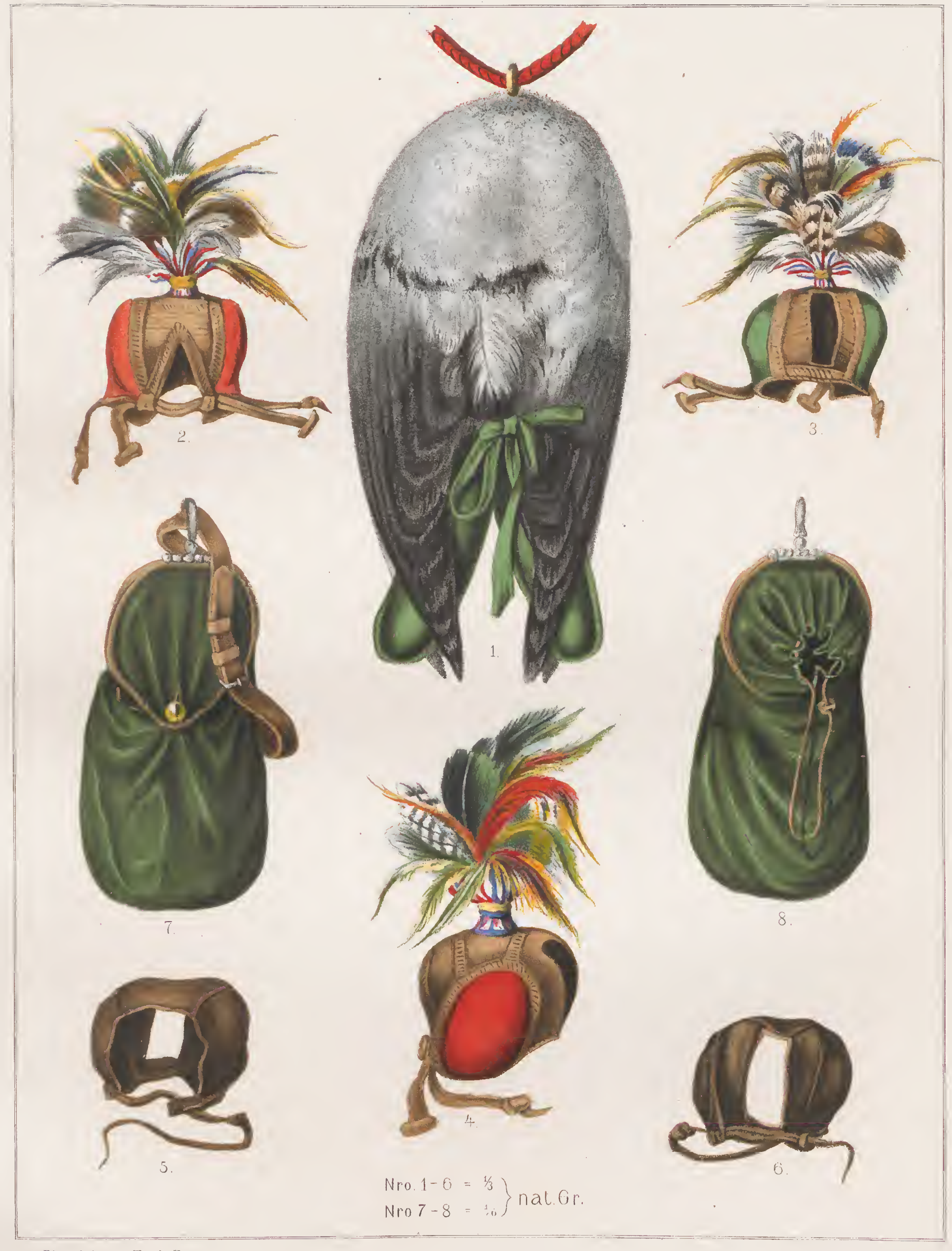

Verlag und Chromo-Lith. von Th. Fischer, Cassel.

Fig. 1. Das Foderspiel. - Fig. 2, 3, 4. Stockhauben für abgetragene Falken. - Fig. 5, 6. Einfaehe Hauben für abzutragende Falken. - Fig. 7. Falknertasehe für die Geräthschaften. - Fig. 8. Falknertasehe für die Taube zur Abriehtung der Falken. 



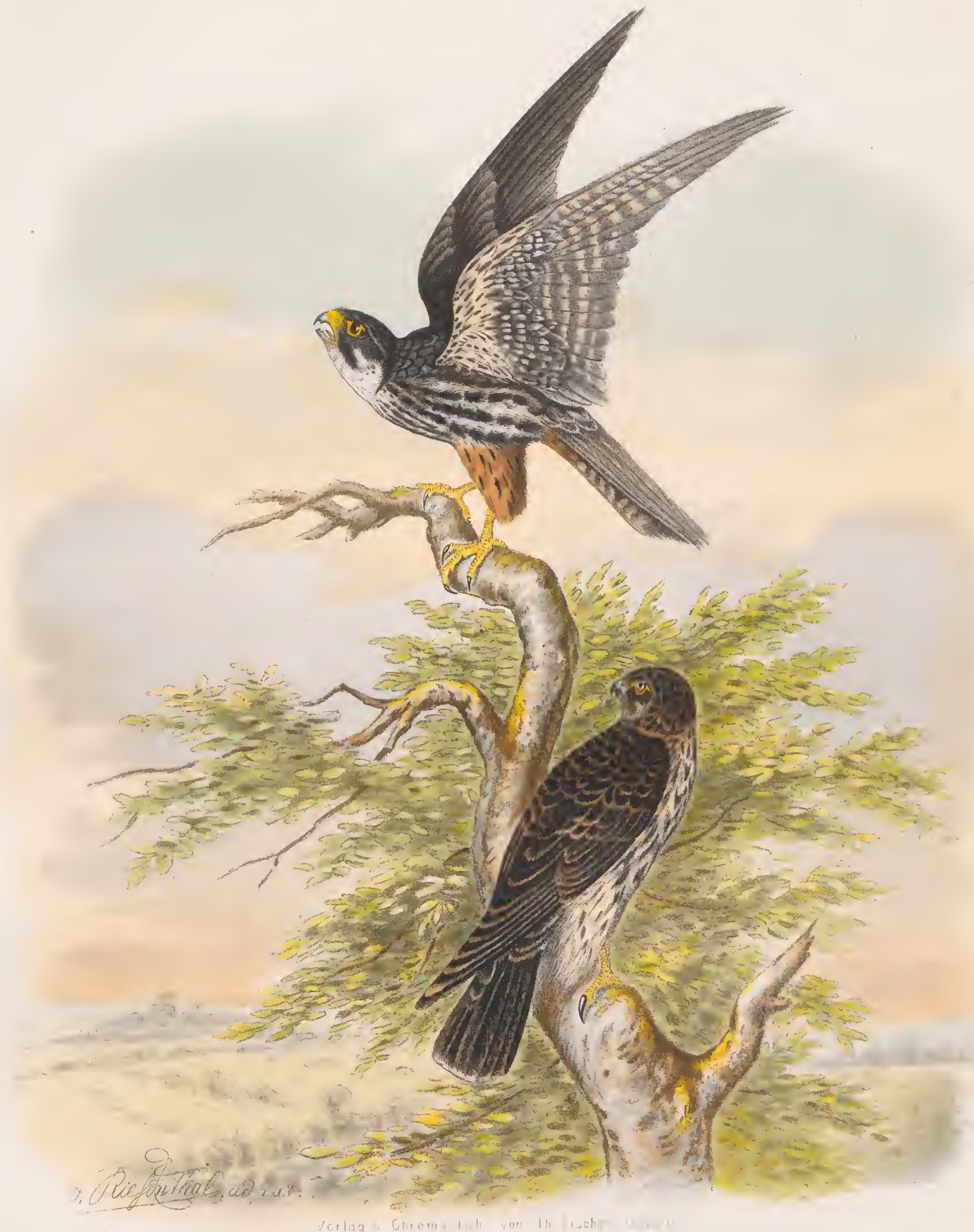

FALGO SUBBUTEO, LINN.

Lerchenfalke. 


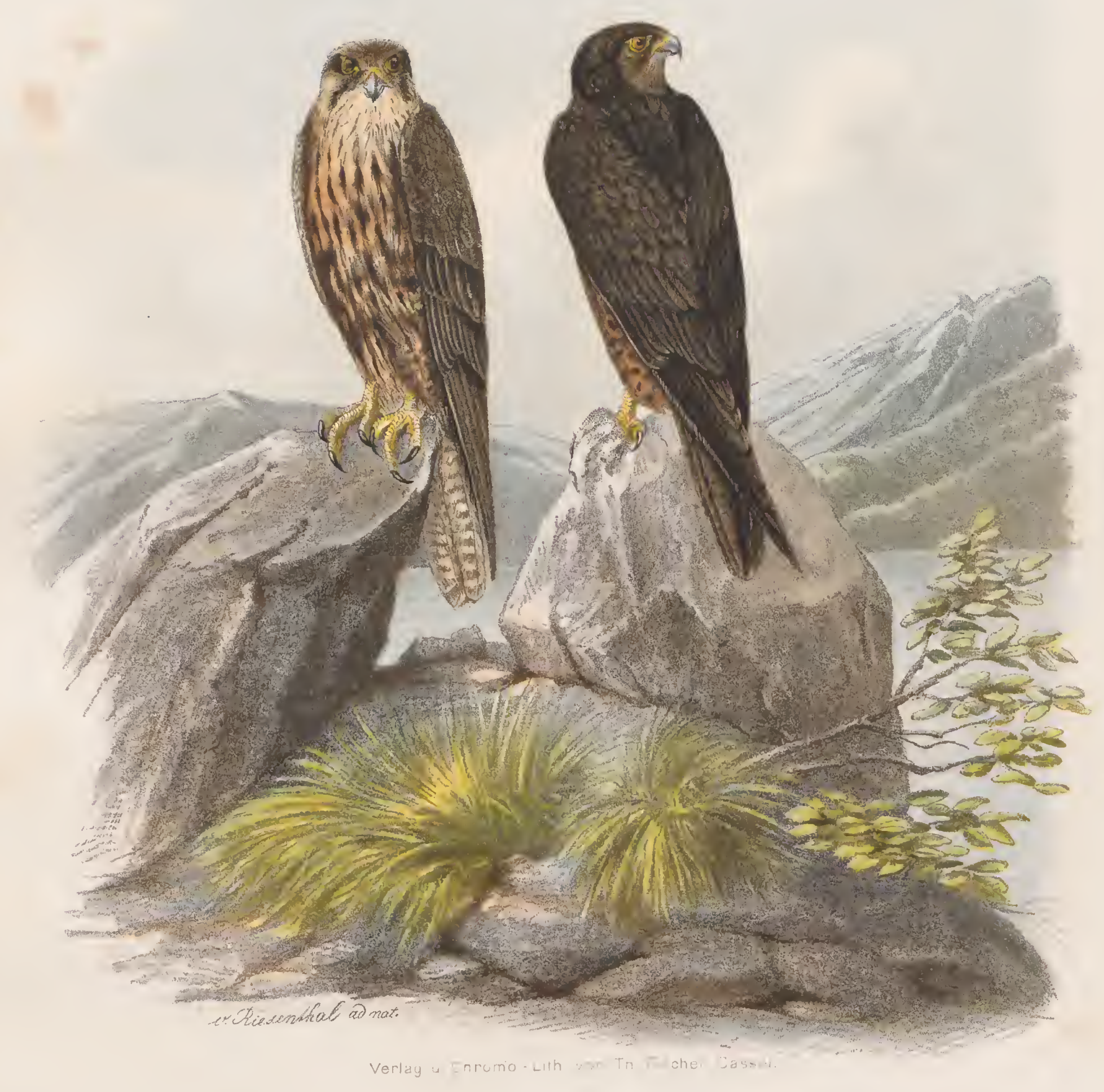

FALCO ELEONORAE, GENÉ.

Eleonoren-Falke. 



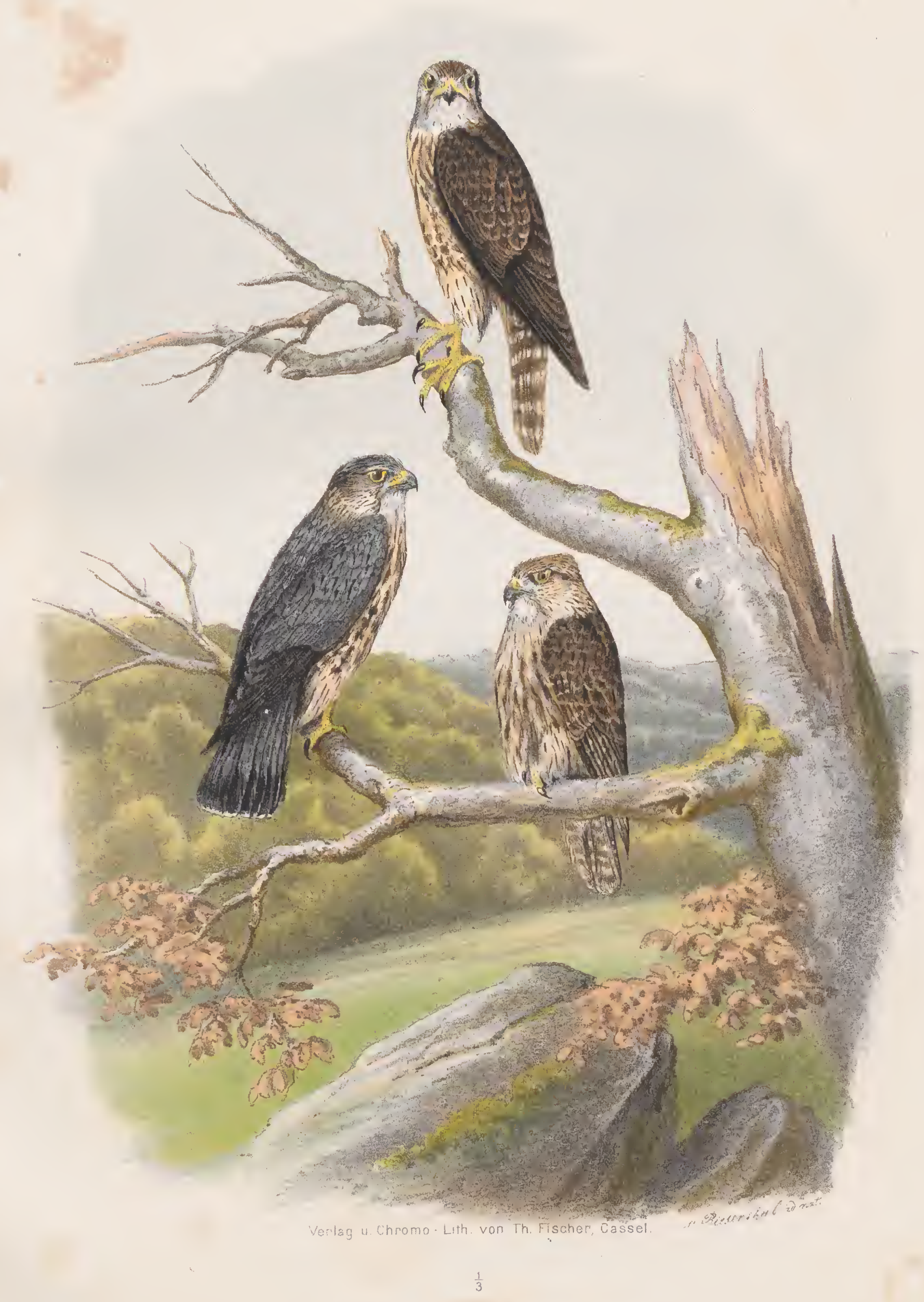

FALCO AESALON, LINN.

Merlin-Falke.

Aites Mannchen Altes Weibchen. Junges Mänchen 



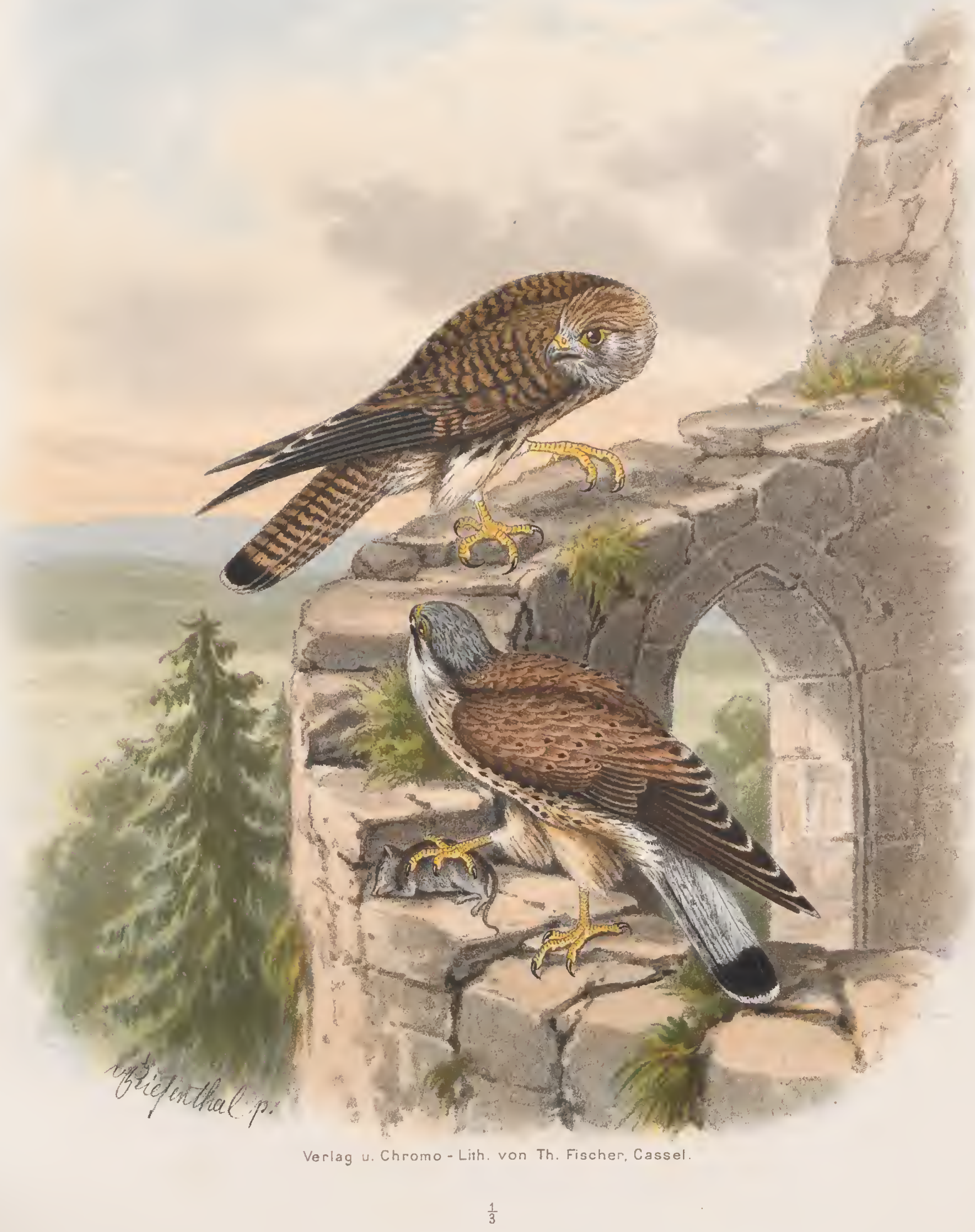

FALCO TINNUNCULUS, LINN.

Thurmfalke.

Aites Woibchen. Altes Männchen 



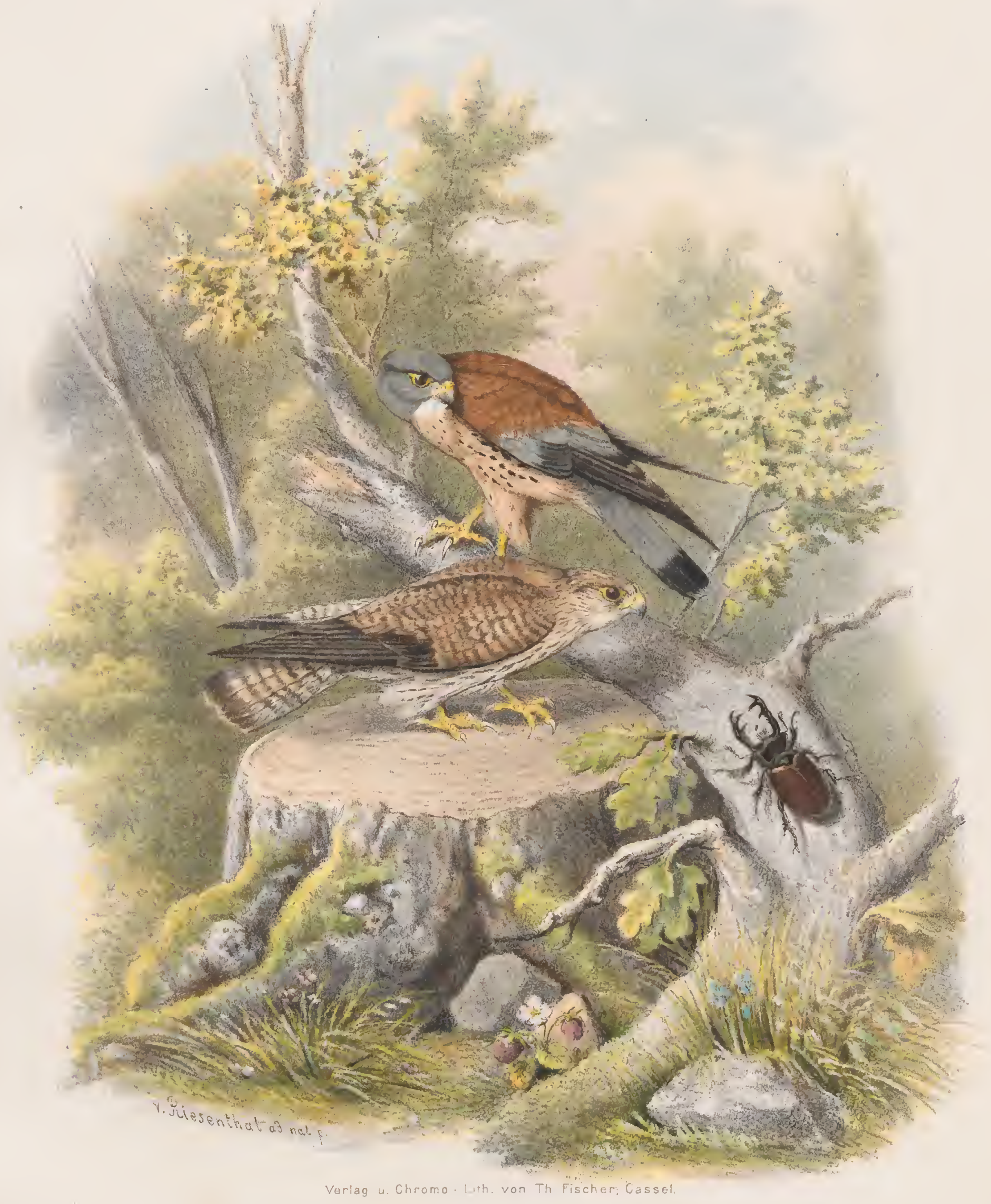

FALCO CENCHRIS, FRISCH.

Röthel - Falke.

Altes Weibchen. Altes Männchen 



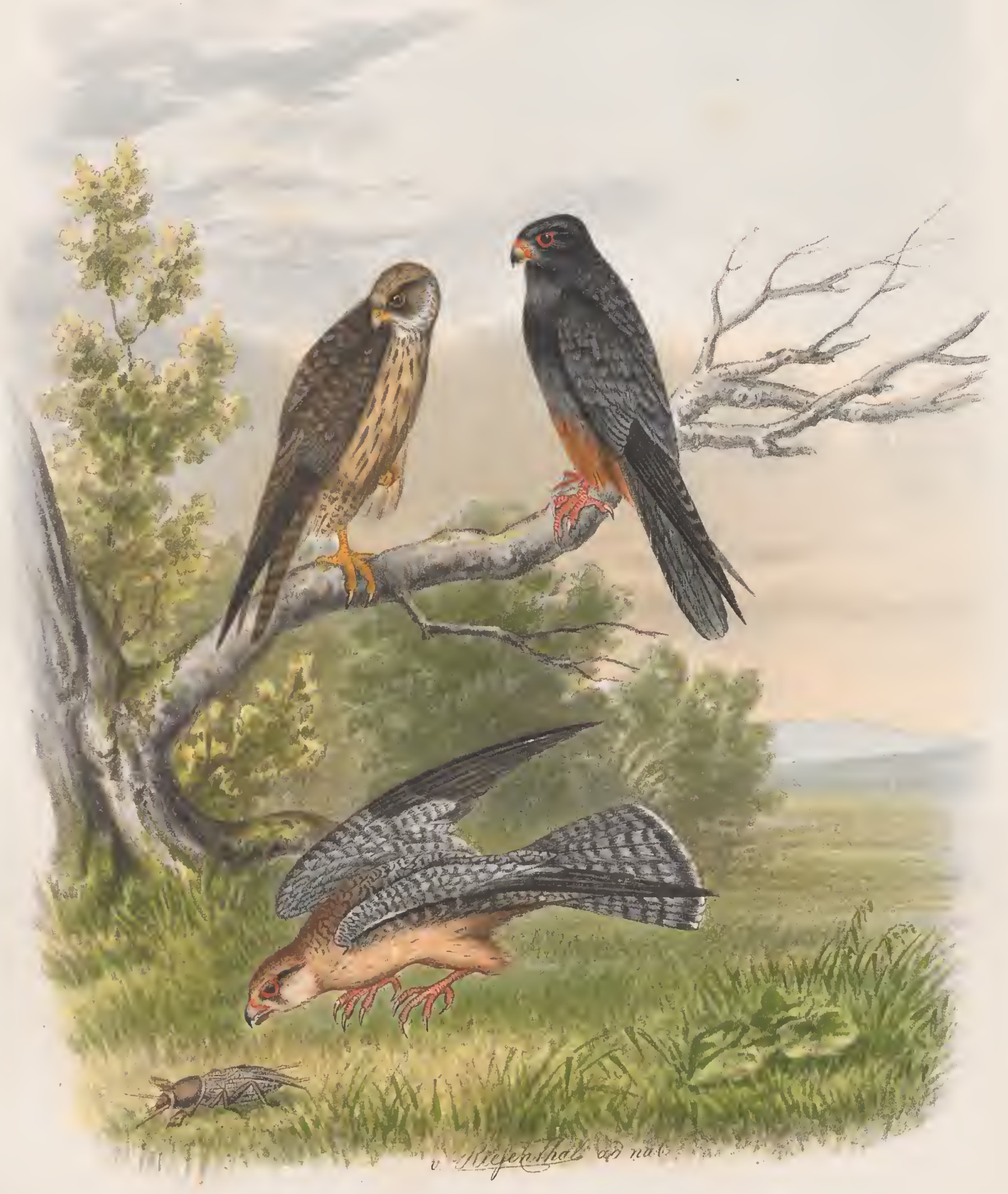

Verlag u. Chromo-Lith. von Th. Fischer, Cassel.

FALCO RUFIPES, BESECKE.

Rothfuss - Falke. 



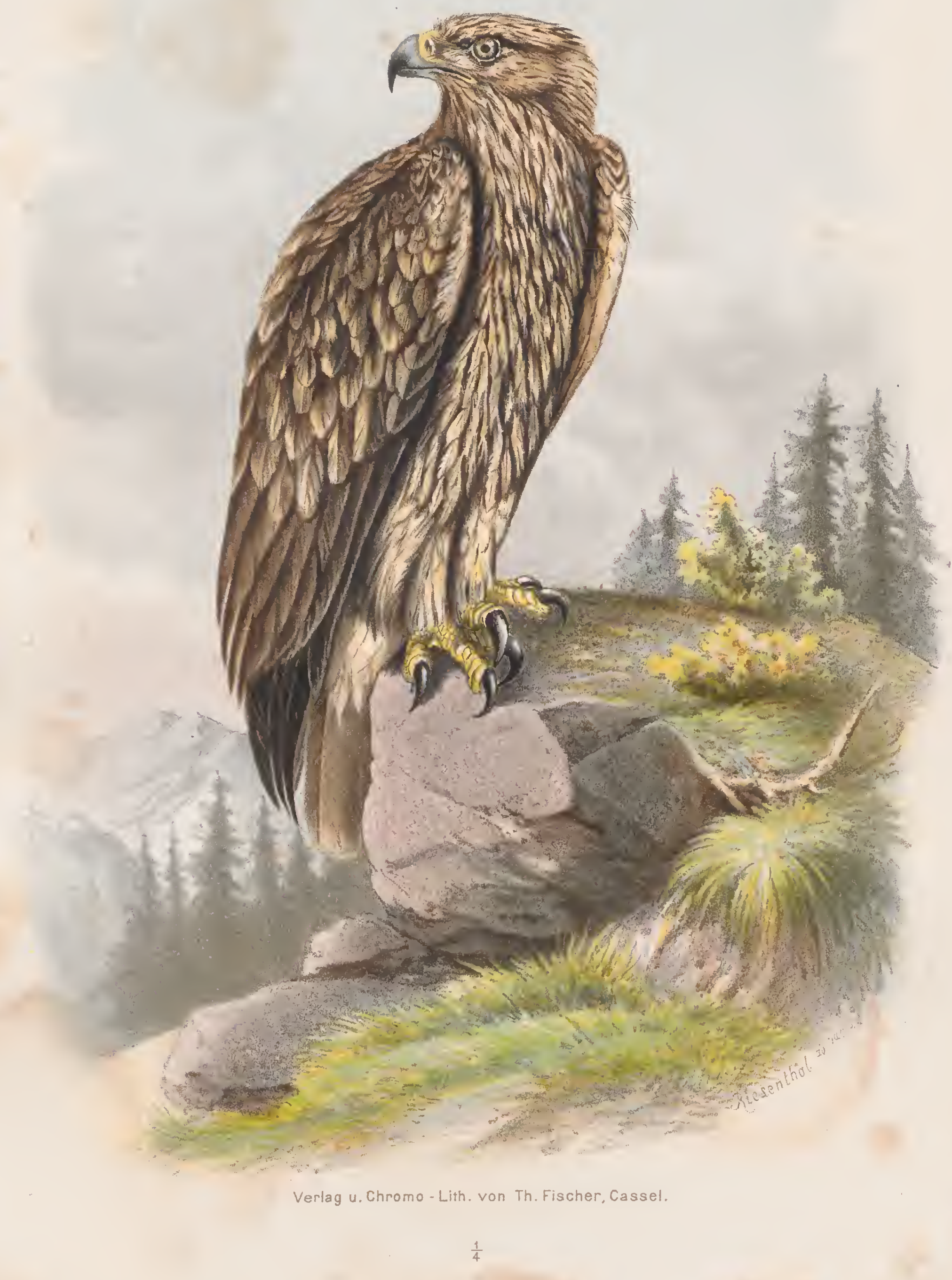

AQUILA IMPERIALIS, BECHST.

Kaiseradler. 


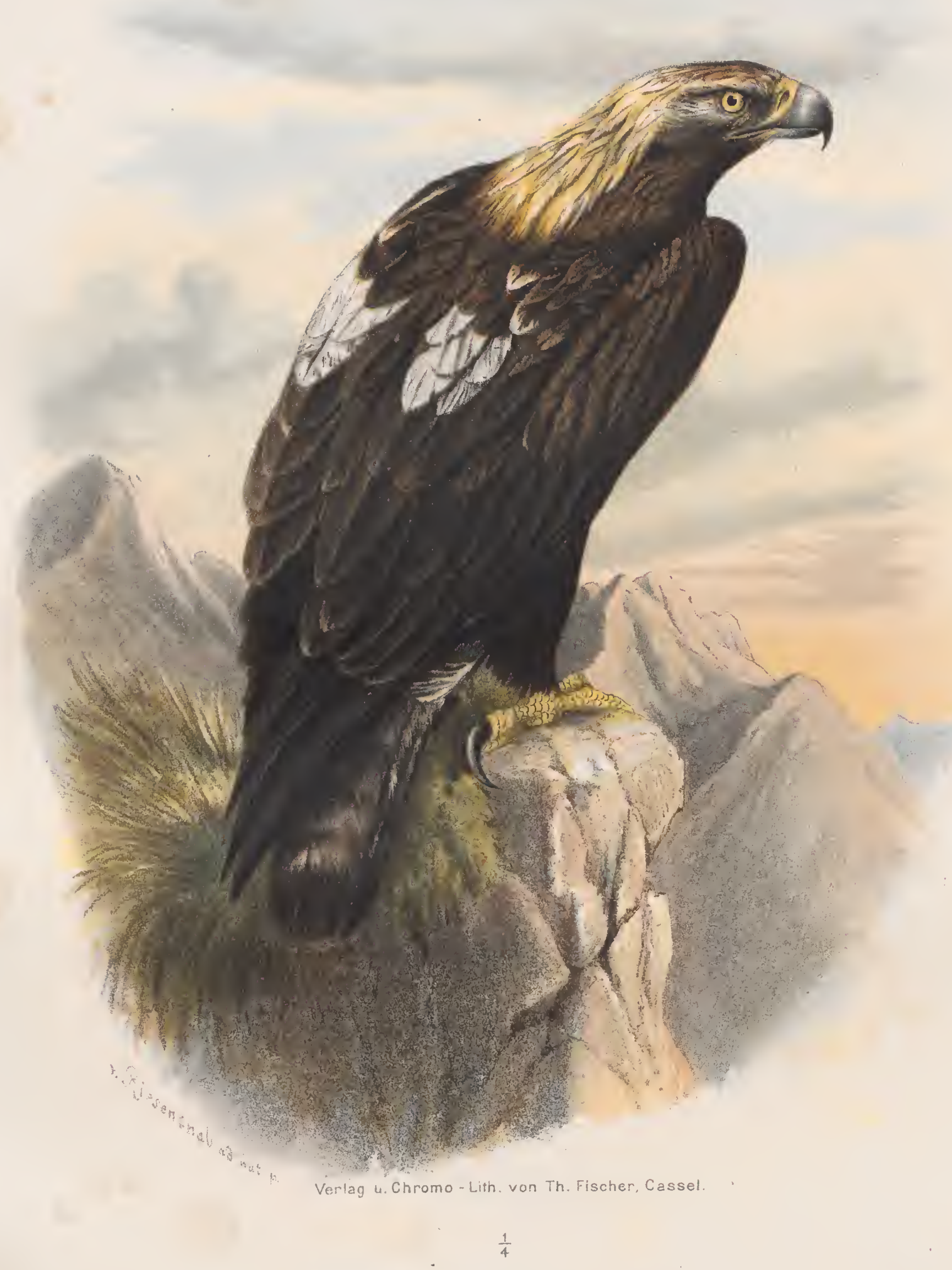

AQUILA IMPERIALIS, BECHST.

Kaiseradler. 


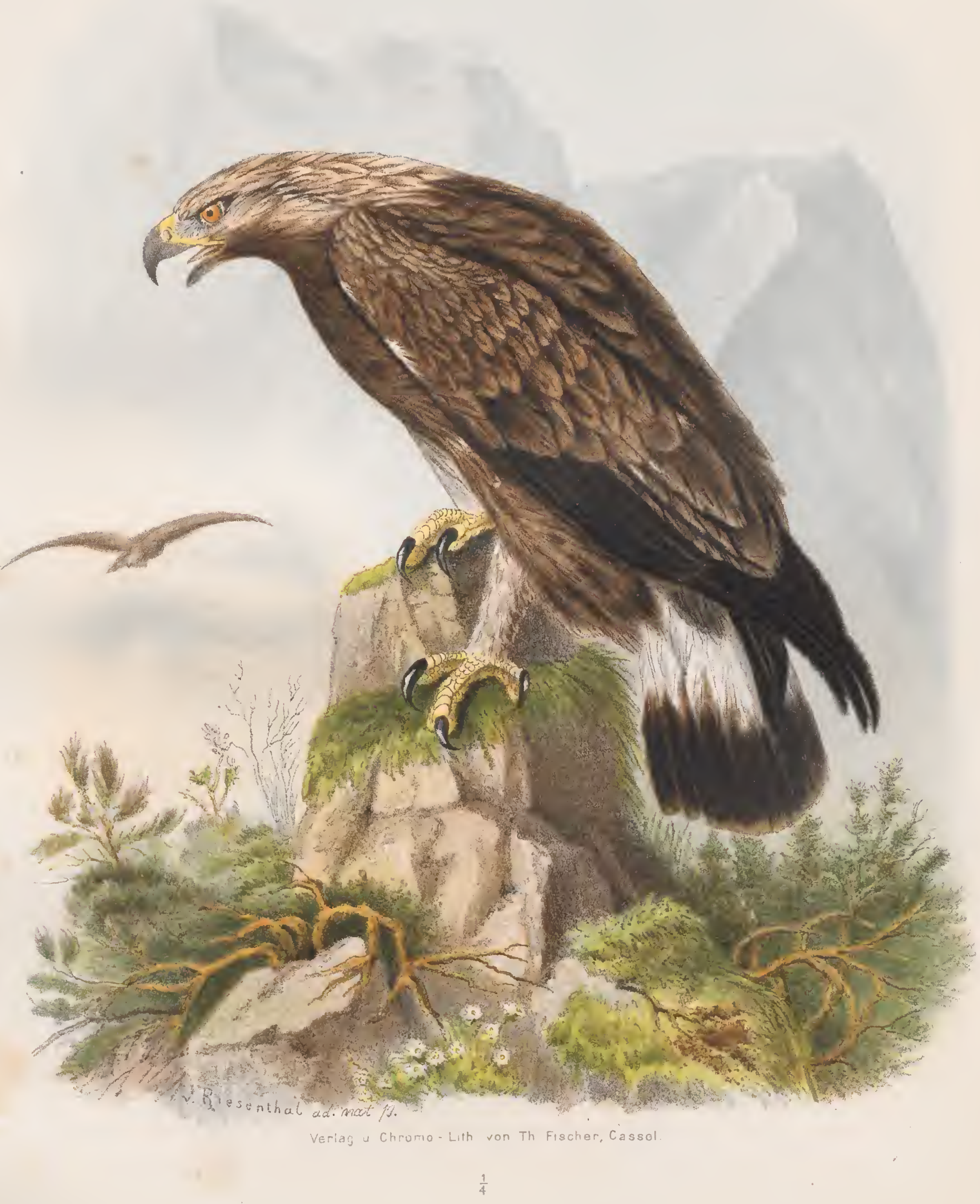

AQUILA FULVA, LINN.

Stein-Adler.

Mittelaltes Weibchen. 



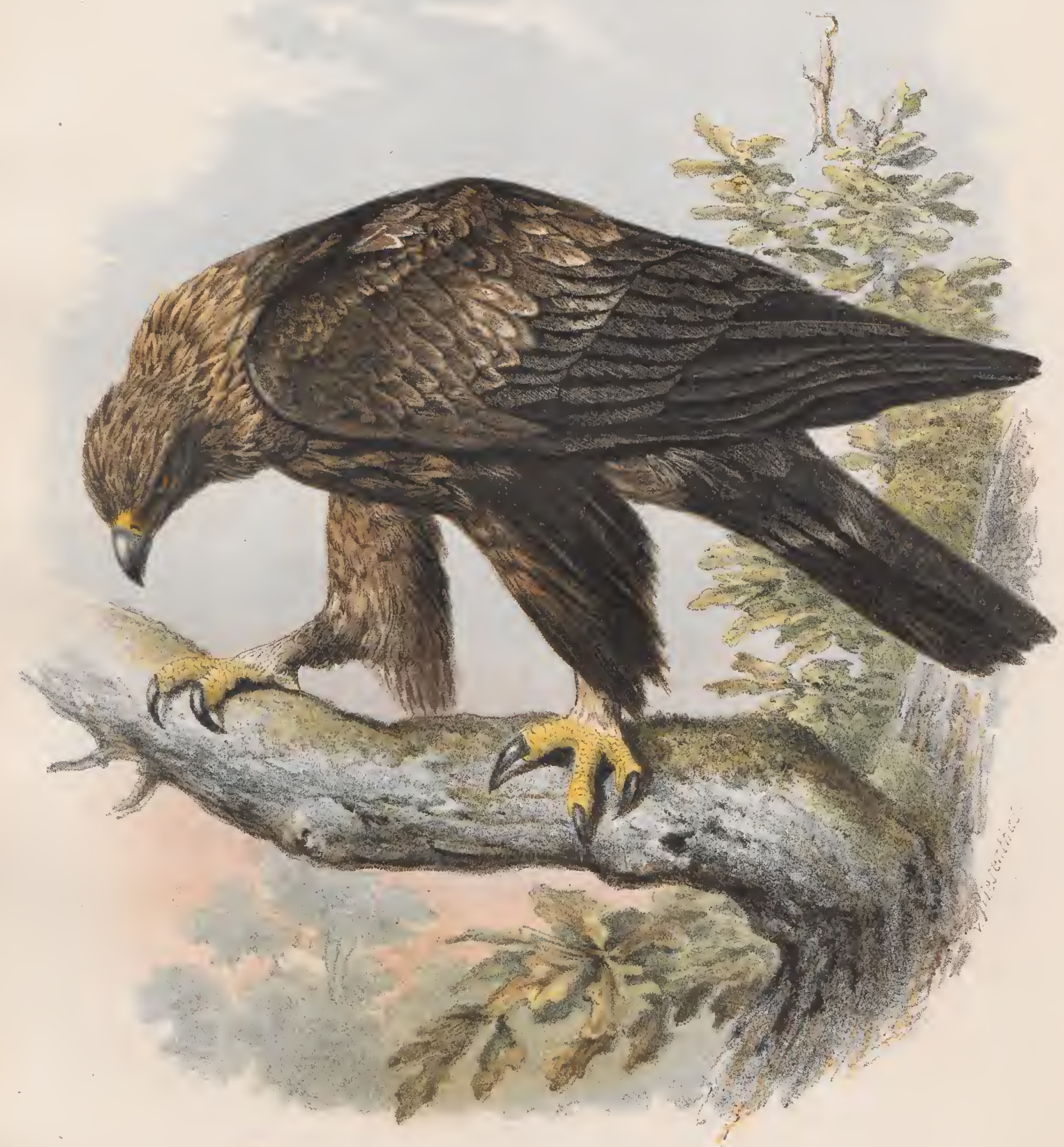

Verlag u. Chromo-Lith. von Th. Fischer, Cassel.

$\frac{1}{4}$

A QUILA CHRYSAËTOS, LINNÉ.

Goldadier.

Alt. 



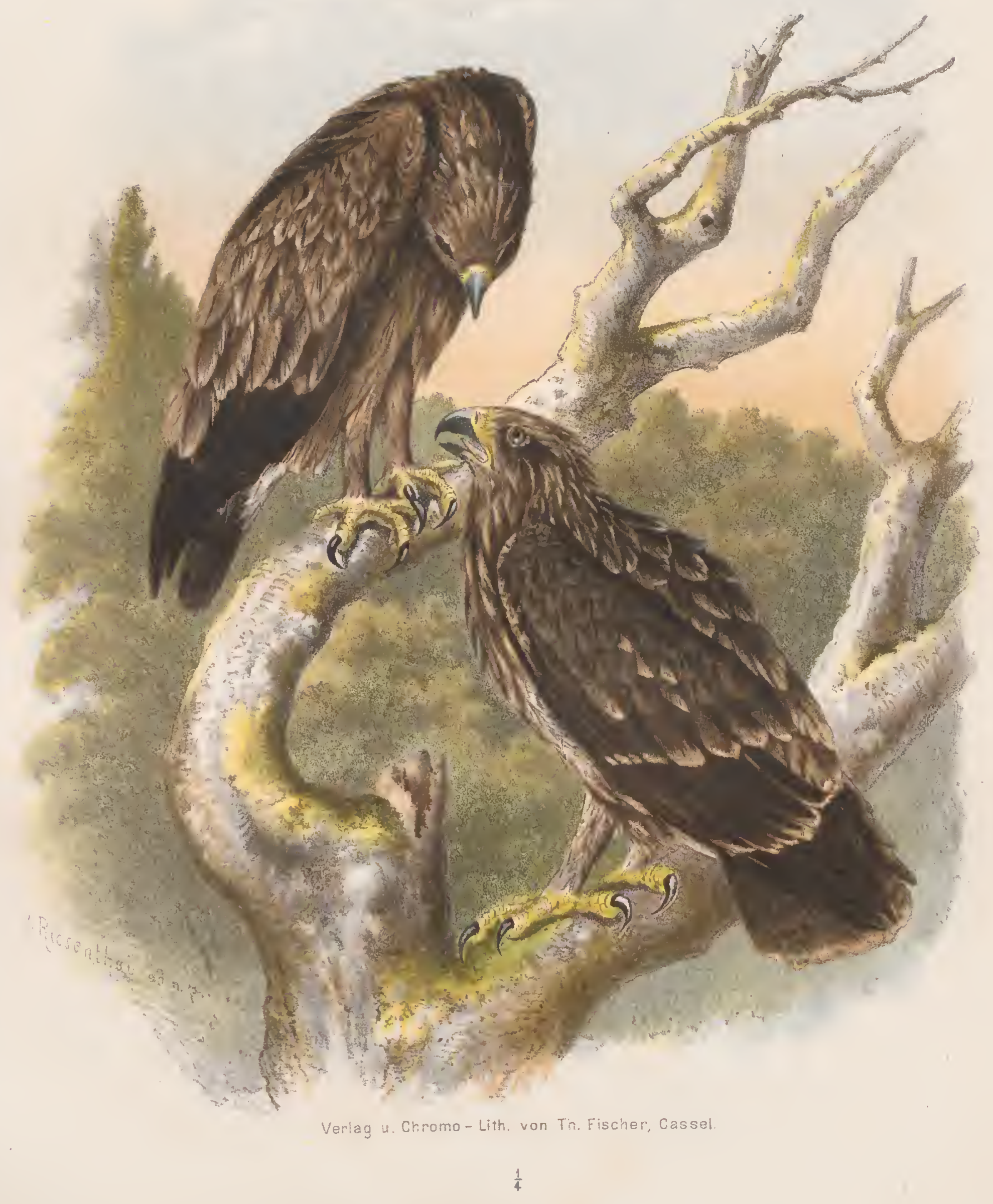

AQUILA NAEVIA, BRISS. Schrei-Adler.

Alt. Jung. 


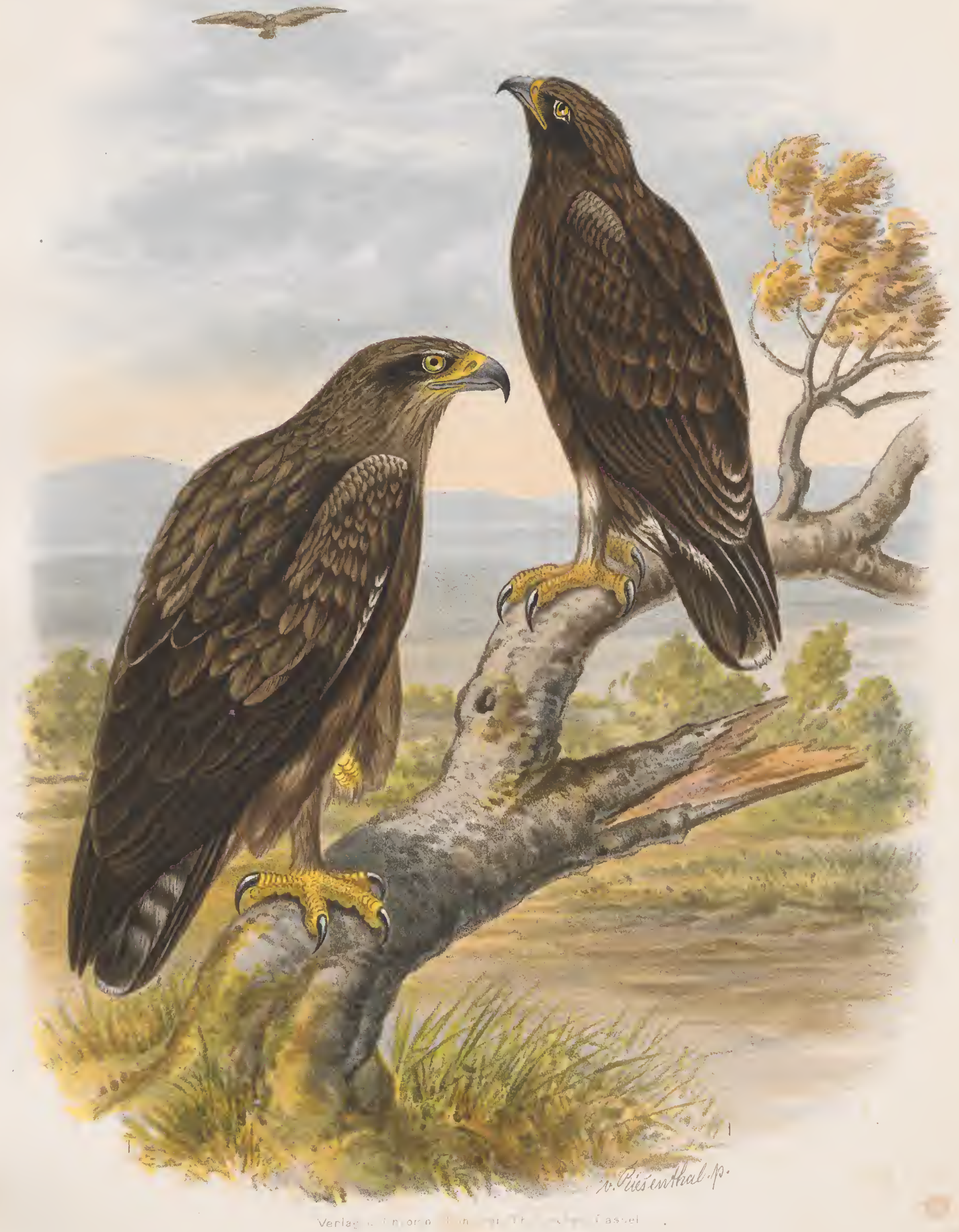

AQUILA ORIENTALIS, CAB.

AQUILA CLANGA, PALL. 


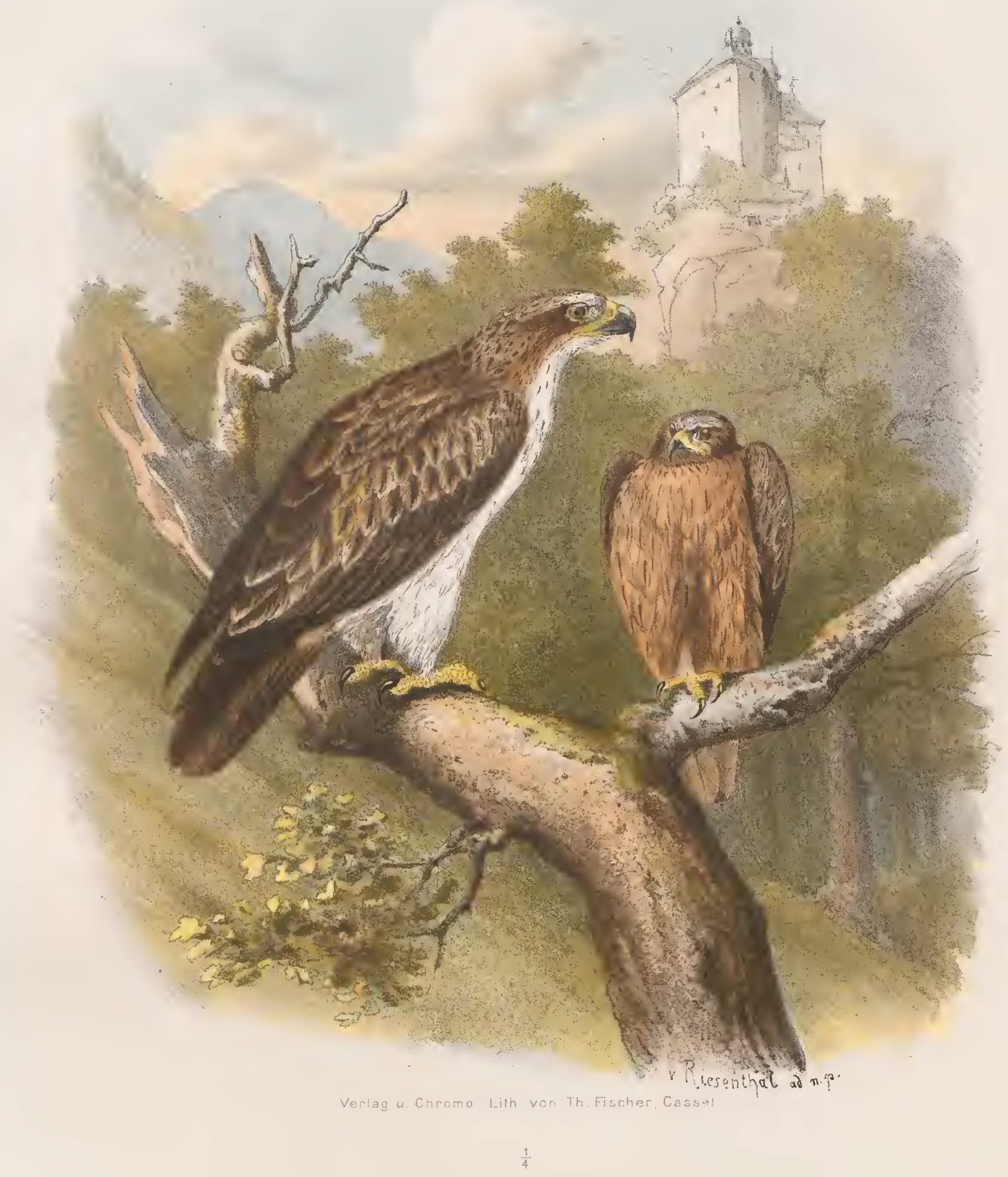

A Q UILA PEN NATA, cuv.

Zwerg-Adler. 


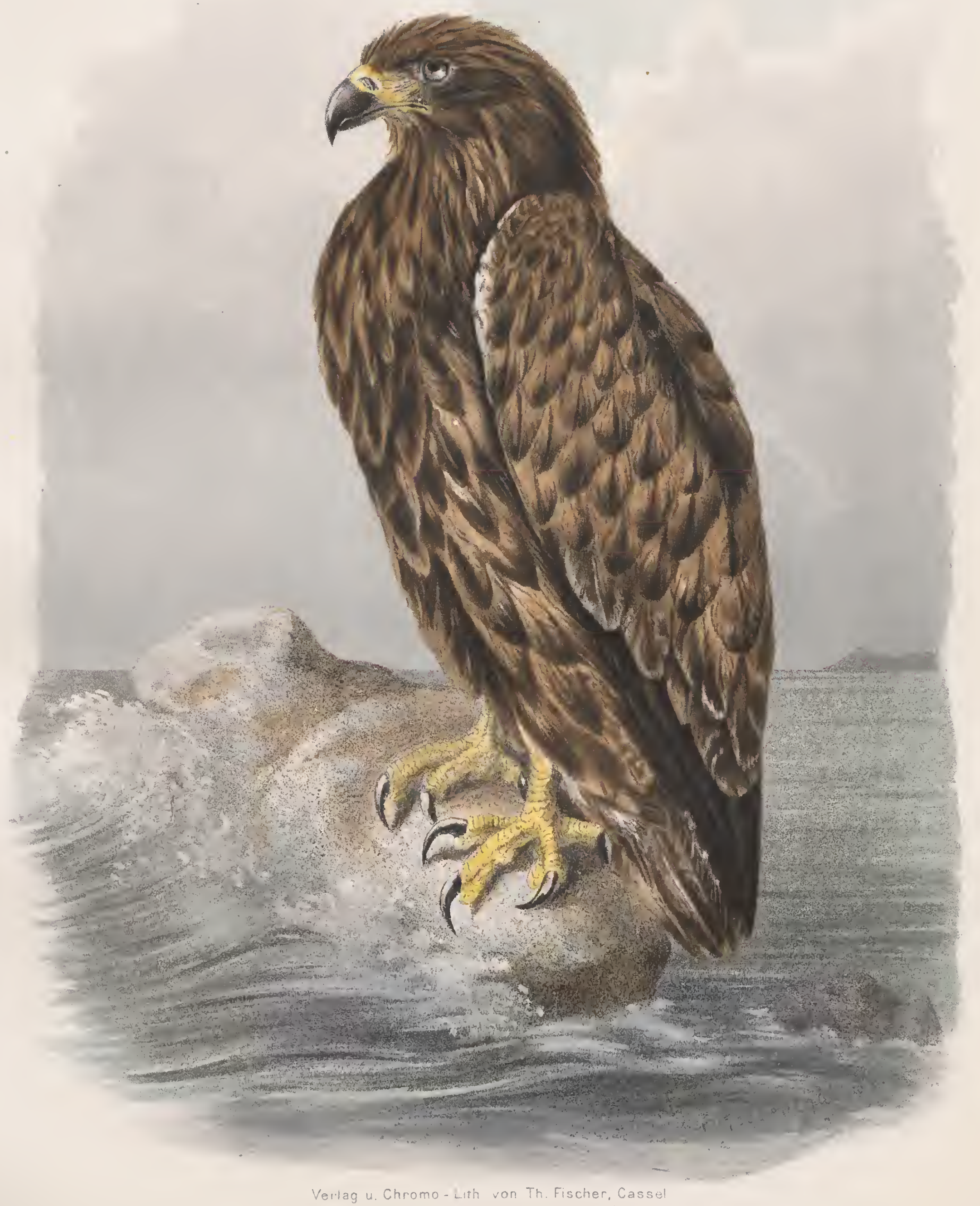

HALIAËTOS ALBICILLA, LINN.

Weissschwänziger Seeadler. 



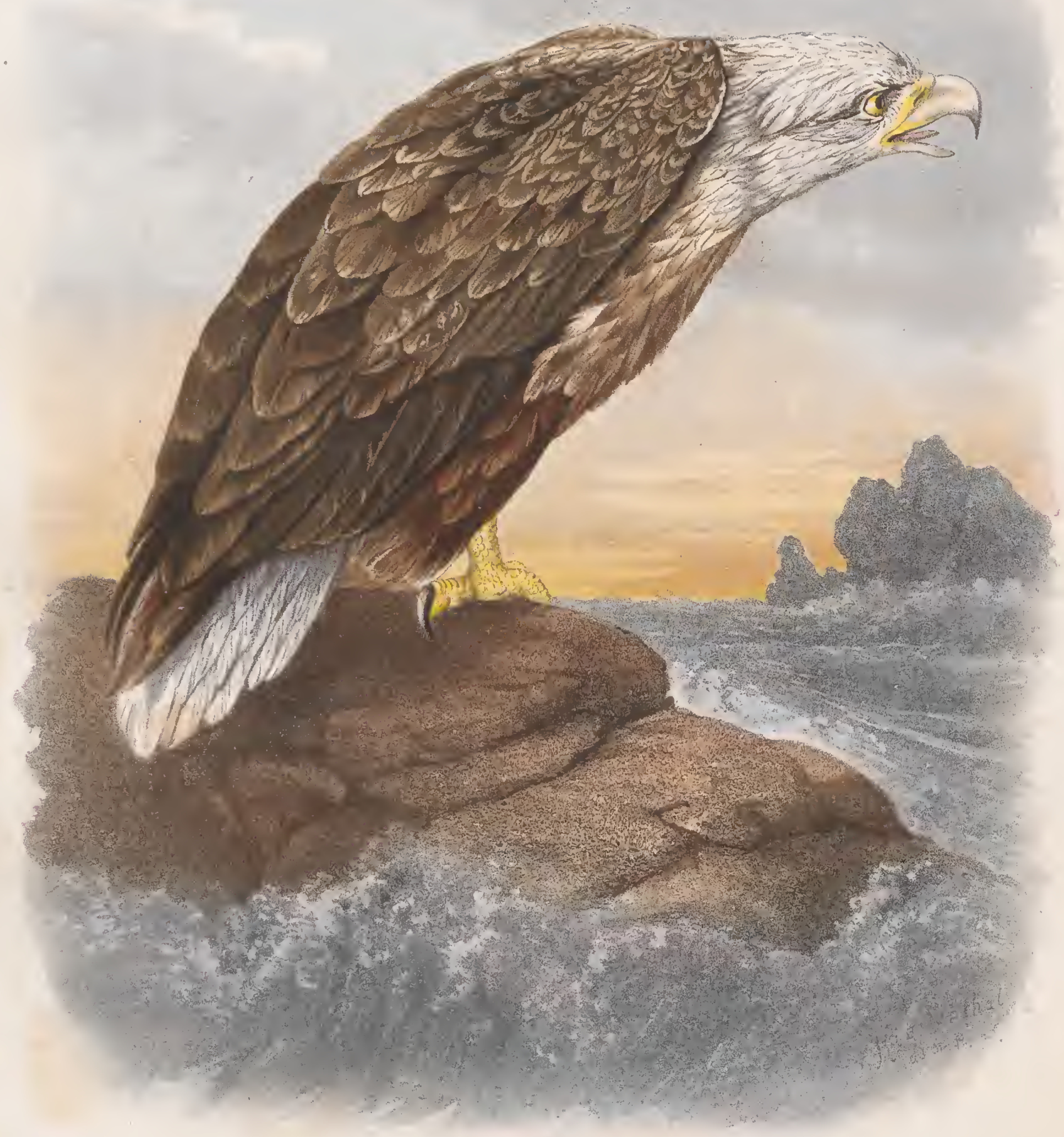

HALIAËTOS ÁLBICILLA, LINN

Weissschwänziger Seeadler.

Altes Männchen 


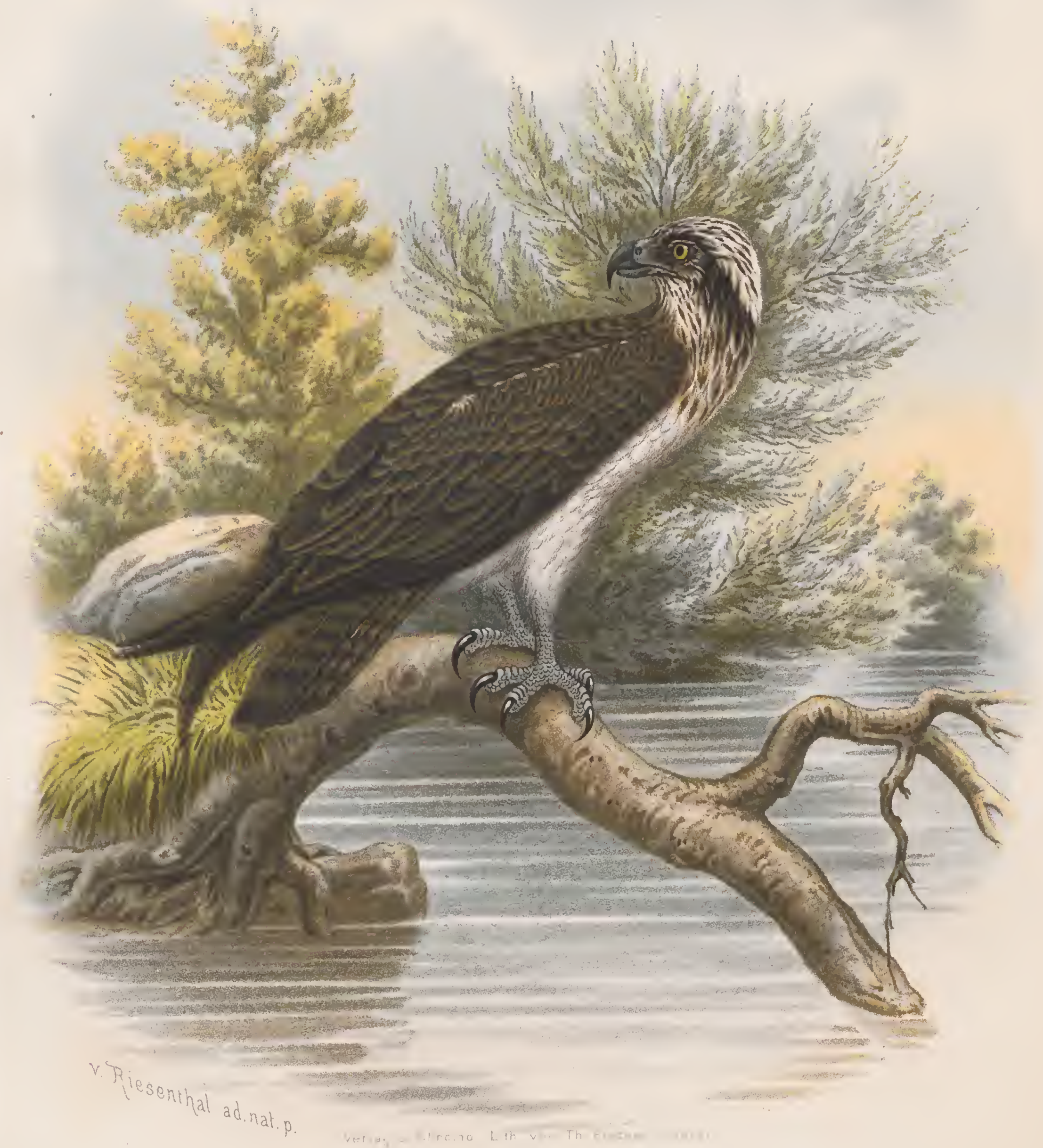

PANDION HALIAÉTOS. 



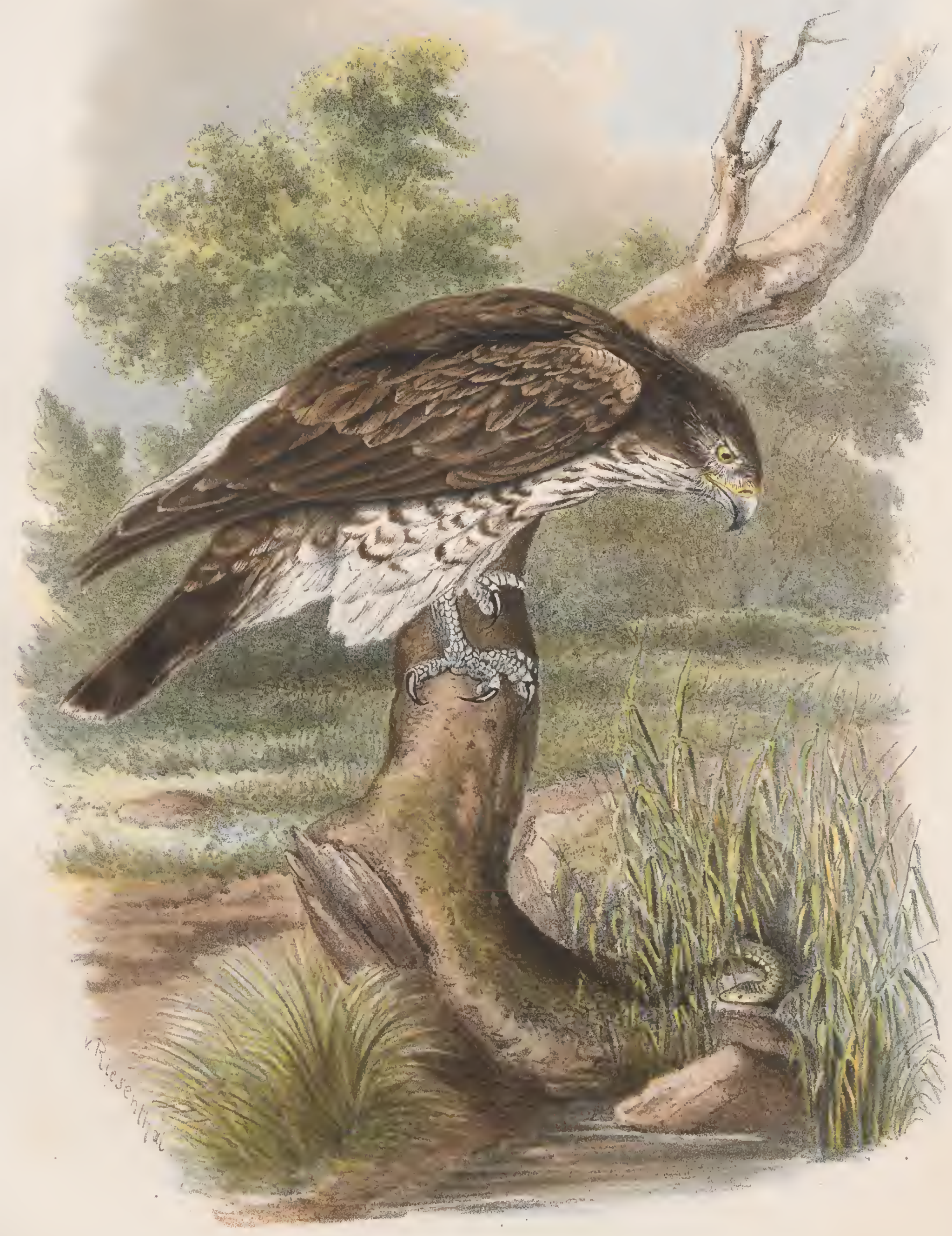

Verlag u. Chromo-Lith van Th. Fischer. Casse

CIRCAËTOS GALLICUS, GMEL.

Schlangenadler. 


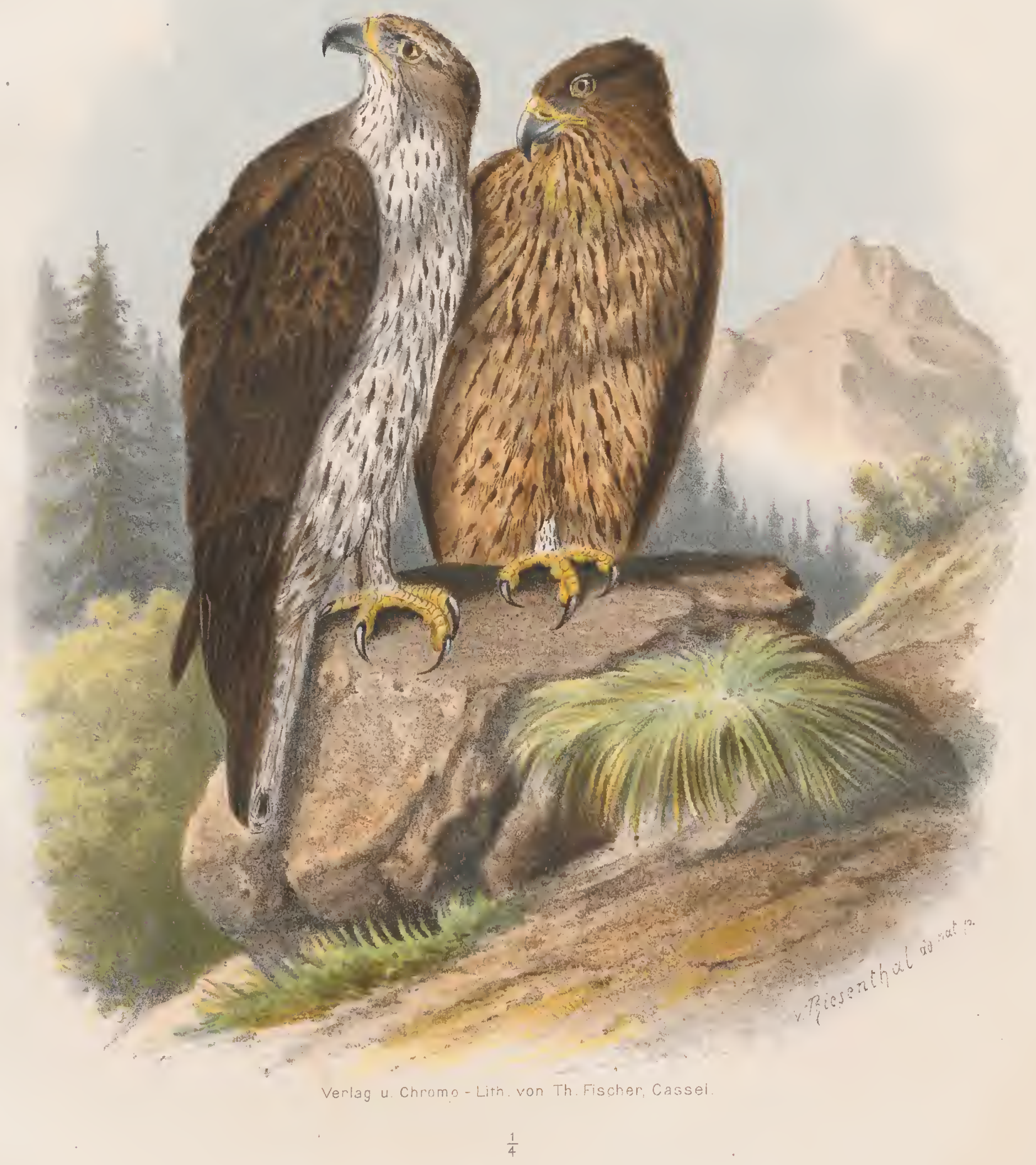

A Q UILA BONELLII, TEMM.

Bonellis Adler.

Ait. Jung. 


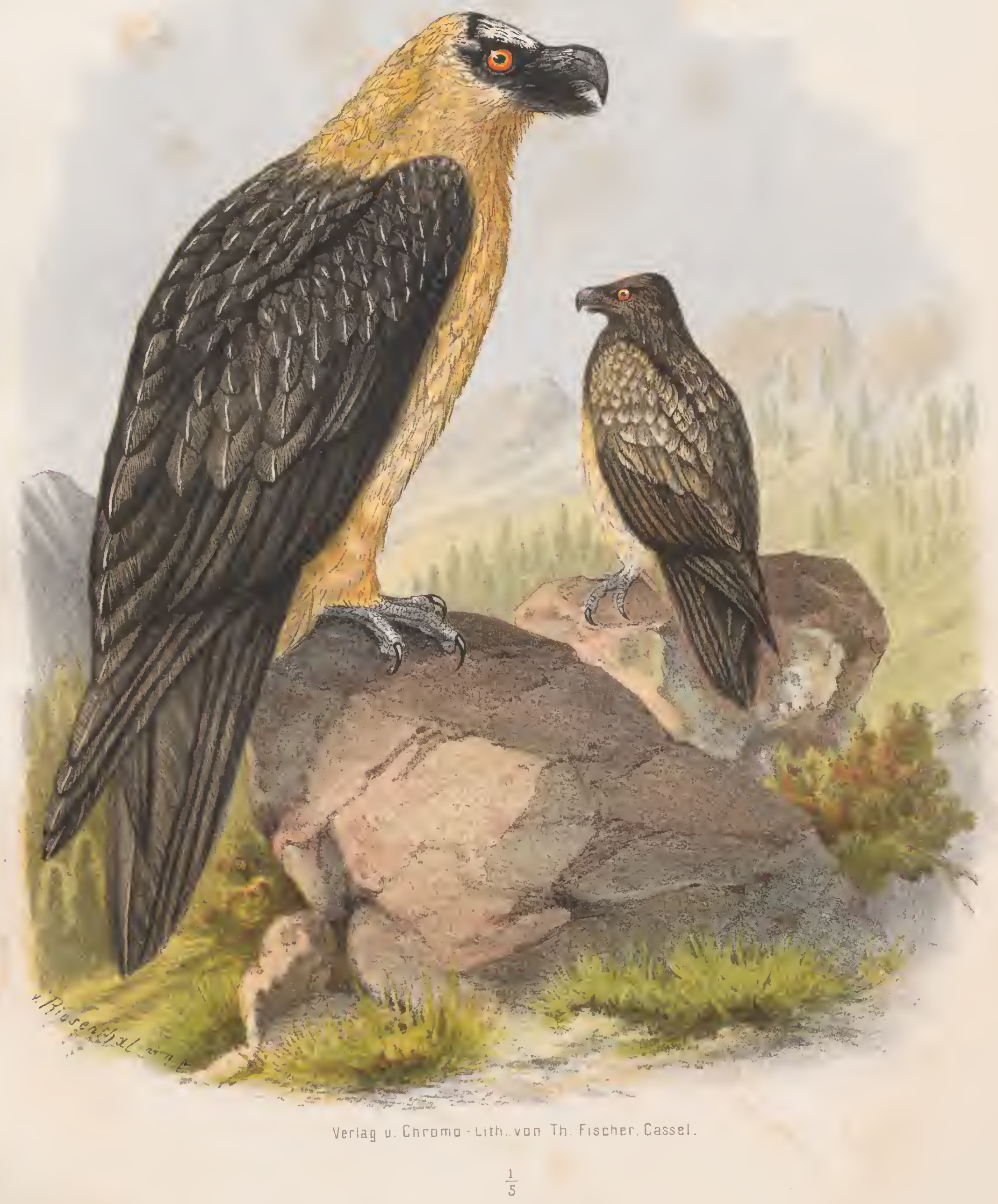

GYPAËTOS BARBATUS EUV.

Bartgeier. 



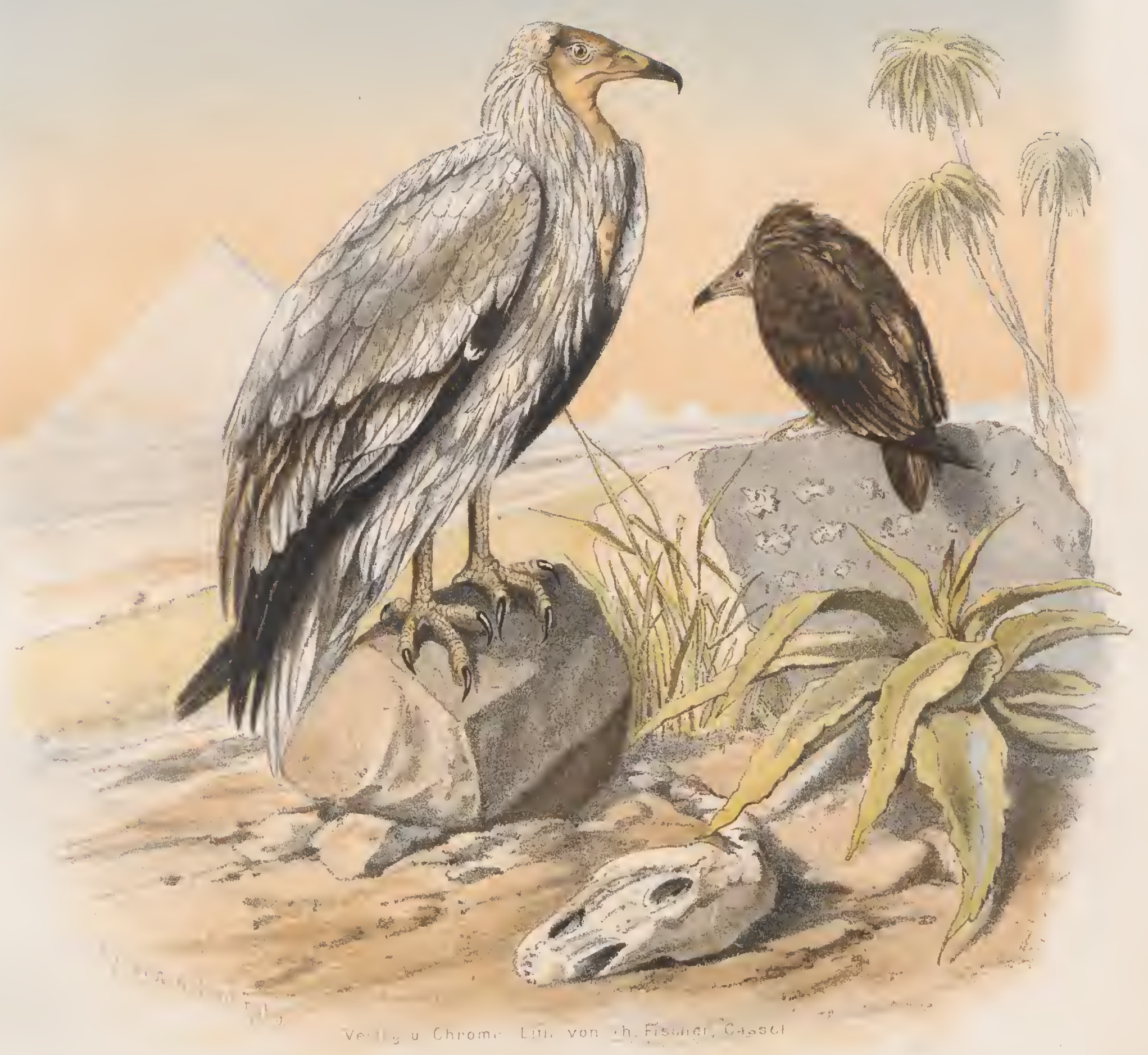

NEOPHRON PERCNOPTERUS, LINN.

Egyptischer Aasgeier. 



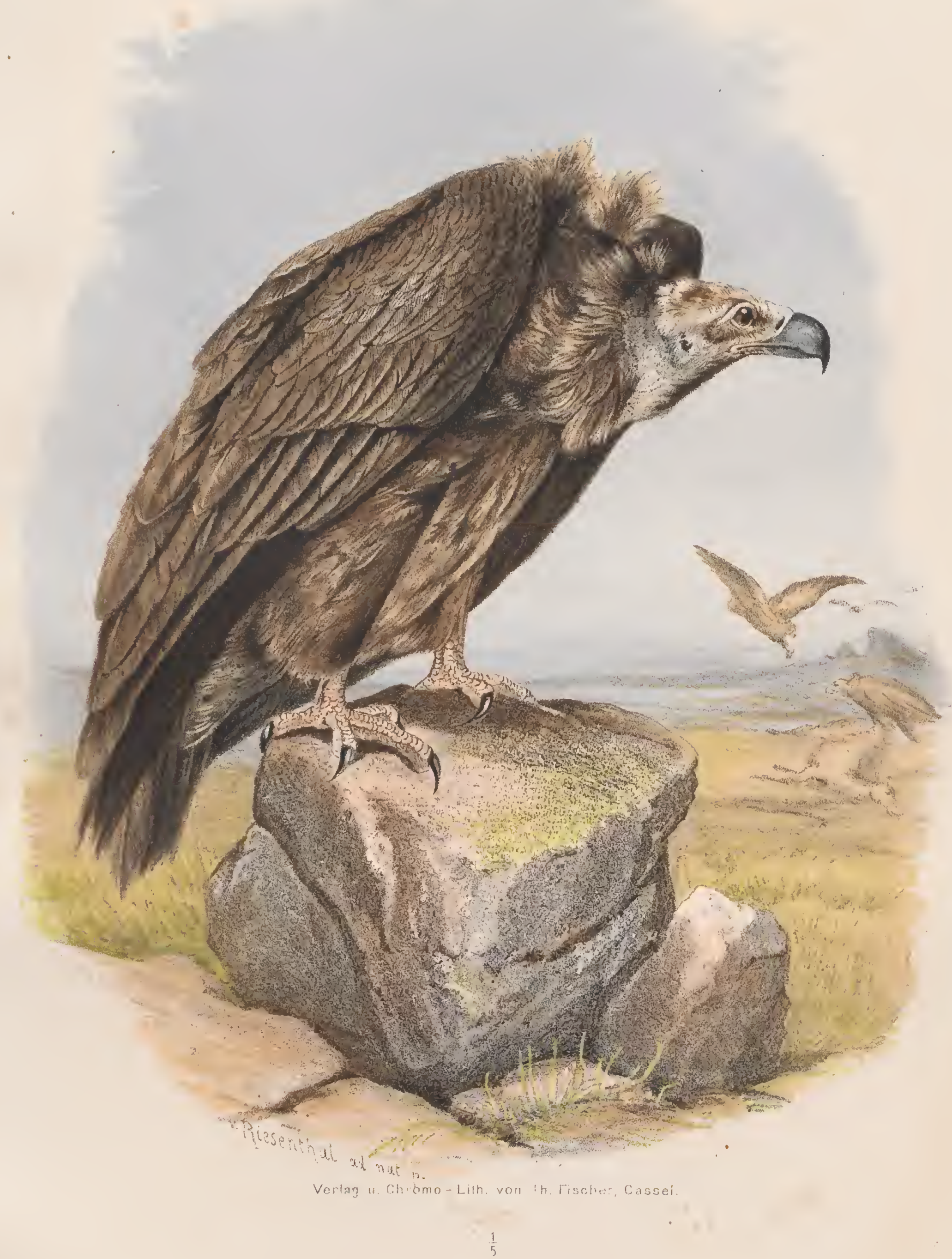

VULTUR MONACHUS, LINN.

Mönchsgeier.

Att. 


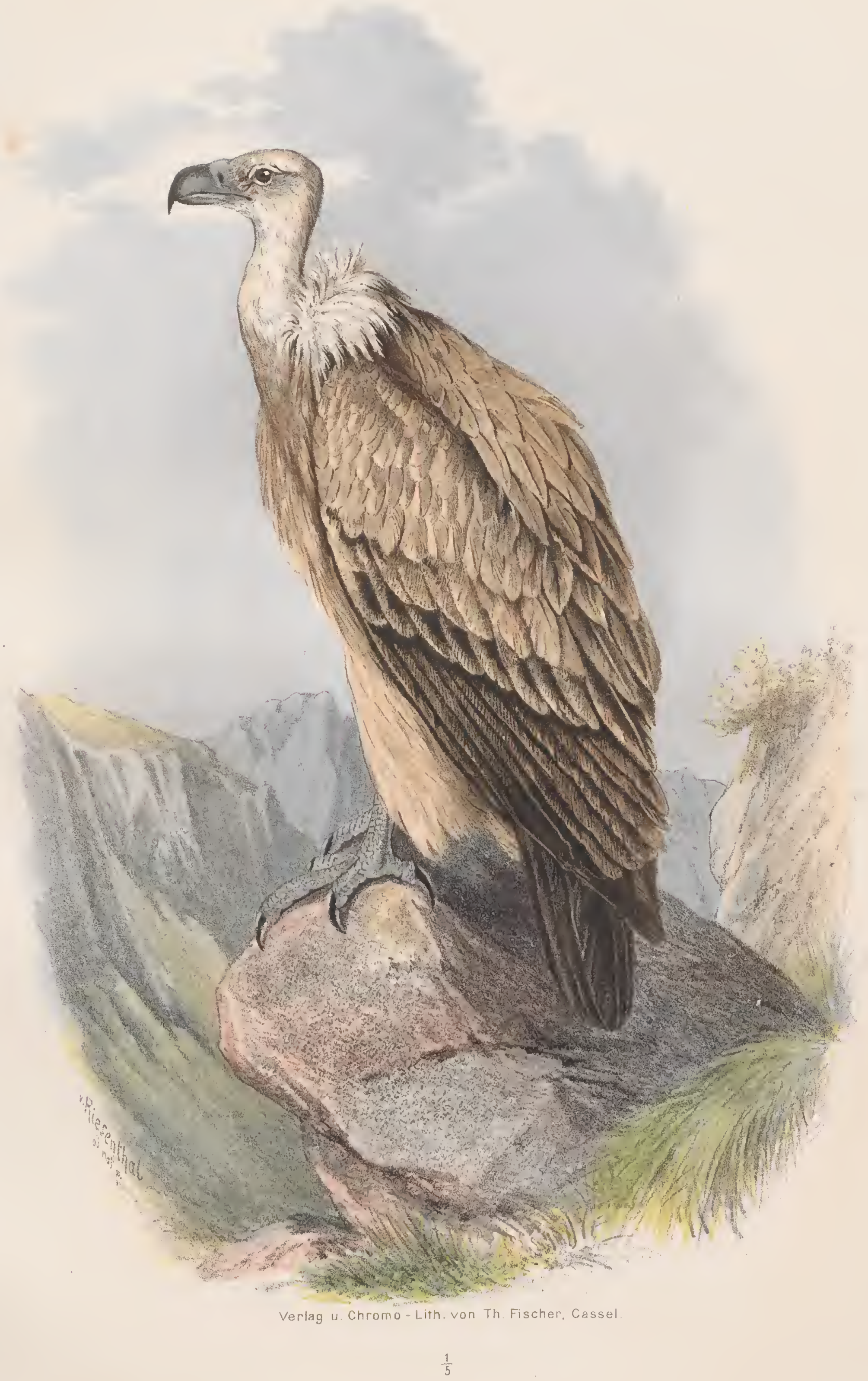

VULTUR FULVUS, GMEL.

Weissköpiger Geier

Sehr altes Mannchen 


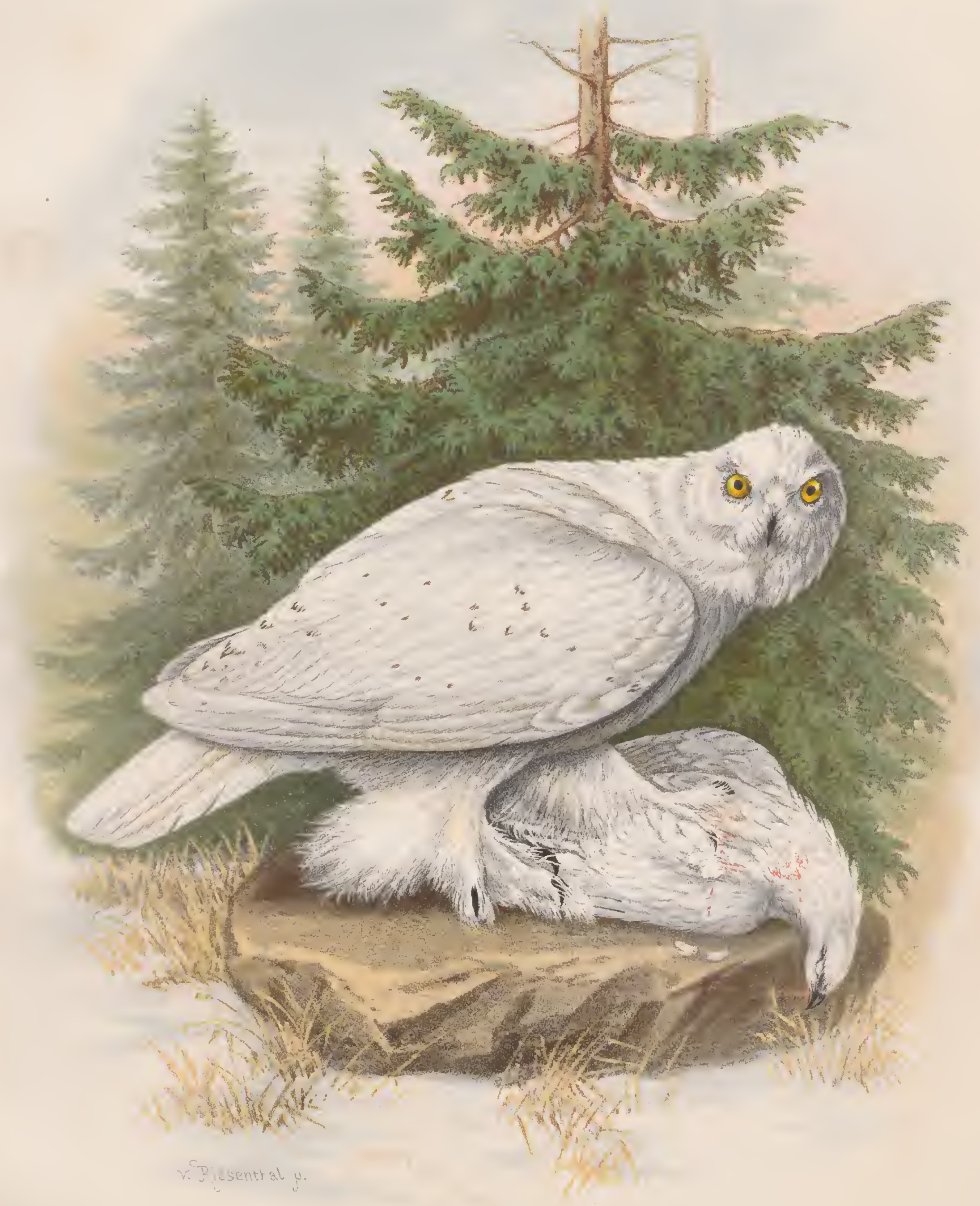

STRIX NIVEA, THNBG 



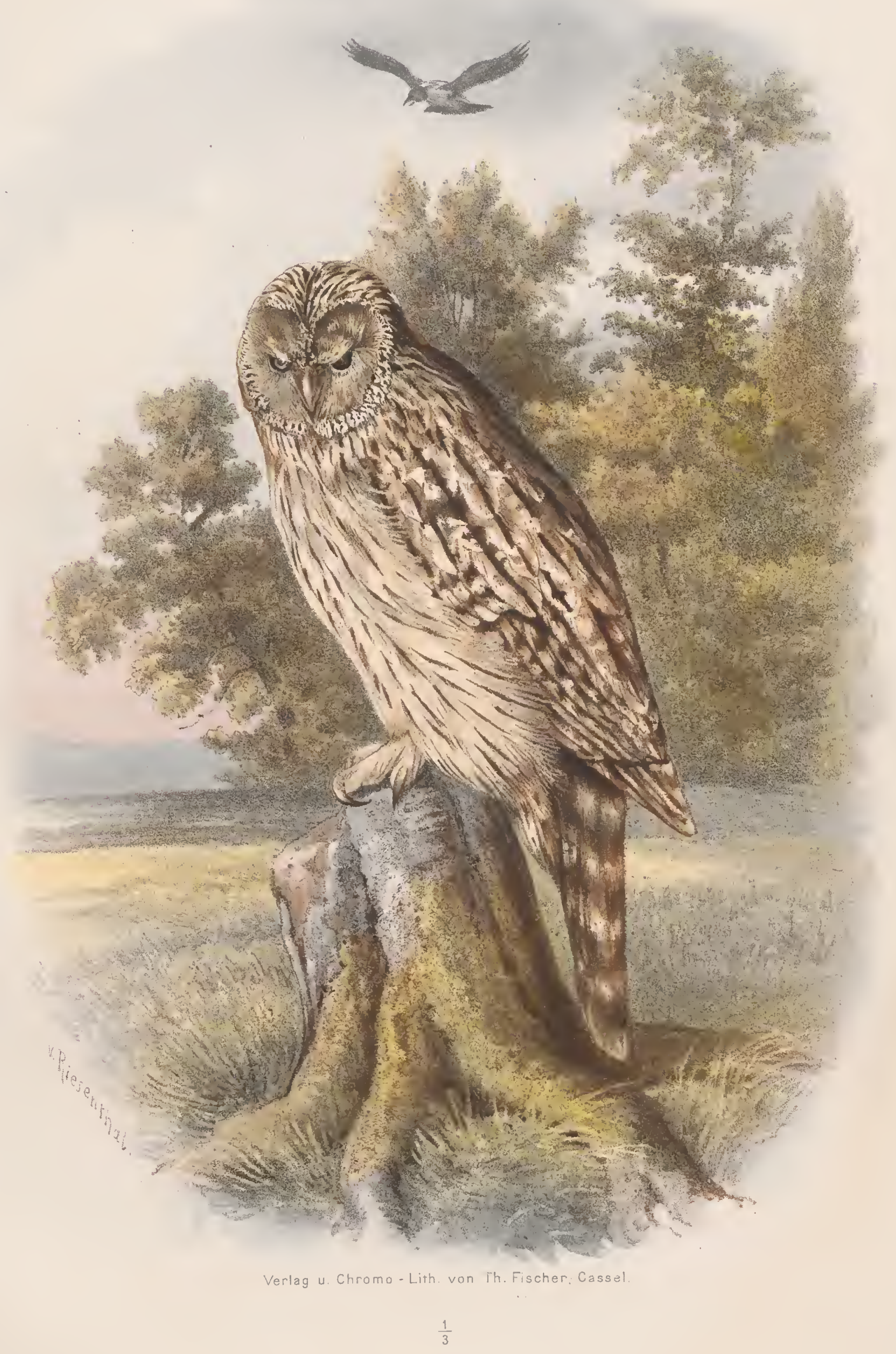

STRIX URALENSIS, PALL. 



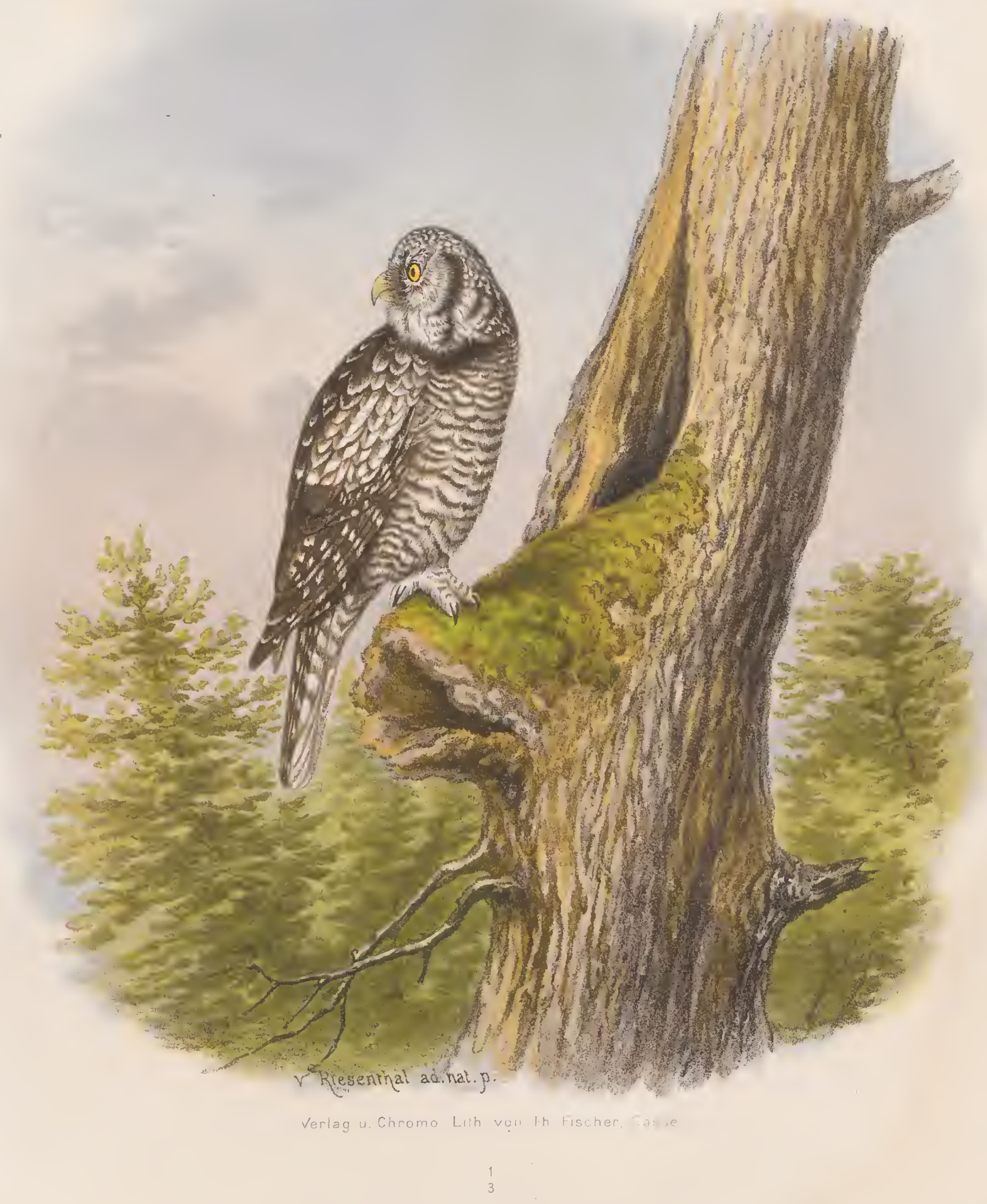

STRIX NISORIA, WOLF.

Sperber-Eule 


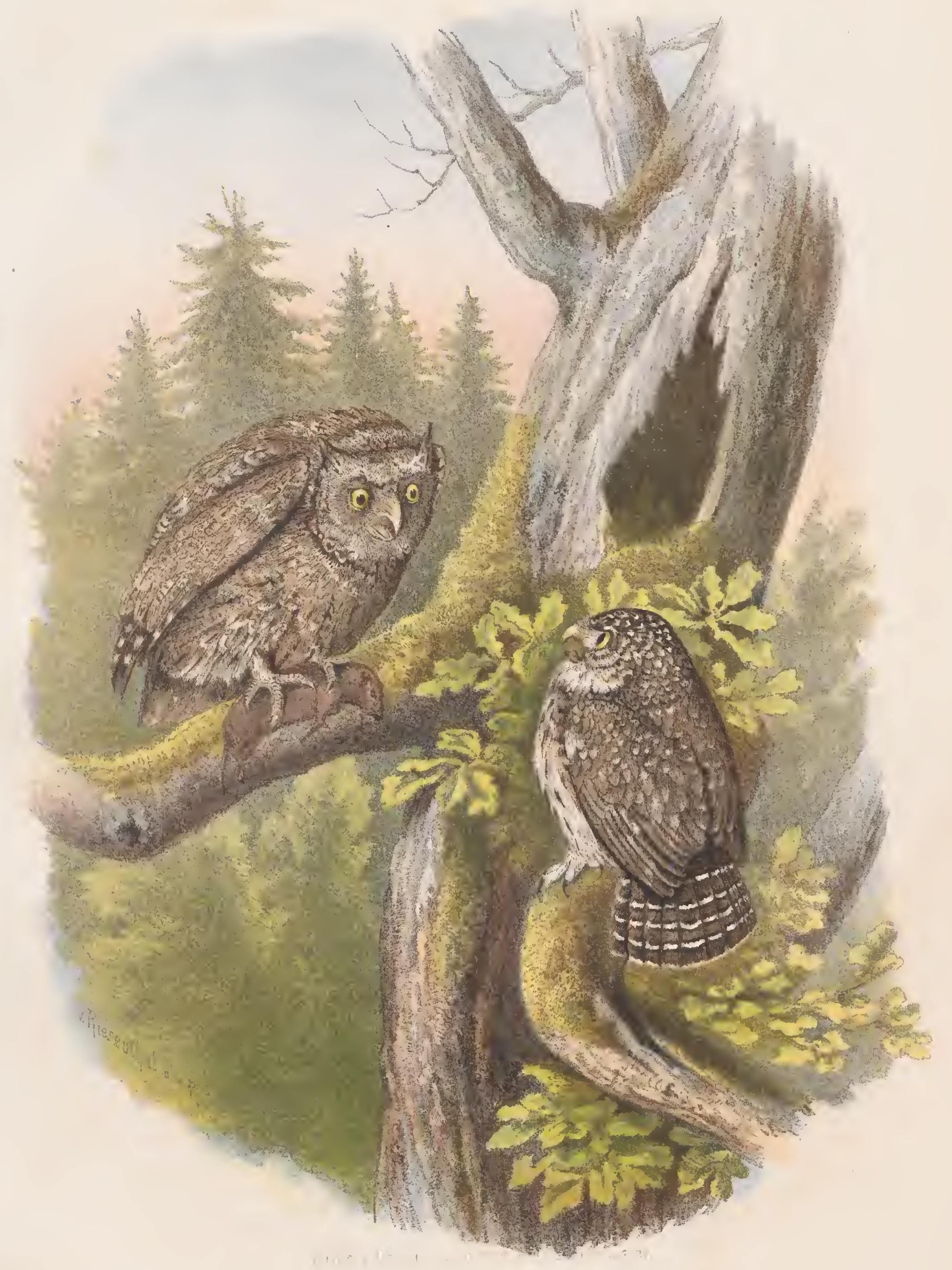

STRIX SCOPS, LIN.

STRIX PYEMAEA, BECHST.

Ewergohreute. 



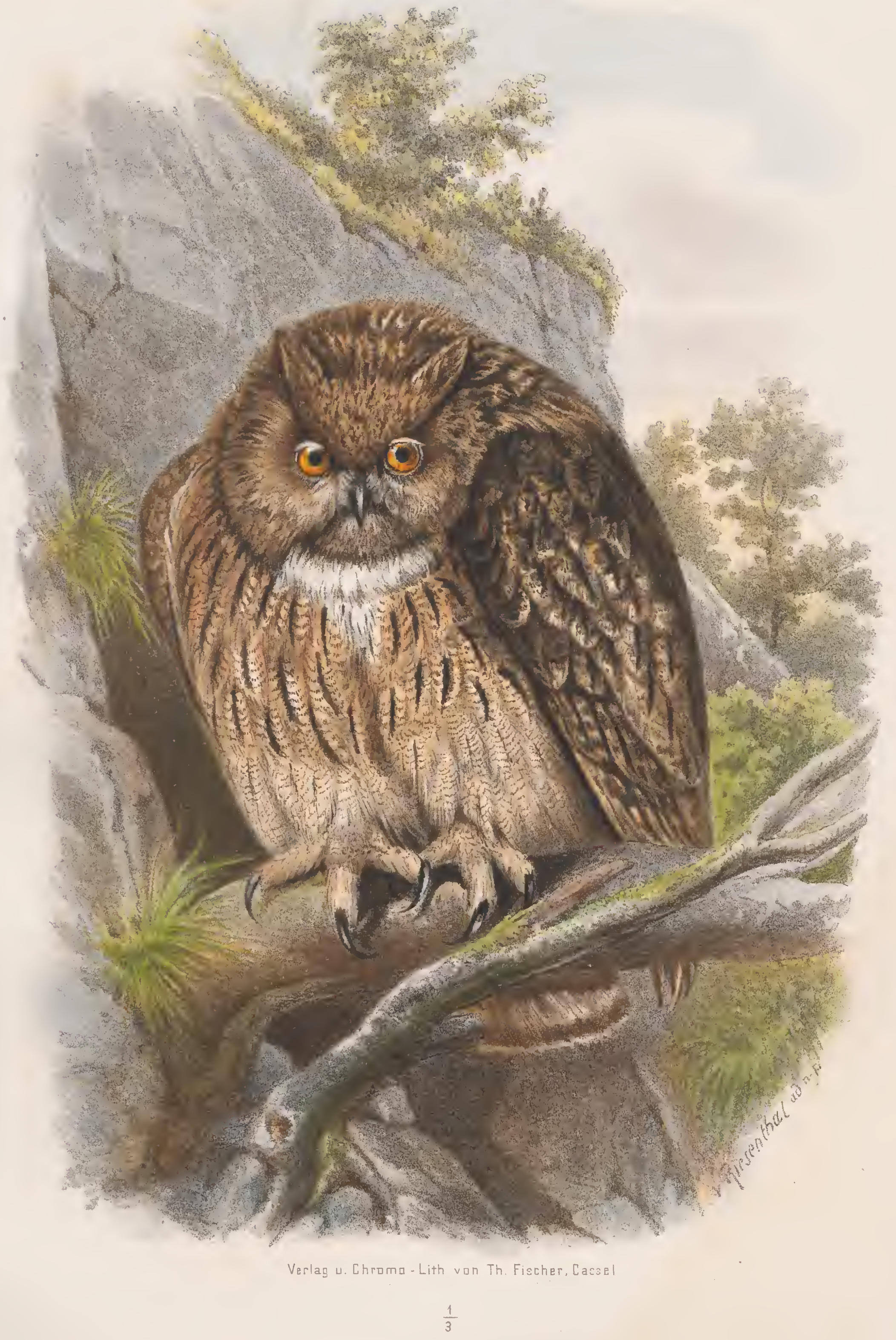

STRIX BUBD, LINN.

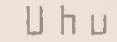

Aìtes Weibchen 


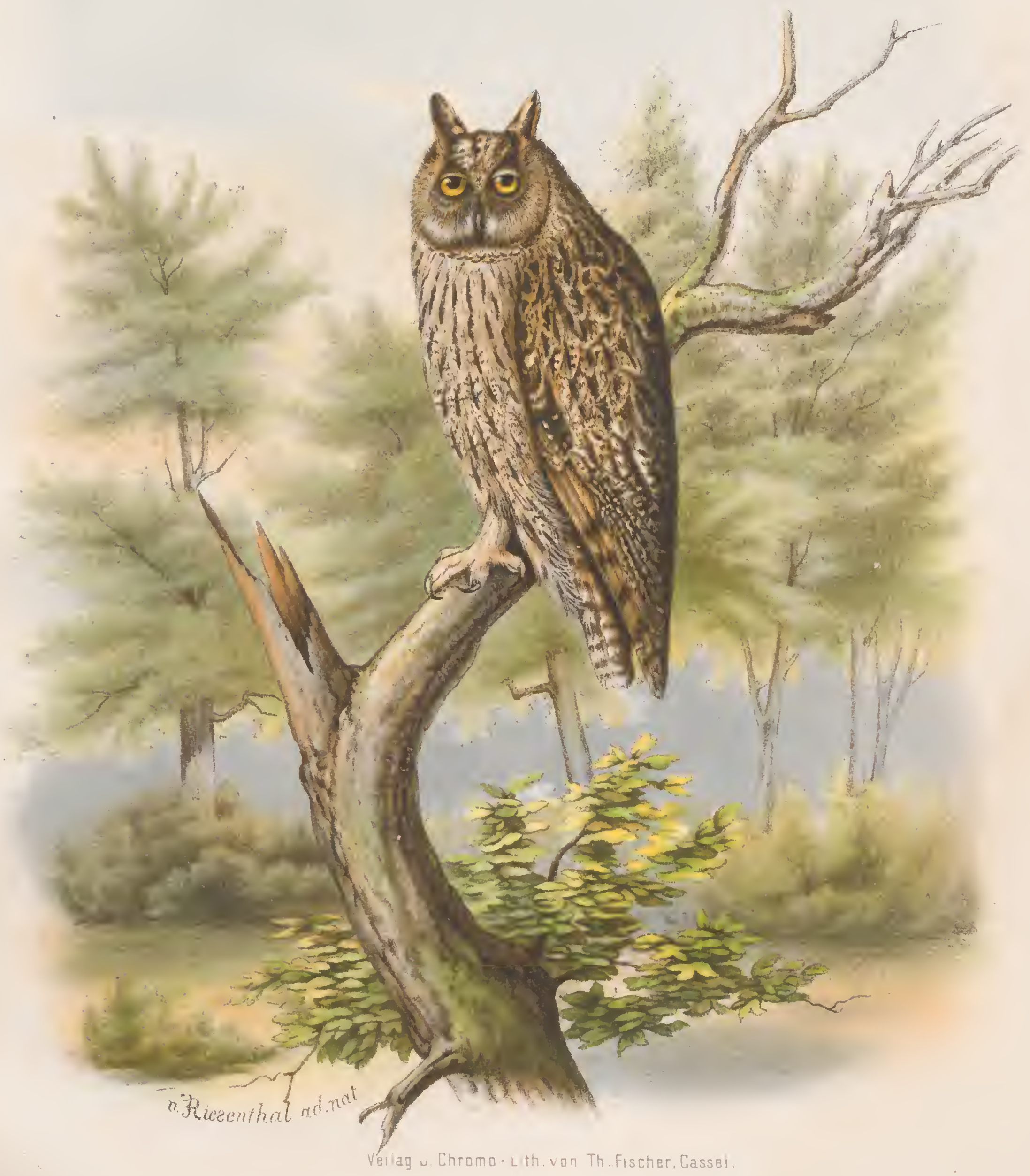

STRIX OTUS, LINN.

Waldahreula. 

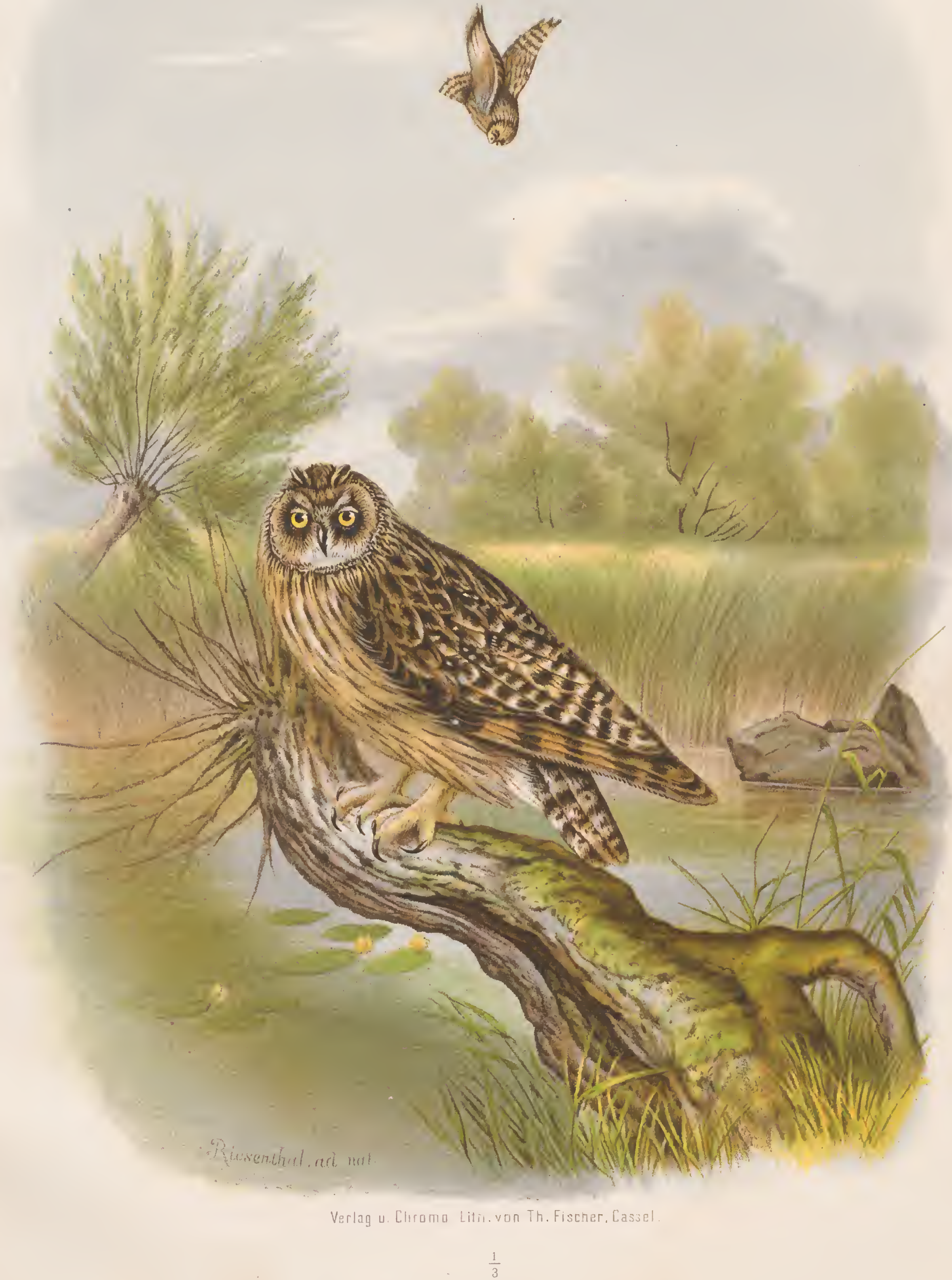

STRIX BRACHYOTUS, GMEL .

Sumpfohreule. 



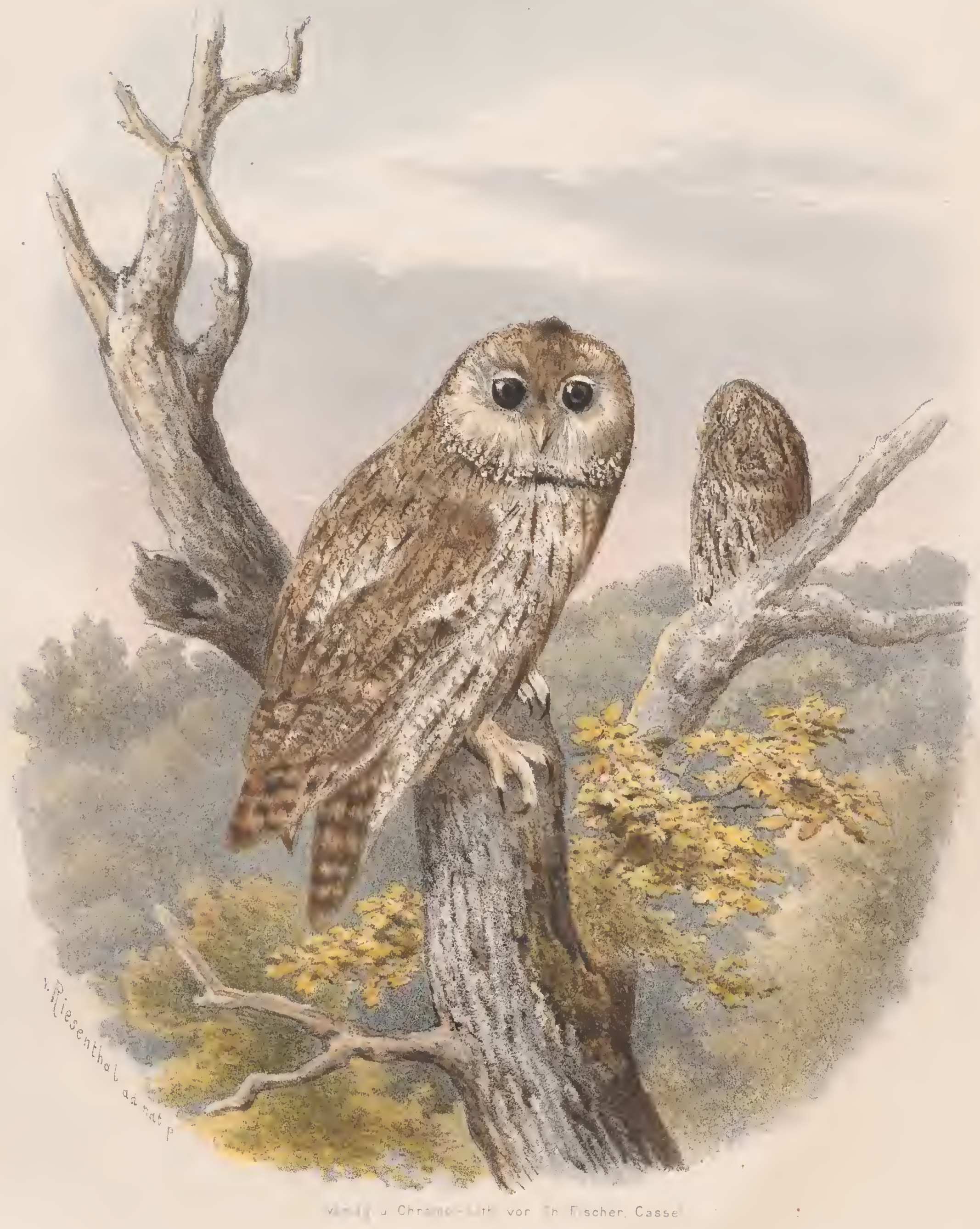

STRIX ALUCO, LINN.

Waldkauz

Weit it on Wannchen 


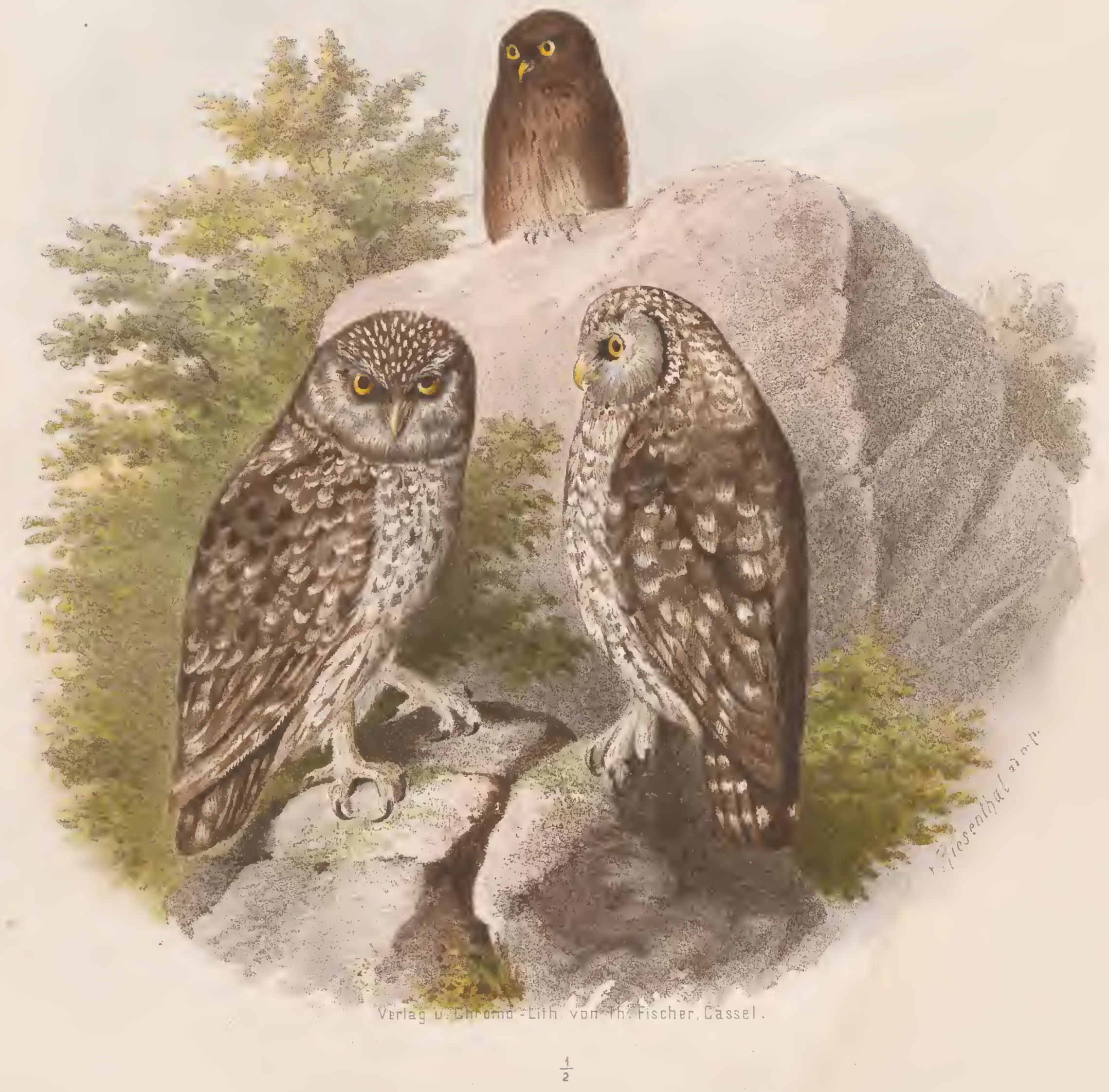

StRIX NOCTUA, RETZ. STRIX DASYPUS, BEEST. 



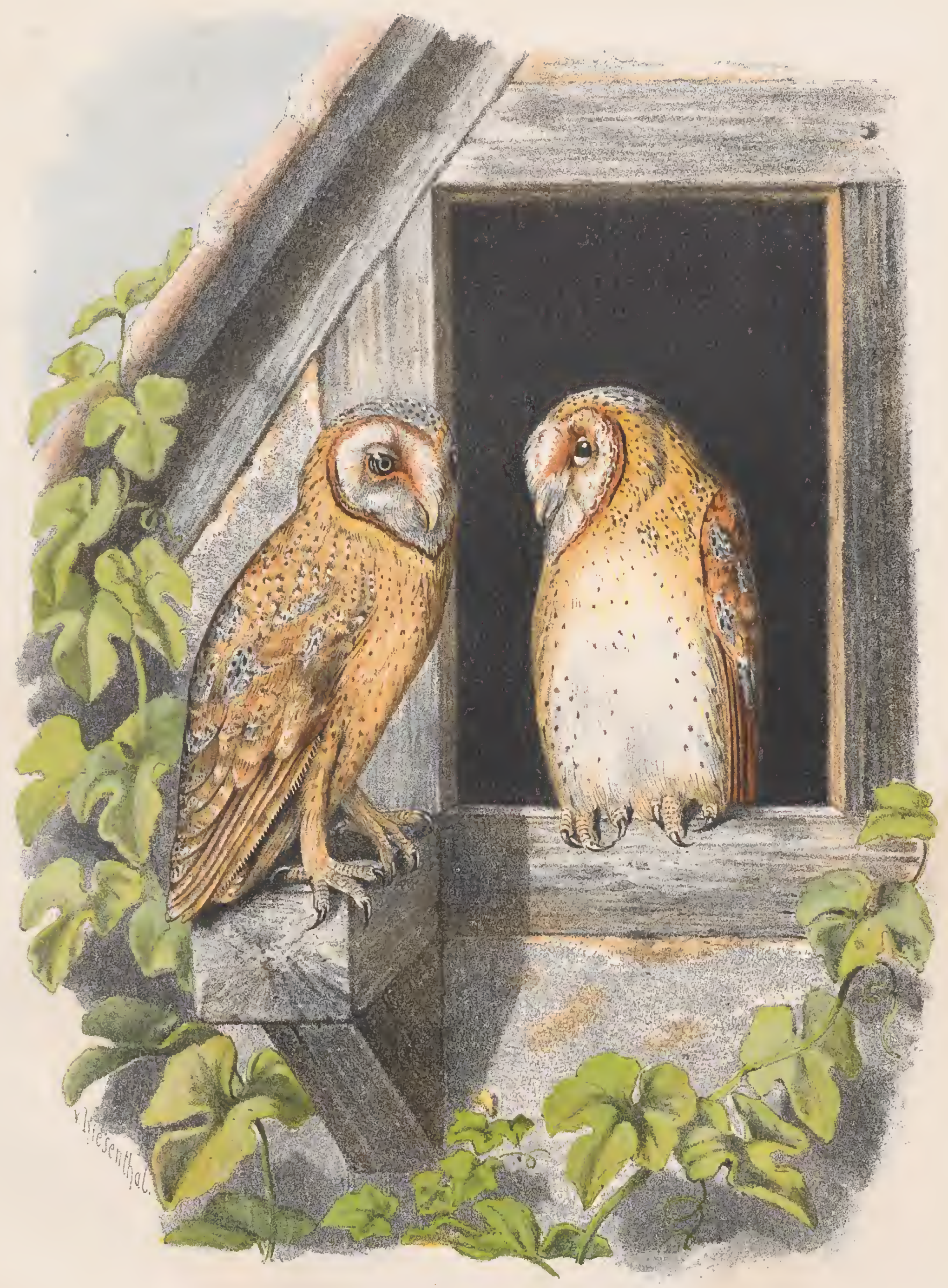

Verlag u. Cotomo-Lith. von Th. Fisrher, Casie,

STRIX FLAMMEA, LINN.

Schleier. Eute. 



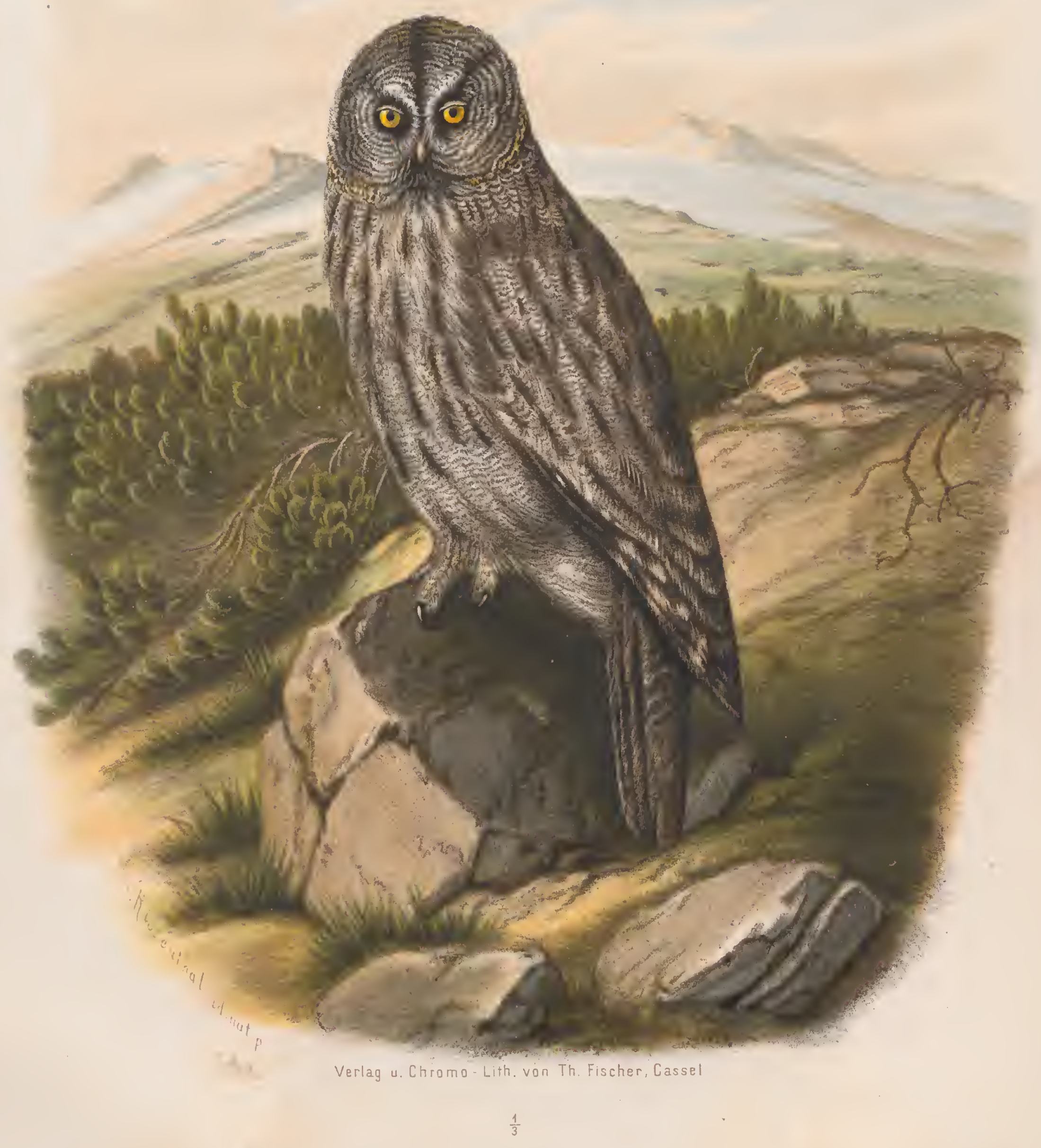

STRIX LAPPONICA, RETZ.

Lapplands - Eule 


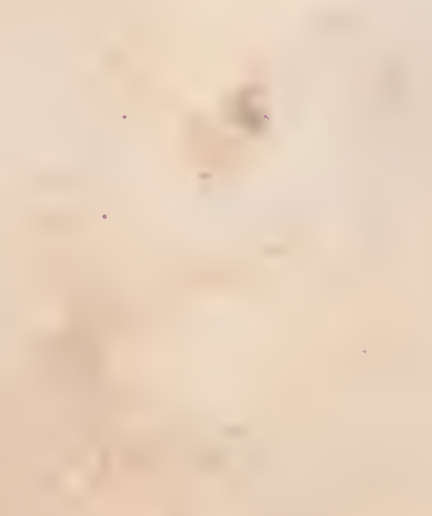

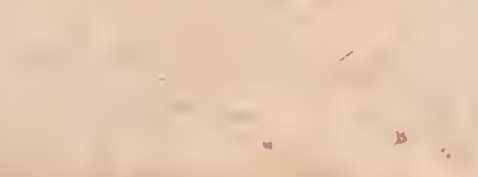

$\because$ 




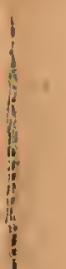


1
4 